\title{
Thermophilic and alkaliphilic Actinobacteria: biology and potential applications
}

\author{
L. Shivlata and Tulasi Satyanarayana * \\ Department of Microbiology, University of Delhi, New Delhi, India
}

Microbes belonging to the phylum Actinobacteria are prolific sources of antibiotics, clinically useful bioactive compounds and industrially important enzymes. The focus of the current review is on the diversity and potential applications of thermophilic and alkaliphilic actinobacteria, which are highly diverse in their taxonomy and morphology with a variety of adaptations for surviving and thriving in hostile environments. The specific metabolic pathways in these actinobacteria are activated for elaborating

OPEN ACCESS

Edited by:

Wen-Jun Li,

Sun Yat-Sen University, China

Reviewed by:

Erika Kothe,

Friedrich Schiller University Jena,

Germany

Hongchen Jiang

Miami University, USA

Qiuyuan Huang,

Miami University, USA

Neeli Habib,

Yunnan University, China

*Correspondence:

Tulasi Satyanarayana,

Department of Microbiology,

University of Delhi, Benito Juarez

Road, New Delhi 110021, India

tsnarayana@gmail.com

Specialty section:

This article was submitted to

Extreme Microbiology,

a section of the journal

Frontiers in Microbiology

Received: 17 June 2015 Accepted: 07 September 2015 Published: 25 September 2015

Citation:

Shivlata L and Satyanarayana T (2015)

Thermophilic and alkaliphilic

Actinobacteria: biology and potential applications. Front. Microbiol. 6:1014.

doi: 10.3389/fmicb.2015.01014 pharmaceutically, agriculturally, and biotechnologically relevant biomolecules/bioactive compounds, which find multifarious applications.

Keywords: Actinobacteria, thermophiles, alkaliphiles, polyextremophiles, bioactive compounds, enzymes

\section{Introduction}

The phylum Actinobacteria is one of the most dominant phyla in the bacteria domain (Ventura et al., 2007), that comprises a heterogeneous Gram-positive and Gram-variable genera. The phylum also includes a few Gram-negative species such as Thermoleophilum sp. (Zarilla and Perry, 1986), Gardenerella vaginalis (Gardner and Dukes, 1955), Saccharomonospora viridis $\mathrm{P}_{101}{ }^{\mathrm{T}}$ (Pati et al., 2009), Ferrimicrobium acidiphilum, and Ferrithrix thermotolerans (Johnson et al., 2009). Actinobacteria are either aerobes or anaerobes, motile or non-motile, and spore-/nonspore forming bacteria with a high $\mathrm{G}+\mathrm{C}$ content (>55 mol\%; Ensign, 1992). The genome size of actinobacteria ranges from $0.93 \mathrm{Mb}$ (Tropheryma whipplei; Bentley et al., 2003) to $12.7 \mathrm{Mb}$ (Streptomyces rapamycinicus; Baranasic et al., 2013), that exists either as a circular or linear form. Actinobacteria occur in diverse ecological niches such as terrestrial and aquatic ecosystems (fresh and marine waters), characterized by a complex life cycle that includes their existence either as dormant spores or actively growing hyphae. They are highly diverse in their morphology ranging from coccoid (e.g., Micrococcus) and rod-coccoid (e.g., Arthrobacter), fragmenting hyphal forms (e.g., Nocardia) to branched mycelium (e.g., Streptomyces; Barakate et al., 2002). Reproduction in actinobacteria occurs either by vegetative mode via fragmentation of mycelia or by asexual mode (spore or conidia formation). They produce either a single spore (monosporic) or a pair of spores (bisporic), or many spores (oligosporic) on aerial or substrate mycelium. The oligosporic actinobacteria show distinct patterns of spore arrangement (hooked, straight, or wavy) on the mycelium, depending on the taxa.

Actinobacteria represent one of the most primitive lineages among prokaryotes (Koch, 2003) which are believed to have evolved about 2.7 billion years ago (Battistuzzi and Hedges, 2009). Antibiotic production by actinobacteria is considered to be a key driving factor in the evolution of prokaryotes that led to the diversification of archaea and Gram-negative bacteria (diderm) from Gram-positive bacteria (monoderm; Gupta, 2011). Actinobacteria form a distinct branch on the 16S rRNA gene tree (Zhi et al., 2009), and are distinguished from other bacterial taxa on the basis 
of their distinct gene arrangement patterns (Kunisawa, 2007) and conserved indels present in both the $23 \mathrm{~S}$ rRNA and proteins (e.g., cytochrome C oxidase subunit I, CTP synthetase, and glutamyltRNA synthetase; Gao and Gupta, 2005). Their classification has been revised many times in the past. According to the recent system of classification, these are placed under Phylum XXVI, Actinobacteria in the Domain II (Bacteria) in Bergey's Manual of Systematic Bacteriology, volume 5. This phylum contains a large array of chemotaxonomically, morphologically and physiologically distinct genera, grouped into six major classes (Actinobacteria, Acidimicrobiia, Coriobacteria, Nitriliruptoria, Rubrobacteria, and Thermoleophilia; Goodfellow et al., 2012).

Actinobacteria are an ecologically significant group, which play a vital role in several biological processes such as biogeochemical cycles, bioremediation (Chen et al., 2015), bioweathering (Cockell et al., 2013), and plant growth promotion (Palaniyandi et al., 2013). They not only produce a large array of pharmaceutically important bioactive compounds (antibiotics, antitumor agents, anti-inflammatory compounds, and enzyme inhibitors) but also an enormous number of industrially and clinically important enzymes. Since the discovery of streptomycin (first discovered antituberculosis drug from actinobacteria), the drug discovery and development programmes have inclined toward the antimicrobial agents than chemical compounds. Subsequently, a large number of actinobacterial species have been searched for the discovery of clinically valuable compounds. The phylum Actinobacteria contains several genera encompassing antibiotic producing species. The genus Streptomyces is a prominent source of secondary metabolites, especially antibiotics. Streptomyces species are known to produce more than $50 \%$ of the total known microbial antibiotics $(\geq 10,000)$. Despite the availability of enormous number of clinical drugs, many pharmaceutical companies and research laboratories are engaged in the search for new therapeutic drugs in order to combat the microbial pathogens. Multidrug resistant pathogenic strains are constantly emerging, which cause severe disease outbreaks in several countries. In order to find novel bioactive compounds of pharmacological and industrial relevance, actinobacteria have been isolated from exotic and unexplored locations such as desert (Kurapova et al., 2012), marine (Manivasagan et al., 2013), and wetland (Yu et al., 2015) areas. On the premise that the extremophilic actinobacteria could be a source of new valuable metabolites (Bull, 2010) with gene clusters for the synthesis of novel biomolecules, attempts are being made to isolate actinobacteria from extreme environments.

\section{Extremophilic/Extremotolerant Actinobacteria}

Actionobacteria are known to occur not only in normal environments, but also in extreme environments, which are characterized by acidic/alkaline $\mathrm{pH}$, low or high temperatures, salinity, high radiation, low levels of available moisture, and nutrients (Zenova et al., 2011). The diverse physiology and metabolic flexibility of extremophilic/extremotolerant actinobacteria enable them to survive under hostile and unfavorable conditions. The high abundance of actinobacterial species was recorded in all extreme environments (Bull, 2010) which had broken the traditional paradigm of restricted predominance of actinobacteria in soil and fresh water habitats. Enormous data has been reported on actinobacteria isolated from normal environments (neutral $\mathrm{pH}$ and temperature ranging $\left.20-40^{\circ} \mathrm{C}\right)$. Only a few investigations have been carried out to understand the diversity of actinobacteria in the extreme environments, their ecological role and adaptation. Polyextremophiles and polyextremotolerant actinobacterial species also exist in environments with two or more extreme conditions. Polyextremophiles can adapt to environments with multiple stresses (Gupta et al., 2014), which include alkalithermophilic, thermoacidophilic, thermophilic radiotolerant, haloalkaliphilic, and thermoalkalitolerant actinobacteria. Their incidence has been documented in distinct extremes of geographical locations such as the Arctic (Augustine et al., 2012) and Antarctic (Gousterova et al., 2014) regions, oceans (Raut et al., 2013), hot springs (Chitte and Dey, 2002), and deserts (Kurapova et al., 2012).

The extremophilic actinobacteria exhibit several adaptive strategies such as antibiosis, switching between different metabolic modes (i.e., autotrophy, heterotrophy, and saprobes) and production of specific enzymes to survive under unfavorable environmental conditions (high temperature, alkaline, and saline). The thermotolerance is attributed to the presence of high electrostatic and hydrophobic interactions and disulfide bonds in the proteins of thermophiles (Ladenstein and Ren, 2006). They have certain special proteins known as chaperones which aid in refolding the partially denatured proteins (Singh et al., 2010). Several other proteins are also synthesized that bind to DNA and prevent their denaturation at elevated temperatures. Some actinobacteria have acquired multiple adaptive mechanisms to survive in environments with two or more stresses. A thermophilic Streptomyces sp., isolated from desolated place, produced enzymes of the autotrophic metabolic pathway such as carbon monoxide dehydrogenase (CODH; Gadkari et al., 1990). The enzyme CODH facilitates the microbial growth in nutrient deprived condition by oxidizing the available inorganic compound such as carbon monoxide into $\mathrm{CO}_{2}$ which is further fixed by RuBisCO enzyme into microbial biomass through Calvin-Benson cycle (King and Weber, 2007). The thermophilic chemolithoautotroph, Acidithiomicrobium sp., isolated from geothermal environment, utilizes sulfur as an energy source (Norris et al., 2011). The antibiosis is another principal strategy through which actinobacteria sustain by killing other microbial flora under nutrient limited conditions. Acidophiles and alkaliphiles have acquired proton pumps to regulate $\mathrm{H}^{+}$ concentrations inside and outside the cell for maintaining physiological pH inside (Kumar et al., 2011). Alkaliphiles contain the negatively charged cell wall polymers which stabilize the cell membrane by reducing the charge density at the cell surface (Wiegel and Kevbrin, 2004). The adaptive strategy of haloalkaliphiles includes additional tolerances to the salt environment by synthesizing and accumulating high amount of compatible solutes (Roberts, 2005) that prevent desiccation through osmoregulation. They also have $\mathrm{Na}^{+} / \mathrm{H}^{+}$antiporter to exclude excessive salt content from inside of the cell. 
Actinobacteria are also known to show tolerance to extremely harmful radiations such as gamma and UV rays, and have been isolated from various radioactive sites. The three thermophilic Rubrobacter species such as $R$. radiotolerans, R. xylanophilus (Ferreira et al., 1999), and R. taiwanensis (Chen et al., 2004) have been reported to be radiotolerant. The resistance mechanism has not been adequately understood, but the complete whole genome analysis of $R$. radiotolerans RSPS- 4 revealed the presence of genes encoding proteins involved in DNA repair system, oxidative stress response, and biosynthetic pathways of compatible sugars (trehalose and mannosylglycerate) which might be playing a role in mitigating the damage caused by radiations (Egas et al., 2014). In recent years, a few more alkalitolerant and radiotolerant actinobacterial species such as Microbacterium maritypicum (Williams et al., 2007), Microbacterium radiodurans GIMN 1.002T (Zhang et al., 2010), Cellulosimicrobium cellulans UVP1 (Gabani et al., 2012), Kocuria sp. ASB 107 (Asgarani et al., 2012), and Kocuria rosea strain MG2 (Gholami et al., 2015) have been documented. These two alkalitolerant Kocuria strains were isolated from Ab-e-Siah radioactive spring of Iran. The Kocuria sp. ASB 107 is a psychrotrophic strain which shows tolerance to ionizing radiation (upto $90 \%$ lethal doses) such as ultraviolet (256 nm-UV) and corona discharge. The Kocuria rosea strain MG2 was shown to endure the high dosage of harmful UV-C radiation. This actinobacterium can grow in a wide $\mathrm{pH}$ range (5-11 with optimum growth at $\mathrm{pH} 9.2)$ and salt concentration (0$15 \%)$. Gholami et al. (2015) performed the cell viability analysis on Kocuria rosea strain MG2 under multiple stresses. After 28 days of incubation under desiccation condition, the cells of Kocuria strain were found to be viable and showed high tolerance to the radiation and strong oxidant such as $\mathrm{H}_{2} \mathrm{O}_{2}(1-4 \%)$. The hydrogen peroxide is a well-known antimicrobial agent which damages biological membranes by generating hydroxyl radicals. They seem to exhibit both enzymatic (catalase and peroxidase) and non-enzymatic antioxidant defense systems (carotenoids) to diminish the effect of radiation or strong oxidants or other stresses (Gholami et al., 2015).

The resilience and adaptability of extremophilic/ extremotolerant actinobacteria confer them a competitive advantage over other microbes. Besides helping them to survive under extreme conditions, the physiology and metabolic flexibility also trigger them to produce industrially valuable compounds (Singh et al., 2013). The production of biomolecules by extremophiles mitigates the risks of other microbial contaminations, besides providing thermostable, alkalistable, and halotolerant compounds. Enzymes produced by the extremophilic/extremotolerant actinobacteria are functional under extreme conditions, thus, making them suitable candidates for application in industrial processes, where harsh conditions/treatment methods are used. This review focuses on the physiology, phylogeny, ecological roles, and potential applications of thermophilic and alkaliphilic actinobacteria.

\section{Thermophilic and Thermotolerant Actinobacteria}

Thermophilic actinobacteria thrive at relatively high temperatures ranging from 40 to $80^{\circ} \mathrm{C}$ (Tortora et al., 2007).
They are widespread, commonly found in moldy hay (Corbaz et al., 1963), self-heating plant residues, cereal grains, sugar cane bagasse (Suihko et al., 2006), decaying vegetable materials, and compost heaps (Henssen and Schnepf, 1967). These are of two types: strictly thermophilic and moderately thermophilic actinobacteria. The former can grow in the temperature range between 37 and $65^{\circ} \mathrm{C}$, but optimum proliferation takes place at $55-60^{\circ} \mathrm{C}$. While moderately thermophilic actinobacteria thrive at $28-60^{\circ} \mathrm{C}$ and require $45-55^{\circ} \mathrm{C}$ for optimum growth (Jiang and $\mathrm{Xu}, 1993$ ). Another group known as thermotolerant actinobacteria can survive at temperatures up to $50^{\circ} \mathrm{C}$ (Lengeler et al., 1999).

\section{Physiology}

Thermophilic actinobacteria are strictly aerobes and obligate chemoorganotrophs in nature and thrive on decaying organic matter (dead animal and plant materials). There are certain thermophilic actinobacteria such as Streptomyces thermoautotrophicus (Gadkari et al., 1990) and Acidithiomicrobium sp. (Norris et al., 2011) which are obligate chemoautotrophs, growing solely on $\mathrm{CO}_{2}+\mathrm{H}_{2}$ and sulfur, respectively. Other nutritive modes such as facultative chemoautotrophy (e.g., Strepyomyces strain G26; Bell et al., 1988) and facultative methylotrophy (e.g., Amycolatopsis methanolica; Boer et al., 1990) have been observed among thermophilic actinobacteria. The diverse metabolic physiology facilitates the colonization of thermophilic actinobacteria in distinct topographical zones. Prevalence of thermophilic actinobacteria has been documented in sites ranging from the Desert Steppe Zone of Mongolia (Kurapova et al., 2012) to the subtropical area of Argentina (Carrillo et al., 2009) and hydrothermal vents to residential heating systems (Fink et al., 1971). Actinobacteria found in these environments are primarily fast growing and spore forming. The spores produced are of thermoduric type and are stable at higher temperatures for longer duration, even for days in some cases. This appears to provide an additional ecological advantage over other bacteria, making them easier to adapt back to their vegetative forms with the advent of favorable conditions.

\section{Systematics, Taxonomy, and Phylogeny}

Thermophilic and thermotolerant species exist in the diverse genera of phylum Actinobacteria (Table 1). Among them, the genera such as Thermopolyspora, Thermomonospora, Thermotunica, Thermocatellispora, Thermobispora, Acidothermus, Acidimicrobium, and Thermoleophilum include only thermophilic species, while other genera include both thermophilic and mesophilic species. All these genera belong to four classes such as Actinobacteria, Acidimicrobiia, Rubrobacteria, and Thermoleophilia of the phylum Actinobacteria (shown in Figure 1).

Monospore producing thermophilic actinobacteria belong to three major genera Saccharomonopora, Thermomonospora, and Micromonopsora. The genus Saccharomonospora was first described by Nonomura and Ohara (1971) for monosporic actinobacteria with cell wall type IV (meso-DAP, arabinose, and galactose), which includes mostly mesophilic actinobacteria except Saccharomonospora xinjiangensis (Jin et al., 1998) and 
TABLE 1 | Thermophilic and thermotolerant actinobacterial species.

\begin{tabular}{|c|c|c|c|c|}
\hline \multirow[t]{2}{*}{ Actinobacteria } & \multicolumn{2}{|c|}{ Growth conditions } & \multirow[t]{2}{*}{ Location of isolation } & \multirow[t]{2}{*}{ References } \\
\hline & Temperature $\left({ }^{\circ} \mathbf{C}\right)$ & pH & & \\
\hline Microbispora siamensis DMKUA $245^{\top}$ & $25-50$ & - & Soil sample, Thailand & Boondaeng et al., 2009 \\
\hline Georgenia sediminis SCSIO $15020^{\top}$ & $24-60$ & $6-10$ & Sea sediment, Austria & You et al., 2013 \\
\hline Actinokineospora soli YIM $75948^{\top}$ & $25-55$ & $7-9$ & Soil sample, China & Tang et al., 2012 \\
\hline Marinactinospora thermotolerans SCSIO $00652^{\top}$ & $10-55$ & $6-9$ & Sea sediment, Northern South China & Tian et al., 2009 \\
\hline Saccharomonospora viridis SJ-21 & $35-60$ & $7-10$ & Hot water spring, India & Jani et al., 2012 \\
\hline Actinomadura miaoliensis $\mathrm{BC} 44 \mathrm{~T}-5^{\top}$ & $22-55$ & 7.0 & Soil sample, Taiwan & Tseng et al., 2009 \\
\hline Streptosporangium sp. & - & - & Soil of Mongolia Desert Steppe Zone & Kurapova et al., 2012 \\
\hline Streptomyces Calidiresistens $\mathrm{YIM} 7808^{\top}$ & $40-65$ & 7.0 & Hot spring sediment, South-west China & Duan et al., 2014 \\
\hline Nocardiopsis yanglingensis A18 & $25-55$ & $6.5-8.5$ & Compost of button mushrooms & Yan et al., 2011 \\
\hline Amycolatopsis ruanii $\mathrm{NMG}_{11}{ }^{\top}$ & $20-50$ & $4-10$ & Soil sample & Zucchi et al., 2012 \\
\hline \multicolumn{5}{|l|}{ A. thermalba SF $45^{\top}$} \\
\hline \multicolumn{5}{|l|}{ A. granulosa $\mathrm{GY} 307^{\top}$} \\
\hline Pseudonocardia thermophila JCM3095 & - & - & - & Yamaki et al., 1997 \\
\hline Thermomonospora curvata B9T & $40-65$ & $7.5-11$ & Composted stable manure & Chertkov et al., 2011 \\
\hline $\begin{array}{l}\text { Thermobifida fusca (formerly named as } \\
\text { Thermomonospora fusca) }\end{array}$ & $35-53$ & $10-11$ & - & McCarthy and Cross, 1984 \\
\hline Thermotunica guangxiensis & $37-65$ & $6-9$ & Mushroom residue compost, China & Wu et al., 2014b \\
\hline Thermopolyspora flexuosa DSM $41386^{\top}$ & $40-60$ & $6-9$ & Soil from the Pamir Mountains & Krasilnikov and Agre, 1964 \\
\hline Thermocatellispora tengchongensis & $28-58$ & $6-8$ & Soil sample, South-west China & Zhou et al., 2012 \\
\hline Saccharopolyspora thermophila $216^{\top}$ & $45-55$ & - & Soil sample, China & Lu et al., 2001 \\
\hline Thermobispora bispora $\mathrm{R}_{51}{ }^{\mathrm{T}}$ & $50-65$ & - & Decaying manure, Berlin & Henssen, 1957 \\
\hline Thermoleophilum album ATCC 35263 & $45-70$ & $6.5-7.5$ & Mud samples & Zarilla and Perry, 1984 \\
\hline Acidothermus cellulolyticus 11B & $37-70$ & $4-6$ & Acidic hot springs, Yellowstone National Park & Barabote et al., 2009 \\
\hline Acidimicrobium ferrooxidans TH3 & $45-50$ & 2 & Icelandic geothermal site & Clark and Norris, 1996 \\
\hline Aciditerrimonas ferrireducens $\mathrm{IC}-180^{\top}$ & $35-58$ & $2.0-4.5$ & Solfataric field, Japan & Itoh et al., 2011 \\
\hline Acidithiomicrobium sp. & 50 & 3 & Geothermal environments & Norris et al., 2011 \\
\hline Ferrithrix thermotolerans Y005T & 43 & 1.3 & Mine site, UK & Johnson et al., 2009 \\
\hline Rubrobacter taiwanensis LS-28 & 30-70 (optimum 60) & $6-11$ & Lu-shan hot springs, Taiwan & Chen et al., 2004 \\
\hline Rubrobacter radiotolerans & $46-48$ & $7.0-7.4$ & Hot springs, Central Portugal & Ferreira et al., 1999 \\
\hline R. xylanophilus & 60 & $7.5-8.0$ & & \\
\hline
\end{tabular}

S. viridis. The genus Thermomonospora was originally proposed only for thermophilic actinobacteria (Henssen, 1957), which comprised three thermophilic species T. curvata, T. lineata, and T. fusca. Only T. curvata could be maintained as pure culture among the three. Afterwards, one mesophilic actinobacterium (T. mesophila) was transferred from the genus Actinobifida to the genus Thermomonospora (Nonomura and Ohara, 1971). Consequently, some other Thermomonospora species such as T. mesouviformis (Nonomura and Ohara, 1974) and T. curvata, T. alba, T. chromogena, T. fusca, and T. mesophila (McCarthy and Cross, 1984) were identified. Later on, the T. mesouviformis was reassigned as a synonym of T. alba (McCarthy and Cross, 1984). One more species, T. formosensis (Hasegawa et al., 1986), was isolated and introduced into this genus. McCarthy (1989) described a total of six species (T. curvata, T. alba, T. chromogena, T. fusca, T. mesophila, and T. formosensis) in the ninth edition of Bergey's Manual of Determinative Bacteriology. Zhang et al. (1998) proposed a polyphasic taxonomy based classification system for the six Thermomonospora species. T. formosensis and T. mesophila were reclassified as Actinomadura formosensis and Microbispora mesophila, respectively. T. alba and T. fusca were transferred to the genus Thermobifida and named as Thermobifida alba and Thermobifida fusca, respectively (Zhang et al., 1998). The genus Themomonospora is now left with only two species (T. curvata and T. chromogena). However, T. chromogena (shown in red square in Figure 1) appears distantly from T. curvata on $16 \mathrm{~S}$ rRNA tree. It shows close ribosomal gene sequence similarity with Thermobispora bispora. The detailed study of $T$. chromogena revealed the presence of total six rRNA operons (rrn) in the genome, among which, one operon (rrnB) shows sequence similarity with rRNA of Thermobispora bispora. The thermophilic actinobacterium T. chromonogena might have acquired this operon from Thermobispora bispora or other related microorganism through horizontal gene transfer (Yap et al., 1999). The species of Thermobifida genus produces single spore on dichotomously branched hyphae. This genus includes only four species (shown in Figure 1). Among them, Thermobifida fusca is well-studied, which produces a 


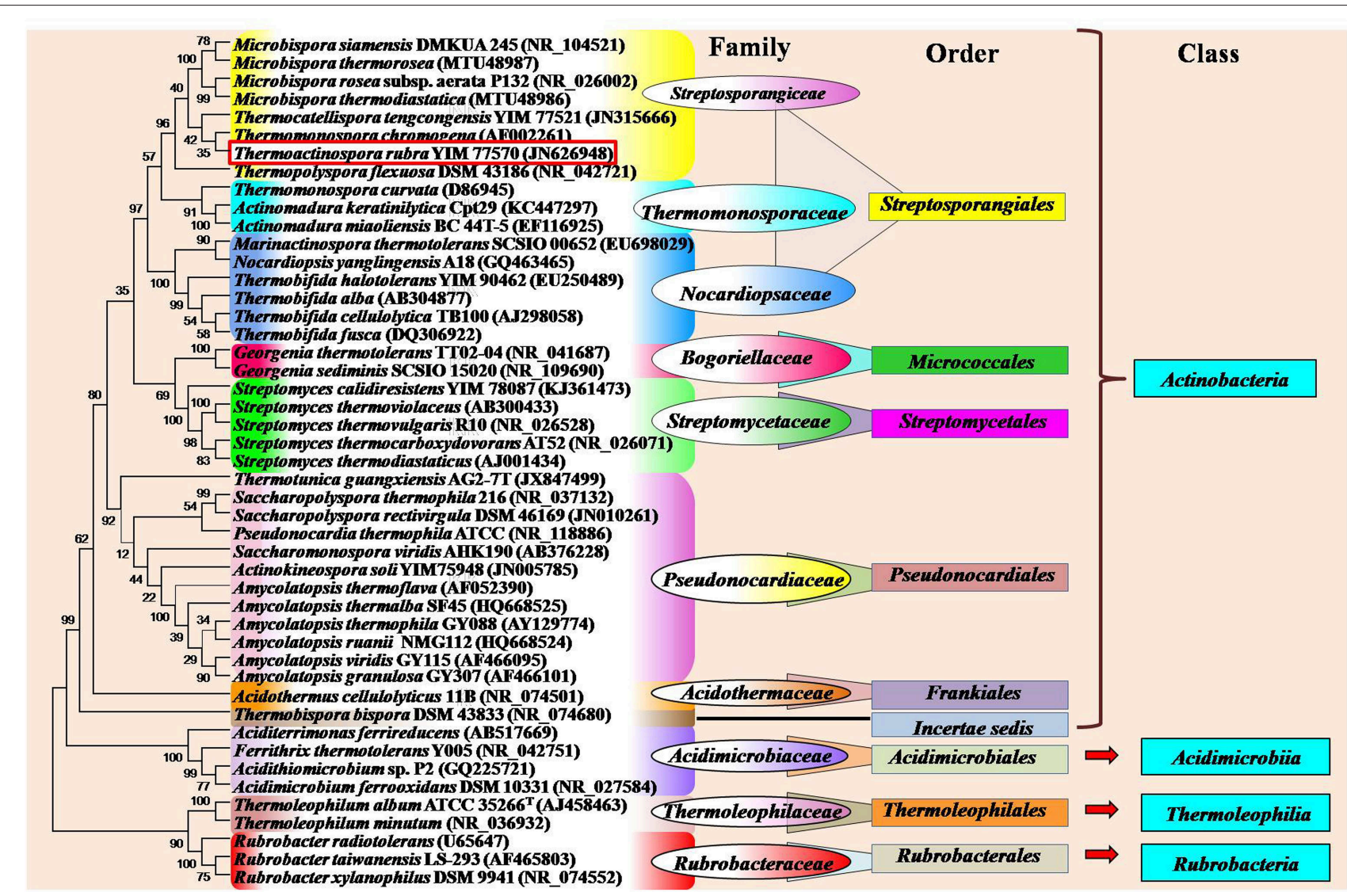

FIGURE 1 | Phylogram indicating the placement and relatedness of some thermophilic and thermotolerant actinobacterial strains belonging to four classes (Actinobacteria, Acidimicrobiia, Rubrobacteria, and Thermoleophilia) of the phylum Actinobacteria. The numbers given at branch nodes indicate (\%) bootstrap value. Phylogenetic tree was generated using Mega5.2 software with 1000 bootstrap replications. Bar 0.02 substitutions per 100 nucleotide positions.

number of industrially important enzymes and other bioactive compounds.

Bisporic thermophilic actinobacteria are included into two genera (Thermobispora and Microbispora). A thermophilic actinobacterium, Thermobispora bispora [earlier known as Microbispora bispora (Lechevalier, 1965) and Thermopolyspora bispora (Henssen, 1957)] has been isolated from decaying manure in Berlin, Germany (Henssen, 1957), and described as a type species of the genus Thermobispora based on thermal preference, chemotaxonomic features, and ribotyping (Wang et al., 1996). The genus contains only single species T. bispora that belongs to the class Actinobacteria (Goodfellow et al., 2012). In recent years, a few thermotolerant species were identified belonging to the genus Microbispora (shown in Figure 1).

Oligospore forming thermophilic actinobacteria are majorly included in the genera Thermopolyspora, Saccharopolyspora, and Streptomyces. A thermophilic actinobacterium, Thermopolyspora flexuosa, is the only species of the genus Thermopolyspora (Krasilnikov and Agre, 1964), which forms a short chain of spores on sporophore. This species had been subjected to several reclassifications and subsequently assigned into different genera such as Nocardia (Becker et al., 1964; Lechevalier et al.,
1966), Micropolyspora (Krasil'nikov et al., 1968), Actinomadura (Cross and Goodfellow, 1973; Lacey et al., 1978), Microtetraspora (Kroppenstedt et al., 1990), and later into the genus Nonomuraea (Zhang et al., 1998). Once again the taxonomic position of this actinobacterium has been reconsidered and transferred from the genus Nonomuraea to the genus Thermopolyspora and rechristened as Thermopolyspora flexuosa on the basis of $16 \mathrm{~S}$ rRNA sequence, chemotaxonomy, morphological, and physiological properties (Goodfellow et al., 2005).

The genus Saccharopolyspora includes both mesophilic and thermophilic species. The thermophilic species such as $S$. rectivirgula [formerly named as Micropolyspora faeni, Thermopolyspora polyspora (Henssen, 1957), and Thermopolyspora rectivirgula (Krasilnikov and Agre, 1964)] has been isolated from moldy hay. It causes severe farmer's lung disease. Another species of thermophilic Saccharopolyspora, S. thermophila was isolated from a garden soil collected from the Xishan Mountain, Beijing (Lu et al., 2001). Goodfellow et al. (1987) isolated a number of thermophilic Streptomyces species from diverse habitats. Streptomyces thermovulgaris had been reported as the causative agent of bacteremia (Ekkelenkamp et al., 2004), which has been further designated 
as a synonym of S. thermonitrificans (Kim et al., 1999). Some other thermophilic Streptomyces such as Streptomyces sp. G26 (Bell et al., 1988), S. thermoautotrophicus (Gadkari et al., 1990), $S$. thermocarboxydovorans, and $S$. thermocarboxydus (Kim et al., 1998) have been reported to be carboxydotroph, which are capable of oxidizing the toxic carbon monoxide gas into innocuous $\mathrm{CO}_{2}$, thus, lowering its atmospheric concentration to safer levels.

Non-sporulating thermophilic actinobacteria belong to the genus Rubrobacter (Suzuki et al., 1988) which includes many thermophiles or radiotolerant thermophiles and mesophiles. A thermophilic and radiotolerant actinobacterium, $R$. radiotolerans was formerly described as Arthrobacter radiotolerans (Yoshinaka et al., 1973), which tolerates both gamma and UV radiations (Suzuki et al., 1988). The complete genome sequence of $R$. radiotolerans $\mathrm{RSPS}-4$ has been recently annotated to elucidate the radiation resistant mechanism (Egas et al., 2014). Other thermophilic actinobacteria belonging to this genus are R. xylanophilus (Carreto et al., 1996), R. taiwanensis (Chen et al., 2004), $R$. calidifluminis, and $R$. naiadicus (Albuquerque et al., 2014). The non-sporulating genus, Amycolatopsis also includes a few thermophilic actinobacteria (shown in Figure 1). Aciditerrimonas ferrireducens (Itoh et al., 2011), Acidithiomicrobium sp. (Norris et al., 2011), Ferrithrix thermotolerans (Johnson et al., 2009) and Acidimicrobium ferrooxidans (Clark and Norris, 1996) are non-spore forming thermoacidophilic actinobacteria belonging to the class Acidimicrobiia. Aciditerrimonas ferrireducens exhibits both heterotrophic and autotrophic mode of nutrition. It is capable of reducing ferric ions to facilitate the autotrophic growth under anaerobic conditions, while the last two catalyze both the processes (dissimilatory oxidation of ferrous iron and reduction of ferric iron). Acidimicrobium ferrooxidans displays facultative autotrophic growth, which is capable of fixing atmospheric $\mathrm{CO}_{2}$ in the absence of organic matter, while Ferrithrix thermotolerans exhibits only heterotrophic mode of nutrition. Another thermoacidophilic actinobacterium, Acidothermus cellulolyticus $11 \mathrm{~B}$ was isolated from hot-springs (Mohagheghi et al., 1986), which belongs to the order Frankiales. It produces a number of thermostable cellulases, among which, a cellulase (endoglucanases E1) shows higher thermostability and substrate specificity as compared to other actinobacterial cellulases (Thomas et al., 1995).

\section{Adaptation of Thermophilic and Thermotolerant Actinobacteria}

Thermotolerant/thermophilic actinobacteria have acquired diverse strategies for homeostasis such as comparatively higher GC content in their genomes, substitution of amino acids in proteins and contain specific components in the cell wall. Mostly thermophiles are known to incorporate comparatively higher quantity of charged amino acids (Asp, Glu, Arg, and Lys) than polar amino acids (Asn, Gln, Ser, and Thr) in their proteins (Suhre and Claverie, 2003). Same trend of increased content of charged amino acids except lysine was observed in the proteins of Thermobifida fusca (Lykidis et al., 2007). The genus Corynebacterium includes mostly mesophilic actinobacteria with the exception of $C$. efficiens which is capable to grow up to $45^{\circ} \mathrm{C}$ (Fudou et al., 2002). The comparatively high GC content may provide the thermotolerance to the $C$. efficiens. Amino acid substitution has also been noticed in the enzymes involved in the biosynthetic pathway of industrial valuable amino acids (glutamic acid and lysine) which enhances the production yield of amino acids, thereby adding an industrial importance to this actinobacterium (Nishio et al., 2003). Another thermotolerant actinobacterium, Saccharomonospora xinjiangensis contains specific phospholipid [unknown glucosamine-containing phospholipids (GluNU)] in the cell wall, which is considered to be involved in favoring the growth at high temperatures (45-50 $\tilde{\mathrm{C}}$; Jin et al., 1998). Acidothermus cellulolyticus belongs to the family Acidothermaceae and the order Frankiales, can grow optimally at $55^{\circ} \mathrm{C}$ and $\mathrm{pH}$ 5.5. It comes close to the genus Frankia on the phylogenetic tree constructed on the basis of the 16S rRNA (Normand et al., 1996), recA (Maréchal et al., 2000), and shc nucleotide sequences (Alloisio et al., 2005). The thermal adaptation in A. cellulolyticus may be attributed to the presence of higher GC content compared to the Frankia species. The inverse nucleotide preference for $\mathrm{G}$ and $\mathrm{A}$ at the first and third codon positions has also been observed. Moreover, the proteins contain repetitive patch of the amino acids (IVYWREL) as compared to proteins of Frankia species. The amino acid patch might provide thermostability to proteins of Acidothermus cellulyticus (Barabote et al., 2009).

\section{Characteristic Features of Thermophilic and Thermotolerant Actinobacteria}

All thermophilic and thermotolerant actinobacteria except the genera (Amycolatopsis, Rubrobacter, Ferrithrix, Acidothermus, Aciditerrimonas, Acidimicrobium, and Thermoleophilum) are spore formers. Mostly they are non-acid fast, non motile, and aerobes except the genus Amycolatopsis which includes both aerobes and facultative anaerobes. All are Gram-positive with the exception of Thermoleophilum sp., Ferrithrix sp., and a species ( $S$. viridis) of the genus Saccharomonospora. The accurate status of thermophilic actinobacteria has been validated only after the advent of polyphasic taxonomy. Cell wall (peptidoglycan) composition is one of the major feature of the genus specific classification. On the basis of amino acid and sugar contents, actinobacterial cell wall is grouped into four major types i.e., type-I [LL-DAP (diaminopimelic acid) and glycine], type-II [amino acids (meso-DAP and glycine) and sugars (arabinose and xylose)], type-III (meso-DAP with or without madurose), type-IV (meso-DAP, arabinose and galactose; Lechevalier et al., 1966), and other cell wall type $\mathrm{V}-\mathrm{X}$. The majority of the thermophilic actinobacteria have a cell wall type-III, while a few genera (Saccharomonospora, Saccharopolyspora, and Amycolatopsis) are known to contain cell wall type IV. Only one species of the genus Streptomyces has cell wall type-I. Other cellular components considered for chemotaxonomic classification include phospholipids, fatty acids, mycolic acid, menaquinones type, and GC content (\% mol). The major respiratory menaquinones of thermophilic and thermotolerant actinobacteria are MK-9 variants. The 
presence of other menaquinones MK-8 (Rubrobacter) and MK10 (Thermobifida) have also been reported (Goodfellow et al., 2012) in thermophilic actinobacteria.

\section{Ecological Importance}

Thermophilic and thermotolerant actinobacteria are known to possess unique metabolic rates and physical properties that prove to be beneficial in a variety of ecological roles.

\section{Composting}

Composting is a self-heating, aerobic, and biodegradation process that supplies humus and nutrients to the soil (Rawat and Johri, 2013). The composting involves the synergistic action of bacteria, actinobacteria, and fungi, wherein the actinobacteria proliferate in the later stages of composting. The predominance of thermotolerant actinobacteria is generally observed in thermobiotic condition generated by the preceding bacteria. During the initial stage of thermobiotic condition, the compost is colonized by thermotolerant actinobacteria (Streptomyces albus and Streptomyces griseus) and subsequently by the thermophilic actinobacteria (Goodfellow and Simpson, 1987). Actinobacteria genera such as Streptomyces, Amycolatopsis, Microbispora, Cellulosimicrobium, Micrococcus, Saccharopolyspora, Micromonospora, Thermobispora, Thermomonospora, Thermobifida, and Planomonospora were reported to be involved in the composting process. The composition of actinobacterial communities varies during various stages of composting (Xiao et al., 2011). They also suppress the growth of plant pathogens by secreting antibiotics along with the breakdown of organic matter which provides an additional advantage of using compost in order to enhance soil nutrients and also suppressing the development of plant diseases. Moreover, the addition of compost to contaminated soil enhances the bioremediation rates of pollutants such as polycyclic aromatic hydrocarbons, petroleum, pesticides, and heavy metals (Chen et al., 2015).

\section{Antimicrobial Activity}

Thermotolerant actinobacteria such as Streptomyces tauricus, S. toxytricini, S. coeruleorubidis, S. lanatus, and Streptosporangium sp. have been found to inhabit the rhizosphere of many plants in the desert of Kuwait during the hot season (Diab and Al-Gounaim, 1985). The rhizosphere inhabiting actinobacteria exhibit antimicrobial activity, thus protect the plant from the attack of phytopathogens (Xue et al., 2013). Some thermotolerant actinobacteria isolated from the Himalayan Mountains, have also been shown to exhibit antagonistic activity against pathogenic bacteria and fungi. They include mostly Streptomyces species such as S. phaeoviridis and S. griseoloalbus, $S$. viridogens, and S. viridogens. The S. phaeoviridis and $S$. griseoloalbus exhibit antibacterial activity against both Grampositive and Gram-negative bacteria, including methicillin resistant and vancomycin resistant strains of Staphylococcus aureus. The other two Streptomyces species (S. viridogens and S. rimosus) are capable of suppressing the growth of pathogenic fungi (Fusarium solani, Rhizoctonia solani, Colletotricum falcatum, and Helminthosporium oryzae), therefore, these
Streptomyces species could be used as the bio-pesticides for agricultural production (Radhakrishnan et al., 2007).

\section{Plant Growth Promotion}

Actinobacteria secrete many volatile secondary metabolites which play significant roles in the suppression of plant diseases and the alleviation of biotic or abiotic stresses. Moreover, many actinobacteria species are known to secrete the iron chelating organic molecules such as siderophores which sequester the solubilized form of iron $\left(\mathrm{Fe}^{+3}\right)$ and immobilize it in the rhizosphere of plants growing in the iron deficient soil. The siderophores modulate either the plant growth, directly or indirectly, by enriching the other plant beneficial microbes in the rhizosphere zone (Palaniyandi et al., 2013). Dimise et al. (2008) showed that a soil dwelling cellulolytic actinobacterium, Thermobifida fusca partakes in plant growth promotion by synthesizing the siderophore (fuscachelins) through nonribosomal peptide biosynthetic pathways.

\section{Nitrogen Fixation}

The Frankia and some non-Frankia actinobacteria have been shown to fix the atmospheric nitrogen (Gtari et al., 2012). A thermophilic actinobacterium, Streptomyces thermoautotrophicus which is an autotrophic carboxydotroph, has an unusual characteristic of nitrogen fixation (Ribbe et al., 1997). In this actinobacterium, the process of nitrogen fixation is coupled to the oxidation of carbon monoxide. The electrons generated during the oxidation process of $\mathrm{CO}$ reduce molecular oxygen into oxygen free radicals. The manganesecontaining superoxide oxidoreductase oxidizes the formed free radicals into $\mathrm{O}_{2}$ and release electrons. The released electrons are further utilized by the enzyme nitrogenase in order to reduce $\mathrm{N}_{2}$ into ammonia. The notable feature of nitrogenase of S. thermoautotrophicus is its insensitivity to $\mathrm{O}_{2}$ and $\mathrm{O}_{2}^{-}$radicals. Furthermore, it also differs from other known nitrogenases in terms of protein structure and requirement of $\mathrm{Mg}^{2+}$ and ATP. Valdes et al. (2005) reported that some Thermomonospora species are also capable of fixing atmospheric nitrogen.

\section{Hypersensitivity Pneumonitis}

Besides their beneficial activities, thermophilic actinobacteria such as Saccharomonospora viridis (Pati et al., 2009) and Saccharopolyspora rectivirgula (Pettersson et al., 2014) have been reported to cause severe respiratory diseases such as Farmer's lung and bagassosis. The Farmer's lung and bagassosis are a type of hypersensitivity pneumonitis (HP). The major cause of these allergic reactions is attributed to the exposure to moldy molasses, when densely colonized by spore-forming thermophilic actinobacteria.

\section{Alkaliphilic and Alkalitolerant Actinobacteria}

The actinobacteria have long been known to thrive in soda lakes, salt alkaline lake, and alkaline soil. Their occurrence has also been observed in neutral environments. The alkalitolerant actinobacteria are capable of growing in the comparatively 
broader range of environments from neutral to alkaline $\mathrm{pH}$. Alkaliphilic actinobacteria are, therefore, categorized into three major groups: alkaliphilic (grow optimally at $\mathrm{pH}$ 10-11), moderately alkaliphilic (grow in a $\mathrm{pH}$ range of $7-10$ ) but show poor growth at $\mathrm{pH} 7.0$, and alkalitolerant actinobacteria (grow in the $\mathrm{pH}$ range between 6 and 11; Jiang and $\mathrm{Xu}$, 1993). Baldacci (1944) presented the first report on alkaliphilic actinobacteria. Thereafter, Taber (1960) isolated alkaliphilic actinobacteria from the soil. The occurrence of alkaliphilic and alkalitolerant actinobacteria has been reported from various habitats including deep sea sediment (Yu et al., 2013), alkaline desert soil (Li et al., 2006), and soda lakes (Groth et al., 1997). Mikami et al. (1982) studied the distinct chemotaxonomic patterns of cell wall of a total six alkaliphilic Streptomyces species [Streptomyces caeruleus ISP 5103 (reclassified as Actinoalloteichus cyanogriseus, Tamura et al., 2008), S. alborubidus ISP 5465 (reclassified as Nocardiopsis alborubida), and S. autotrophicus ISP 5011, S. canescens ISP 5001, S. cavourensis ISP 5300, and S. hydrogenans ISP 5586] which show optimum growth at $\mathrm{pH}$ 11.5. Among them, the first three contained mesodiaminopimelic acid. Subsequently, the taxonomic positions and applications of alkaliphilic actinobacteria in various fields have been described by Groth et al. (1997) and Duckworth et al. (1998).

\section{Physiology, Characteristic, and Taxonomic Features of Alkaliphilic and Alkalitolerant Actinobacteria}

The alkaliphilic and alkalitolerant actinobacteria are known to occur in environments of high salinity (known as haloalkaliphiles or haloalkalitolerants) or in thermobiotic conditions (termed as alkalithermophile or alkalithermotolerants). Alkalithermophiles and alkalithermotolerant actinobacteria have also been isolated from saline habitats with their halophilic and halotolerance characteristic (Zenova et al., 2011). One such polyextremotolerant actinobacterium, Microbacterium sediminis has been isolated from deep sea that possesses the psychrotolerance, thermotolerance, halotolerance, and alkalitolerance attributes (Yu et al., 2013). Other reported polyextremophilic actinobacteria include alkaliphilic and thermotolerant actinobacteria [Streptomyces alkalithermotolerans (Sultanpuram et al., 2014) and Georgenia satyanarayanai (Srinivas et al., 2012)], thermophilic and alkalitolerant (Streptomyces thermoalcalitolerans; Kim et al., 1999), and haloalkaliphilic actinobacteria [Nitriliruptor alkaliphilus (Sorokin et al., 2009)]. They are either aerobes or microaerobes or facultative anaerobes. All alkaliphiles and alkalitolerants are Gram-positive. These exist as either halophiles or non-halophiles. Most alkaliphilic and alkalitolerant actinobacteria are non-motile and spore- or non-spore formers.

Some alkaliphilic actinobacterial species belonging to the genus Streptomyces (Mikami et al., 1982), Micromonospora (Jiang and Xu, 1993), Nocardioides (Yoon et al., 2005), Microcella (Tiago et al., 2005), Cellulomonas (Jones et al., 2005), Nesterenkonia (Luo et al., 2009), Streptosporangium (Gurielidze et al., 2010), Corynebacterium (Wu et al., 2011b), Georgenia (Srinivas et al., 2012), Nocardiopsis, Isoptericola, Nesterenkonia (Ara et al.,
2013), Saccharomonospora (Raut et al., 2013), Saccharothrix (Jani et al., 2014), and Arthrobacter (Kiran et al., 2015) have been isolated and well-characterized. Among them, the genus Nocardiopsis has been found to be prominent in alkaline environments (Ara et al., 2013). All the genera belong to the class Actinobacteria except the genus Nitriliruptor that belongs to the class Nitriliruptoria (shown in Figure 2). There are a few well-characterized alkalitolerant species such as Citricoccus alkalitolerans (Li et al., 2005), Spinactinospora alkalitolerans (Chang et al., 2011), and Haloactinopolyspora alkaliphila (Zhang et al., 2014) which proliferate in sites ranging from neutral to alkaline $\mathrm{pH}$.

\section{Ecological Significance \\ Microbial Decomposition in Hypersaline or Haloalkaline Sites}

The microbial degradation of recalcitrant molecules takes place rapidly in the environment with acidic or neutral $\mathrm{pH}$. However, the hypersaline and extreme haloalkaline conditions of lakes and mangroves limit most of the microbial hydrolytic activity on complex biomolecules such as cellulose, lignin, and chitin. Only haloalkaliphilic or haloalkalitolerant bacteria and actinobacteria are capable to proliferate and contribute in the decomposition of recalcitrant biopolymers in haloalkaline zones. A number of alkalitolerant or alkaliphilic actinobacteria have been isolated from mangrove, soda lakes and marine sediment. The two Isoptericola species i.e., Isoptericola chiayiensis (Tseng et al., 2011) and Isoptericola rhizophila (Kaur et al., 2014) were isolated from mangrove soil sample, Taiwan and rhizosphere of Ficus benghalensis (banyan tree) in Bhitarkanika mangrove forest, India, respectively. These two species are capable of hydrolyzing organic matter into simpler forms which are further assimilated by plants. The second most abundant biopolymer, chitin is produced by brine shrimp in bulk quantities in hypersaline soda lakes. Sorokin et al. (2012) showed the high prevalence of haloalkaliphilic chitinolytic bacteria and actinobacteria in hypersaline sediments and soda soils. The other chitinolytic actinobacteria species include Isoptericola halotolerans, Nocardiopsis sp., Glycomyces harbinensis, and Streptomyces sodiiphilus which are capable of degrading chitin completely and more rapidly than the bacterial population (Sorokin et al., 2012). Other alkaliphiles, Nocardiopsis prasina OPC-131 (Tsujibo et al., 2003), Streptomyces and Nocardia sp. (Bansode and Bajekal, 2006) are reported to display chitinolytic activity.

\section{Chitin Amendment}

Chitin amendment is a soil management approach to suppress or inhibit the growth of plant pathogens or parasites. The addition of chitin enhances the pathogenic suppressiveness of soil (Kielak et al., 2013). This strategy not only involves the chitinolytic action of the soil or rhizosphere microflora but also induces desired changes in the metabolism of the endophytic microflora of plants (Hallmann et al., 1999). The Arthrobacter sp., Corynebacterium aquaticum, Micrococcus luteus, Mycobacterium parafortuitum, and other bacterial species were found during the chitin facilitated amendment of the soil and rhizophere 


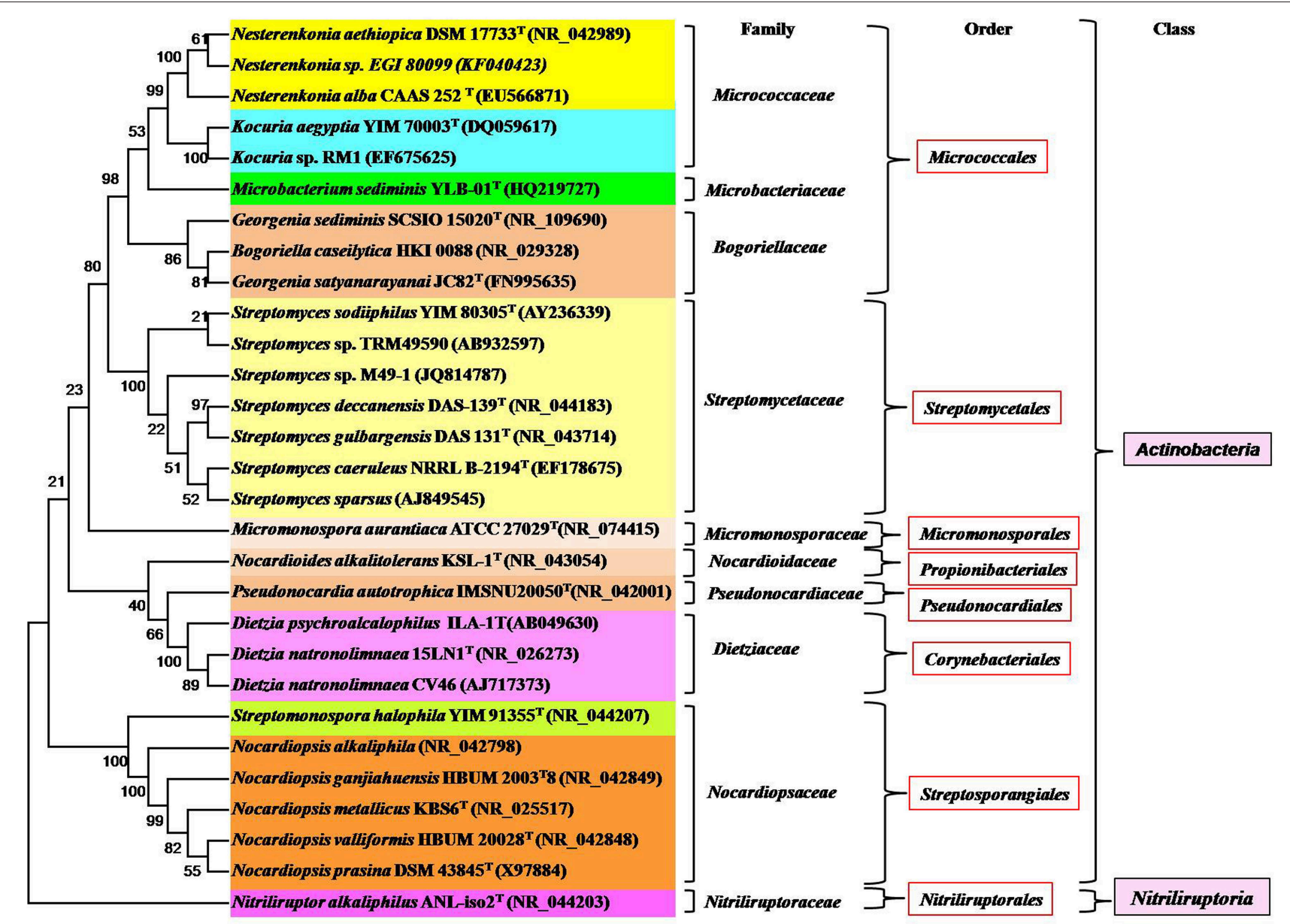

FIGURE 2 | Phylogram indicating the placement and relatedness of some alkaliphilic, alkalitolerant, alkalithermophilic and alkalithermotolerants actinobacterial strains belonging to two classes (Actinobacteria and Nitriliruptoria) of the phylum Actinobacteria. The numbers given at branch nodes indicate (\%) bootstrap value. Bar 0.02 substitutions per 100 nucleotide positions.

zone of cotton plants (Hallmann et al., 1999). The microbial community has been found to change with the alteration of physical properties ( $\mathrm{pH}$ and temperature) of soil. The enzyme chitinase produces short oligosaccharide chains and chitin derivatives which have various industrial applications. Besides biotechnological applications, the chitinases that are particularly active at high $\mathrm{pH}$ find application in plant pathogen suppression by hydrolyzing the cell wall component (chitin) of fungi, thereby inhibiting the fungal growth and spread of infection. The alkalistable chitinase producing Isoptericola jiangsuensis (Wu et al., 2011a) and Nocardioides sp. (Okajima et al., 1995) can be applicable for such soil amendment practices. The amendment of chitin with apatite has also been found to sequester the metals in marine sediments (Kan et al., 2013).

\section{Biotransformation}

The nitriles $(\mathrm{RC} \equiv \mathrm{N})$ are organic compounds, synthesized by chemical methods (ammoxidation, hydrocyanation, and dehydration of amides and oximes) or biologically produced by anaerobic degradation of amino acids (Harper and Gibbs, 1979). The cyanogenic plants also release nitrile compounds in the environment (Vetter, 2000). The nitriles are commonly used in the synthesis of other useful organic compounds or manufacturing of rubber (gloves) and super glue. Moreover, the selective hydrolysis or reduction of nitriles yields valuable compounds such as amides, acids, and amines. Despite their various uses, nitriles cannot be easily degraded and are known to persist for longer periods in the environment, causing toxic or hazardous effects on biological systems, therefore, nitriles have to be metabolized into non-toxic forms. The two enzymatic pathways [nitrile hydrolase/amidase (two steps) and nitrilases (single step)] are reported to be involved in the conversion of nitriles into carboxylic acid and ammonia. Some nitrile degrading bacteria, actinobacteria, and fungi have been isolated and characterized. Most of the well-known nitrile degraders are neutrophiles. Sorokin et al. (2007) showed that a microbial consortium could degrade nitriles completely. This consortium consists of an actinobacterium (Nitriliruptor alkaliphilus ANL-iso $2^{\mathrm{T}}$ ) and a bacterium (Marinospirillum sp. 
strain ANL-isoa). Nitriliruptor alkaliphilus ANL-iso2 $2^{\mathrm{T}}$ is an obligate alkaliphile and moderately salt-tolerant which plays a major role in the hydrolysis of isobutyronitrile (iBN; Sorokin et al., 2009). This actionobacterium has a nitrile hydratase/amidase pathway to metabolize isobutyronitrile (iBN) into isobutyroamide, isobutyrate and ammonia which are further scavenged by Marinospirillum sp. strain ANL-isoa. Nitriliruptor alkaliphilus ANL-iso $2^{\mathrm{T}}$ is also capable of utilizing propionitrile (C3), butyronitrile (C4), valeronitrile (C5), and capronitrile (C6) as carbon and nitrogen source, thus, indirectly cleaning the environment. This strain can, therefore, be applied as a potential candidate for bioremediation or other environmental biotechnological purposes.

\section{Bioweathering}

Weathering is a disintegration process of rock constituents into smaller fragments. These components are further broken down into mobilized forms of essential nutrients (e.g., $\mathrm{P}$ and $\mathrm{S}$ ) and elements (e.g., $\mathrm{Na}, \mathrm{K}, \mathrm{Mg}, \mathrm{Ca}, \mathrm{Mn}, \mathrm{Fe}, \mathrm{Cu}, \mathrm{Zn}, \mathrm{Co}$, and $\mathrm{Ni}$ ). The essential nutrients and elements are brought into crop lands or fields through wind or water. Microbial populations (bacteria and actinobacteria) occupying the rock zones show high resistance to radiations, desiccation and limited nutrient conditions. The filamentous microbes are capable of enhancing the weathering process as they penetrate through the rocks by the growing mycelia. The Streptomyces species are most commonly observed in rock weathering sites, since they have filamentous structure and are capable of growing as oligotroph (Cockell et al., 2013). They have a great efficiency to utilize the recalcitrant organic matter and form anthrospore under water stress. Cockell et al. (2013) reported that the indigenous microbial population of Icelandic volcanic rocks includes Arthrobacter, Knoellia, Brevibacterium, Rhodococcus, and Kribbella species. The investigation of the altered stones and monuments in the Mediterranean basin also revealed the presence of actinobacterial species which involved in the weathering of stones and monuments. These species belong to the three genera Geodermatophilus, Blastococcus, and Modestobacter of the family Geodermatophilaceae (Urzì et al., 2001). Similarly, other actinobacterial species such as Nocardioides, Kibdelosporangium (Abdulla, 2009), Arthrobacter, and Leifsonia (Frey et al., 2010) are known to accelerate the weathering process. Furthermore, some other actinobacteria capable of carrying out withering of rocks are also alkalitolerant such as [Isoptericola nanjingensis $\mathrm{H} 17 \mathrm{~T}$ (Huang et al., 2012) and Arthrobacter nanjingensis A33T (Huang et al., 2015)] and have been isolated from soil samples of Nanjing, China.

\section{Plant Growth Promotion}

Actinobacteria are well-known to exhibit antimicrobial and insecticidal properties and help in suppression of plant pathogenesis, thereby indirectly promoting plant growth. They also make iron available to plants for their growth (Francis et al., 2010). The plants and microbes can take up iron only in its reduced form $\left(\mathrm{Fe}^{+2}\right)$, while the iron exists as oxidized form $\left(\mathrm{Fe}^{+3}\right)$ in alkaline soils. Alkaliphilic actinobacteria reduce the iron (from $\mathrm{Fe}^{+3}$ to $\mathrm{Fe}^{+2}$ forms) and make it into soluble form which can be assimilated by plants and microbes for their growth (Valencia-Cantero et al., 2007). These actinobacteria are also capable of solubilizing phosphorus in alkaline conditions as solubility of phosphorus decreases in acidic or alkaline soils (Palaniyandi et al., 2013). An alkaliphilic strain, Kocuria rosea HN01 reduces $\mathrm{Fe}^{+3}$ into the soluble form $\left(\mathrm{Fe}^{+2}\right)$, thus, making the iron available to plants growing in the alkaline soil (Wu et al., 2014a).

\section{Humic Acid Reduction}

The oxidation and reduction of humic acid have a significant importance during the anaerobic biotransformation of organic and inorganic pollutants. The quinone moieties of humic acid act as center for oxido-reductive reactions (Lovley et al., 1996). The oxidized form of humic acid accepts electrons released from mineralization of organic pollutants. In addition, the reduced form of humic acid is also involved in biotransformation by reducing insoluble pollutants (oxidized) to soluble form (reduced). An alkaliphilic actinobacterium, Corynebacterium humireducens is capable of carrying out such biotransformation and catalyzes the reduction of the humic acids ( $\mathrm{Wu}$ et al., 2011b) as well as the reduction of a quinone into hydroquinone. The hydroquinone speeds up the process of mineralization of pollutants such as 2,4dichlorophenoxy acetic acid (Wang et al., 2009). The reduced humic acid could further be used to reduce the insoluble $\mathrm{Fe}^{+3}$ into soluble $\mathrm{Fe}^{+2}$ ions making them available for plant assimilation.

\section{Applications of Thermophilic and Alkaliphilic Actinobacteria}

Thermophilic and alkaliphilic actinobacteria are useful in bioremediation, gold nanoparticle synthesis, biofertilizers and biopesticides (Figure 3). In addition, they produce novel bioactive compounds and enzymes with commercial applications.

\section{Synthesis of Gold Nanoparticles}

The prokaryotes (bacteria and actinobacteria) as well as eukaryotes (algae, fungi, and yeast) have been currently being explored for the manufacturing of nanoparticles. The mechanism of gold particle synthesis involves the reduction of $\mathrm{Au}^{3+}$ by microbes when they are incubated with gold chloride (Beveridge and Murray, 1980). They synthesize nanoparticles either intracellularly or extracellularly. Among them, the use of prokaryotes is preferred because of their capability to tolerate high concentration of metal (Silver, 2003), leading to the production of a higher yield of nanoparticles. Moreover, the synthesis of nanoparticles by actinobacteria has an additional advantage of polydispersity property which prevents selfaggregation of nanoparticles (Ahmad et al., 2003a). The synthesis of gold nanoparticles by Thermomonospora sp. (Ahmad et al., 2003a) and alkalitolerant actinomycete Rhodococcus sp. (Ahmad et al., 2003b) was studied. The gold particles find various applications in diagnostics, therapeutic, and catalytic purposes. 


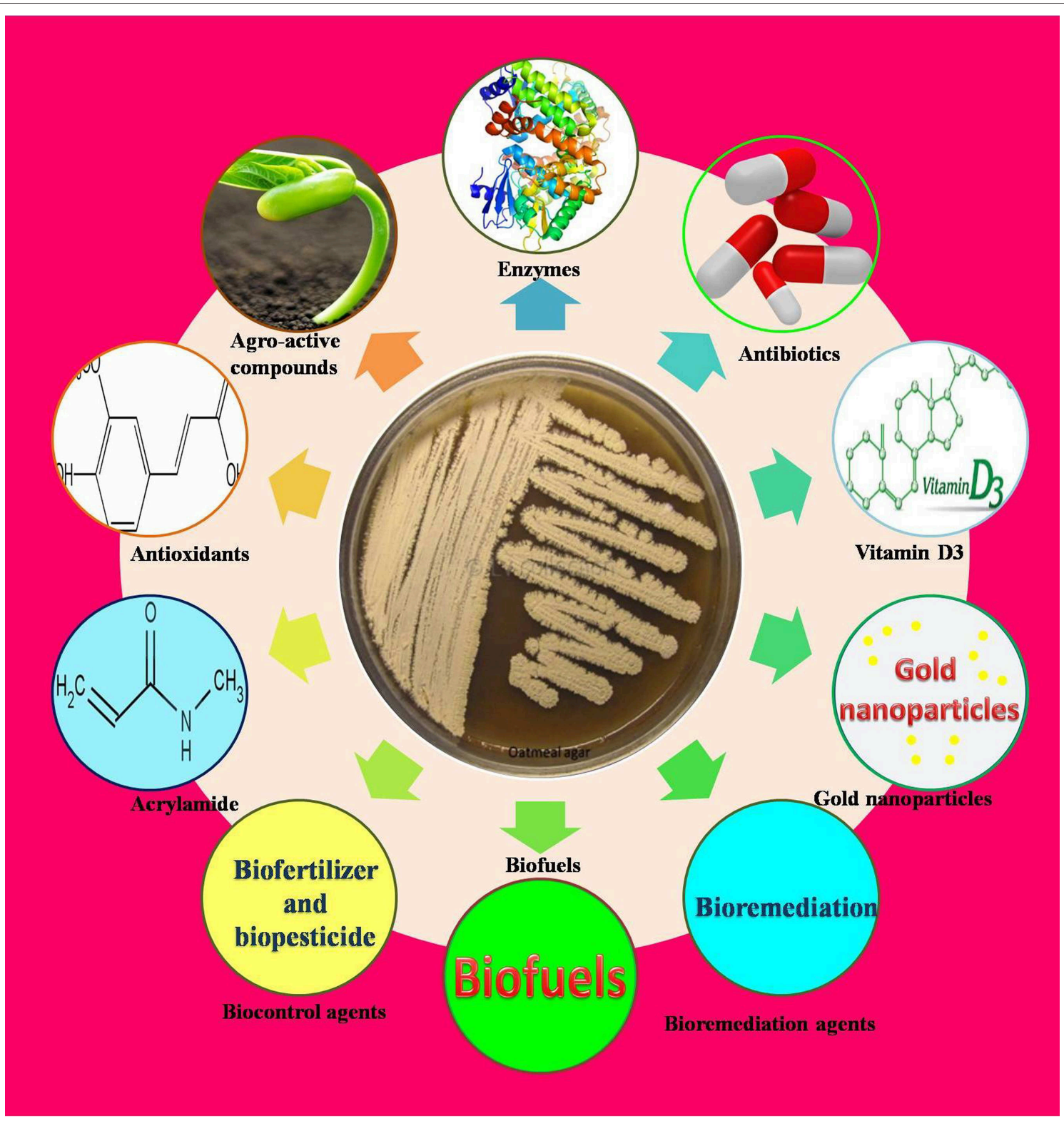

FIGURE 3 | Potential applications of Industrial thermophilic and alkaliphilic actinobacteria

\section{Bioremediation of Hydrocarbon Contaminated Sites}

The thermophilic actinobacteria decompose a large number of biomolecules (lignin, cellulose, and hemicellulose) and recycle the nutrient back into soil which enhances the soil productivity. The process of biodegradation of interactive complex substrates necessitates actinobacteria to secrete a range of extracellular hydrolytic and oxidative enzymes. The rapid hyphal colonization and enzyme secretion enable them as being a good candidate for bioremediation process. Moreover, they are capable of metabolizing recalcitrant polymers (hydrocarbons, xenobiotic, and toxic pesticides), plastics, and rubber. Tseng et al. (2007) isolated several plastic degrading actinobacterial species belonging to the genera (Actinomadura, Microbispora, Streptomyces, and Saccharomonospora). These actinobacteria degrade various biodegradable polyesters such as poly(ethylene succinate) (PES), poly(e-caprolactone) (PCL), poly(D-3hydroxybutyrate) (PHB), poly(tetramethylene succinate) PTMH, poly(L-lactide) (PLA), and terephthalic acid, and reduce their environmental impacts. A few other thermophilic actinobacteria are reported to act on polymer (rubber) and produce valuable chemicals such as carbonyl carbon atoms (aldehydes and ketone) and bifunctional isoprenoid species (Table 2). The toxic organic compounds include phenol and nitriles such as acrylonitrile and adiponitrile which are hazardous to human health. These harmful chemicals need 
TABLE 2 | List of thermophilic and alkaliphilic actinobacteria degrading plastics, rubber and organic pollutants.

\begin{tabular}{|c|c|c|}
\hline Actinobacteria strains & Substrate degraded & References \\
\hline \multicolumn{3}{|l|}{ PLASTICS DEGRADATION } \\
\hline Actinomadura miaoliensis BC $44 \mathrm{~T}-5^{\top}$ & $\mathrm{PHB}$ & Tseng et al., 2009 \\
\hline Actinomadura keratinilytica T16-1 & PLA & Sukkhum et al., 2012 \\
\hline Thermobifida fusca & Terephthalic acid & Kleeberg et al., 1998 \\
\hline Thermobifida alba AHK119 & Terephthalic acid. & Hu et al., 2010 \\
\hline \multicolumn{3}{|l|}{ Excellospora japonica IFO 144868} \\
\hline \multicolumn{3}{|l|}{ E. viridilutea JCM 339} \\
\hline Streptomyces sp. strain MG & PTMH and PCL & Tokiwa and Calabia, 2004 \\
\hline Streptomyces thermoviolaceus subsp. thermoviolaceus 76T-2 & PCL & Chua et al., 2013 \\
\hline Streptomyces bangladeshensis 77T-4 & $\mathrm{PHB}$ & Hsu et al., 2012 \\
\hline Actinomadura nitritigenes & Poly(cis-1,4-isoprene) & Ibrahim et al., 2006 \\
\hline \multicolumn{3}{|l|}{ Nocardia farcinica } \\
\hline \multicolumn{3}{|l|}{ Thermomonospora curvata } \\
\hline \multicolumn{3}{|l|}{ ORGANIC POLLUTANTS DEGRADATION } \\
\hline Streptomyces setonii strain ATCC 39116 & Phenol and benzoate & An et al., 2000 \\
\hline Pseudonocardia thermophila JCM3095 & Acrylonitrile & Yamaki et al., 1997 \\
\hline Kocuria rosea HNO1 & DDT (1,1,1-trichloro-2,2-bis(4-chlorophenyl) ethane) & Wu et al., 2014a \\
\hline Dietzia natronolimnaea JQ-AN & Aniline & Jin et al., 2012 \\
\hline Georgenia daeguensis & 4-Chlorophenol & Woo et al., 2012 \\
\hline Nocardioides sp. & 2,4-Dichlorophenol and 2,4,5-trichlorophenol & Maltseva and Oriel, 1997 \\
\hline Dietzia sp. Strain DQ12-45-1b & Petroleum hydrocarbons and crude oils & Wang et al., 2011 \\
\hline
\end{tabular}

to be degraded. Some thermophilic actinobacteria (listed in Table 2) are capable of metabolizing these lethal chemicals into non-toxic form by producing various enzymes such as phenol hydroxylase, polyphenol oxidase, catechol 2,3 dioxygenase, laccase, peroxidase, and nitrile converting enzymes (amidases, nitrilases, and nitrile hydratases). The pentachlorophenol is an organochlorine compound which works as a broad spectrum biocide and is used mainly in sawmills to preserve the woods. The soil and water resources of an area surrounding sawmills are contaminated with the chlorophenols causing hazardous effects on biological systems. The chlorophenols, therefore, need complete degradation. The Saccharomonospora viridis isolated from mushroom compost is capable of hydrolyzing this phenolic compound into non-toxic form (Webb et al., 2001).

A number of alkalitolerant and alkaliphilic actinobacteria have been reported to mineralize the hydrocarbon and other pollutants. The Dietzia species were found to have organic pollutant degradability and produce biosurfactants or bioemulsifiers by degrading n-alkanes (Nakano et al., 2011). The biosurfactants can be used in pharmaceuticals, detergents, textiles, and cosmetics. The species of other genera have also been reported to degrade hydrocarbons (listed in Table 2). A biofilm isolated from hypersaline liquids, has been shown to remove the hydrocarbon pollutants $(60-70 \%$ of crude oil, pure n-hexadecane, and pure phenanthrene; Al-Mailem et al., 2015). The two alkalitolerant actinobacteria such as Kocuria flava and Dietzia kunjamensis along with other bacterial community was reported in the biofilm. A biofilm is densely packed microbial community, formed by irreversible organization, cooperation, and secretion of polymers which facilitate the adherence of microbes to the substrates and hasten the process of biodegradation of toxic compounds. The alkaliphilic and alkalitolerant actinobacteria are known to play a role in bioremediation of hydrocarbon and other organic contaminants are listed in Table 2.

\section{Bioleaching}

Bioleaching is a process of extracting the metals from ores. The occurrence of alkaliphiles is comparatively less than acidophiles in metal leaching sites. The two alkaliphilic actinobacteria such as 
Nocardiopis sp. (Kroppenstedt, 1992) and Nocardiopsis metallicus strain KBS6 $^{\mathrm{T}}$ (Schippres et al., 2002) have a tendency to leach metals from the alkaline slag dump, could be applied in the process of metal extraction in alkaline sites.

\section{Bioremediation of Radionuclides Contaminated Sites}

The nuclear power plants generate huge amount of radioactive wastes (radionuclides) which contaminate the land areas and water resources e.g., lakes and rivers. The radionuclides contaminated sites contain other toxic compounds as well such as heavy metals (e.g., mercury) and toxic hydrocarbons. Exposures to these lethal compounds cause cancer, birth defects, and other abnormalities. Conventionally, the chemical (solvent extraction and chemical oxidation) or physical remediation (soil washing and soil vapor extraction) methods are employed to extract these hazardous pollutants. However, these methods are quite less efficient and expensive. The microbial remediation has been found to be cost effective with high efficacy and prevents spreading of radioactive wastes over a wider area. However, the radionuclides are highly unstable and disintegrate spontaneously to emit energy in the form of harmful radiations, which act as a principle factor to limit the use of bioremediation. Since most of the microbial population is sensitive to radiations and other stresses which necessitates to search and use of radiation resistant microbes for removal or oxidation of toxic metals (Gholami et al., 2015). Some alkaliphilic (Kocuria rosea MG2) and alkali tolerant actinobacterial species [Kineococcus radiotolerans (Phillips et al., 2002), Rubrobacter taiwanensis (Chen et al., 2004), Microbacterium radiodurans (Zhang et al., 2010), and Cellulosimicrobium cellulans UVP1 (Gabani et al., 2012)] are resistant to lethal radiations and can sustain under harsh conditions, thus, could be potential candidates for this purpose.

\section{Biocontrol Agent}

Actinobacteria are known to improve the quality of compost and increase its nutrient content. In addition, they also reduce the odor of compost as they are able to completely digest the organic matter present in compost (Ohta and Ikeda, 1978). The thermophilic actinobacteria (Streptomyces sp. No. 101 and Micromonospora sp. No. 604) have been shown to degrade yeast debris completely and deodorize the compost (Tanaka et al., 1995). Mansour and Mohamedin (2001), reported that the Streptomyces thermodiastaticus produced many extracellular enzymes involved in the cell lysis of pathogenic fungi like Candida albicans. Some thermophilic actinobacteria are capable of suppressing plant diseases, thereby promoting good health of crop plants which leads to increase in crop yield (Iijima and Ryusuke, 1996), therefore, these thermotolerant actinobacteria could be used as alternative to commercial pesticides.

\section{Bioactive Compounds Production}

Actinobacteria are a rich source of clinically important compounds, most importantly the compounds having antitumor, antimicrobial and immunosuppressive activities (Pritchard, 2005). They are the largest antibiotic producers among all microbes, and produce approximately $55 \%$ of the total known antibiotics (Raja and Prabakarana, 2011). Among these, 75\% were discovered from Streptomyces and remaining 25\% were from non-Streptomyces species. The bioactive compounds discovered till date are largely of mesophilic origins. A very few natural compounds have been reported from thermophilic and alkaliphilic actinobacteria (shown in Table 3). Most of the antibiotics of mesophilic origin are thermolabile that is they require low temperature to sustain their effectiveness, which may be problematic for longer storage and shipping practices. Routine use of such antibiotics leads to their degradation due to repeated freezing and thawing (Eisenhart and Disso, 2012). Some antibiotics are water insoluble (Stone, 1960) and organic solvent labile, therefore, need to be dissolved in warm water to improve their solubilization; this necessitates exploring thermophilic actinobacteria that produce thermostable alternatives to currently available antibiotics.

\section{Synthesis of Pharmaceutical Valuable Compounds}

Actinobacteria synthesize a large array of secondary metabolites (antioxidant, anti-inflammatory compounds, and clinically important enzymes; shown in Table 4). The antioxidants produced by the thermophilic and alkaliphilic actinobacteria are melanin, ferulic acid, and canthaxanthin. These antioxidants have multiple uses in the medical field, which have been used in the treatment of cancer, heart diseases and neurodegenerative disorders such as Alzheimer and Parkinson's diseases. Ferulic acid is a component of lignin, which is linked via the ester bonds to the polysaccharides (Scalbert et al., 1985). Ferulic acid is formed upon hydrolysis of lignin by feruloyl esterase (Huang et al., 2013). Apart from functioning as antioxidants, ferulic acid can also be used as a precursor for the synthesis of vanillin (food aromatic compounds), polymers, epoxides, and aromatic compounds (alkylbenzenes, protocatechuic acidrelated catechols, guaiacol, and catechol; Rosazza et al., 1995). An alkalitolerant, Dietzia sp. K44 produces canthaxanthin (diketocarotenoid) which has comparatively more antioxidant property than $\beta$-carotene and zeaxanthin. Canthaxanthin is naturally produced in animal and plant tissues to scavenge the free radicals (Venugopalan et al., 2013). Another important secondary metabolite, carotenoids (tetraterpenoid) is produced by Dietzia natronolimnaea HS-1 (Gharibzahedi et al., 2014). Carotenoids can be used as vitamin A precursor, free radicals scavenger and enhancer of the in vitro for the production of antibodies. Dietzia natronolimnaea HS-1 also produces canthaxanthin which was tested in the formulation of stable nanoemulsion (NE). The nanoemulsion system is a method to solubilize the hydrophobic antitumor compounds, which uses 2-hydroxypropyl-b-cyclodextrin (HP- $\beta$-CD) to formulate the water based drugs. The stability of NE was enhanced by mixing canthaxanthin with HP- $\beta$-CD to yield the stable inclusion complex. The stable NE has imperative therapeutical applications (Gharibzahedi et al., 2015).

Some clinically important enzymes have also been reported from thermophilic actinobacteria such as Streptomyces sp. (Chitte and Dey, 2002; Chitte et al., 2011) which have been shown 
TABLE 3 | List of bioactive compounds produced by thermophilic and alkaliphilic actinobacteria.

\begin{tabular}{|c|c|c|c|}
\hline Actinomyces isolates & Bioactive compounds & Activity & References \\
\hline \multicolumn{4}{|l|}{ THERMOPHILIC ACTINOBACTERIA } \\
\hline $\begin{array}{l}\text { Excellospora viridilutea SF2315 [reclassified as } \\
\text { Actinomadura viridilutea (Zhang et al., 2001)] }\end{array}$ & SF2315A and B & Antibacterial & Sasaki et al., 1988 \\
\hline Streptomyces thermophilus & Thermomycin & Antibacterial & Schone, 1951 \\
\hline Thermomonospora sp. & T-SA-125 & Antibacterial & Dewendar et al., 1979 \\
\hline Streptomyces refuineus subsp. thermotolerans & Anthramycin & Antitumor Antimicrobial & Hu et al., 2007 \\
\hline Microbispora aerata & Diketopiperazine & Neuroprotective agents & Ivanova et al., 2013 \\
\hline Microbispora aerata & Microbiaeratin & Antiproliferative and cytotoxic drug & Ivanova et al., 2007 \\
\hline Marinactinospora thermotolerans & $\beta$-Carboline and indolactam alkaloids & Antimalarial & Huang et al., 2011 \\
\hline \multicolumn{4}{|l|}{ ALKALIPHILIC ACTINOBACTERIA } \\
\hline Streptomyces werraensis & Erythromycin & Antibacterial & Sanghvi et al., 2014 \\
\hline Nocardiopsis dassonvillei WA52 & WA52-A Macrolide & Antifungal & Ali et al., 2009 \\
\hline Streptomyces sp. No. 1543 & Antimycin A & Antifungal & Sato et al., 1985 \\
\hline Streptomyces sp. DPTTB16 & 4'Phenul-1-napthyl-phenyl acetamide & Antifungal & $\begin{array}{l}\text { Dhanasekaran and } \\
\text { Panneerselvam, } 2008\end{array}$ \\
\hline Streptomyces griseus Var. autotrophicus & Faeriefungin & Antimicrobial and insecticidal activity & Nair et al., 1989 \\
\hline Streptomyces strain & Pyrocoll & Antiparasitic Antitumor & Dietera et al., 2003 \\
\hline Nocardiopsis sp. & Griseusin D & Anticancer & Li et al., 2007a \\
\hline Nocardiopsis alkaliphila YIM-80379 & Nocardiopyrones A and B & Antimicrobial & Wang et al., 2013 \\
\hline Nocardiopsis terrae YIM 90022 & Quinolone alkaloid and N-acetyl-anthranilic acid & Antimicrobial & Tian et al., 2014 \\
\hline
\end{tabular}

to produce fibrinolytic enzymes. Fibrinolytic enzymes dissolve the blood clot (fibrin) into smaller peptides and decrease the blood viscosity, and can be used for reducing the risk of arteriosclerosis, heart attack, and stroke. Asparaginase is a well-known anticancer enzyme which inhibits the growth of uncontrolled rapidly dividing cells by hydrolyzing the amino acid asparagine which is required by the rapidly proliferating cancer cells. Hatanaka et al. (2011a) cloned and expressed the asparaginase of Streptomyces thermoluteus subsp. fuscus NBRC 14270 Another pharmaceutically valuable enzyme, X-prolyldipeptidyl aminopeptidase (XDAP) is known to be produced by thermophilic Streptomyces sp. (Hatanaka et al., 2011b), which acts on proline rich proteins and produces short peptides. These peptides act as inhibitors of dipeptidyl peptidase-4 (DPP-IV) and can regulate the blood sugar levels as DPP-IV degrades glucagon like protein-1 (GLP-1) which regulates insulin production and lowers the blood sugar level. Thus, it could be used along with GLP-1 to treat diabetes (Hatanaka et al., 2011b). Another clinically important enzyme, vitamin D3 hydroxylase converts cholecalciferol $\left(\mathrm{VD}_{3}\right)$ to its biologically active form calcitriol $\left[1 \alpha, 25(\mathrm{OH})_{2} \mathrm{VD}_{3}\right]$. The cholecalciferol $\left(\mathrm{VD}_{3}\right)$ is an inactive form, synthesized from 7-dehydrocholesterol in the epidermal layer of skin through electrocyclic reaction on irradiance of ultraviolet. The bioconversion of $\mathrm{VD}_{3}$ is a two step process, first it gets converted to calcidiol $\left[25(\mathrm{OH}) \mathrm{VD}_{3}\right]$ by $\mathrm{P} 450$ in the liver, and then subsequently hydrogenated to calcitriol by P450 in the kidney. The calcitriol is a physiologically active form of vitamin $\mathrm{D}$, which is involved in the regulation of calcium and phosphate concentration in the blood plasma. This calcidiol and calcitriol can be artificially synthesized from cholesterol by a multistep chemical process, but the yield is very low. There is, thus, a need of an enzyme that can catalyze the hydrogenation of $\mathrm{VD}_{3}$ in a single step. Fujii et al. (2009) showed that Pseudonocardia autotrophica produces vitamin D3 hydroxylase catalyzing the conversion of VD3 into calcitriol, thus, could be used in the production of vitamin D (Fujii et al., 2009). Another important enzyme, aldose reductase catalyzes the conversion of glucose into sorbitol through polyol pathway. The high accumulation of sorbitol causes diabetes and other complications like retinopathy and neuropathy. An inhibitor YUA001 was identified from alkaliphilic Corynebacterium sp., that acts as a potent inhibitor of aldose reductase (Bahn et al., 1998). The two thermophilic species, Thermomonospora alba (Suzuki et al., 2001) and Thermobifida alba (Suzuki et al., 1998) produce compounds such as topostatin and isoaurostatin, respectively. These two compounds act as inhibitors of DNA topoisomerase and interfere with cellular processes like replication, transcription and translation of viruses, and therefore, could function as potential antiviral compounds.

\section{Industrially Important Enzymes}

Other than the listed uses, thermophilic and alkaliphilic actinobacteria produce a number of enzymes (amylase, proteases, lipase, cellulase, xylanase, inulinase, dextranase, and keratinase; Table 5) which are being produced commercially and used in industries all over the world (shown in Figure 4). Some important actinobacterial enzymes are briefly described below.

\section{Amylase}

A starch hydrolyzing process yields oligosacchharides and other simpler sugars (glucose, maltose, and maltotriose) which are either used in food application or syrup industry. The industrial 
TABLE 4 | Pharmaceutically valuable compounds and enzymes produced by thermophilic and alkaliphilic actinobacteria.

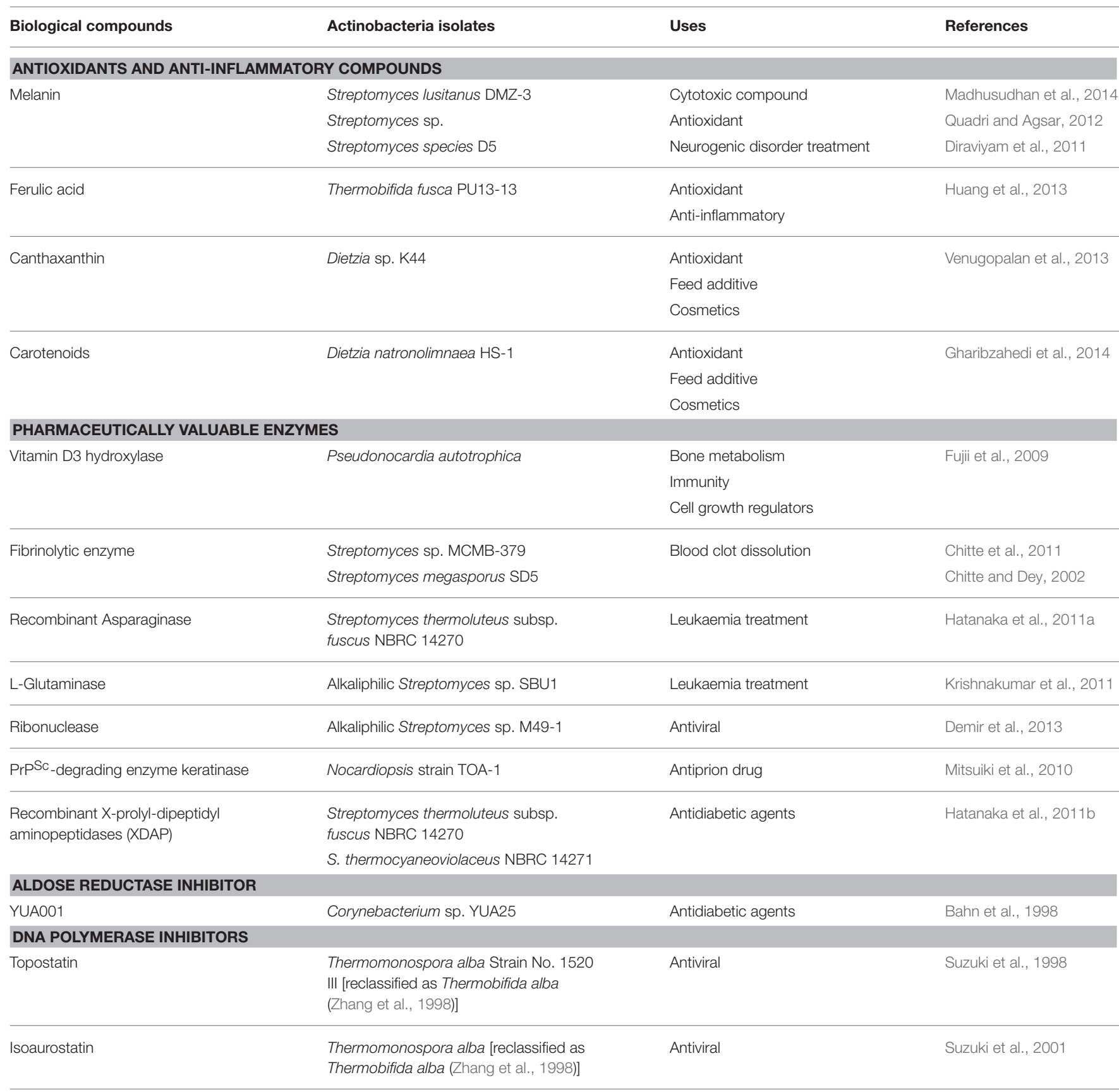

starch processing involves two high energy requiring steps: (1) Liquefaction (or gelatinization of starch molecules) which runs at very high temperature $\left(105-110^{\circ} \mathrm{C}\right)$ for $5 \mathrm{~min}$. (2) Saccharification (conversion of starch into simpler sugars) which requires the temperature at $55-60^{\circ} \mathrm{C}$ (Vieille and Zeikus, 2001). The raw starch binding thermostable amylases have become increasingly attractive to lower the process cost since they do not require gelatinized substrate for hydrolysis. The two thermophilic actinobacteria such as Streptomyces sp. (Kaneko et al., 2005) and Streptomyces sp. No. 4 (Primarini and Ohta,
2000), produce raw starch binding amylases which could be applied to reduce the energy input at industrial level making the overall process cost effective. Few other thermophilic actinobacteria are known to produce high maltotriose forming thermostable amylases which could be applicable in the food industries (listed in Table 5). Some alkaliphilic/alkalitolerant actinobacteria were reported to produce amylases functioning at alkaline $\mathrm{pH}$, which are being used in detergent formulation to improve the detergency. At present, many modern laundries prefer amylase containing detergent for washing clothes at a 
TABLE 5 | Commercially relevant enzymes produced by thermophilic and alkaliphilic actinobacteria and their potential uses.

\begin{tabular}{|c|c|c|c|c|}
\hline Enzyme & Actinobacteria strains & Optimum temperature and $\mathrm{pH}$ & Industrial applications & References \\
\hline \multirow[t]{3}{*}{ Amylase } & Thermomonospora viridis TF-35 & $60^{\circ} \mathrm{C}$ and 6.0 & Detergent & Takahashi et al., 1992 \\
\hline & & & Baking & \\
\hline & Thermomonospora curvata & $65^{\circ} \mathrm{C}$ and $5.5-6.0$ & Textile industry & Glymph and Stutzenberger, 1977 \\
\hline \multirow[t]{3}{*}{ Protease } & Saccharomonospora viridis SJ-21 & $70^{\circ} \mathrm{C}$ and $\mathrm{pH} 9$ & Detergents & Jani et al., 2012 \\
\hline & Nocardiopsis prasina $\mathrm{HA}-4$ & $55^{\circ} \mathrm{C}$ and $\mathrm{pH} 7-10$ & Leather & Ningthoujam et al., 2009 \\
\hline & & & Brewing & \\
\hline \multirow[t]{2}{*}{ Keratinase } & Actinomadura keratinilytica strain Cpt29 & $70^{\circ} \mathrm{C}$ and $\mathrm{pH} 10$ & Leather industry & Habbeche et al., 2014 \\
\hline & Thermomonospora curvata & $65^{\circ} \mathrm{C}$ and $\mathrm{pH} 6$ & Pharamaceutical uses & Stutzenberger, 1971 \\
\hline Xylanase & Streptomyces sp. Ab 106 & $60^{\circ} \mathrm{C}$ and $\mathrm{pH} 9.0$ & & Techapun et al., 2002 \\
\hline Acetylxylan esterase & Thermobifida fusca NTU22 & $80^{\circ} \mathrm{C}$ and 8.0 & Paper and pulp & Yang and Liu, 2008 \\
\hline Dextranase & Streptomyces sp. NK458 & $60^{\circ} \mathrm{C}$ and 9.0 & Sugar mills & Purushe et al., 2012 \\
\hline Nitrile hydratase & Pseudonocardia thermophila JCM 3095 & Thermostable $\left(50-80^{\circ} \mathrm{C}\right)$ & Acrylamide production & Martinez et al., 2014 \\
\hline \multirow[t]{2}{*}{ Laccase } & Thermobifida fusca BCRC 19214 & Stable at $50^{\circ} \mathrm{C}$ and $\mathrm{pH} 10.0$ & Waste treatment & Chen et al., 2013 \\
\hline & & & Textile dye treatment & \\
\hline $\begin{array}{l}\text { Carbon monoxide } \\
\text { dehydrogenase }\end{array}$ & Streptomyces sp. strain G26 & $69^{\circ} \mathrm{C}$ & $\begin{array}{l}\text { Bioenergy generation } \\
\text { Biofilters }\end{array}$ & Bell et al., 1988 \\
\hline
\end{tabular}

lower temperature in order to save energy (Chakraborty et al., 2012).

\section{Proteases}

Proteases are one of the most important class of hydrolytic enzymes, which constitute $>65 \%$ of the total industrial applications. A large array of actinobacterial species (including both alkalitolerant and alkaliphiles) produces alkalistable proteases and keratinase of commercial interest. The alkalistable proteases possess considerable applications in various industries such as detergent, leather, and food industries (Ellaiah et al., 2002). The alkalistable proteases are also used in the process of silver recovery from used X-ray or photographic film. The proteases of alkaliphilic actinobacteria are not only alkalistable but also thermostable (Gohel and Singh, 2012a), salt tolerant, and function actively in the presence of organic solvent (Thumar and Singh, 2009). The alkali-thermostable proteases could be a potent candidate in leather industries where the alkaline condition and high temperature are maintained during tanning process. In addition, salt and organic solvent tolerant proteases of actinobacteria find various applications in industrial processes requiring high salt concentration and solvents. The organic solvent tolerance increases the industrial value of proteases as organic solvents enhance the catalytic properties of hydrolytic enzymes (Klibanov, 2001) and preclude the occurrence of undesirable side reactions during the process.

\section{Cellulases, Xylanase, and Acetyl Xylan Esterase}

Cellulase and xylanase are the two industrially important enzymes that enable us to utilize the agricultural residues in generation of biofuel in a sustainable manner. The extreme operational conditions of industries demand highly thermostable enzymes. The two thermophilic actinobacteria, Acidothermus cellulolyticus (Mohagheghi et al., 1986) and Thermobifida fusca (Kim et al., 2005) are significantly fascinating the biofuel industry as well as several others (food, animal feed, textile, paper and pulp industry) as they are known to possess the robust enzymatic system to degrade cellulose and xylan fractions of lignocelluloic residues. The cellulases of T. fusca and A. cellulyticus have extensively been studied and are being used in bioethanol production from plant cell components. A cellulase from T. fusca has an additional advantage of extracting phenolics from apple peel, which can be used as antioxidants (Kim et al., 2005). This moderately thermophilic actinobacterium also secretes thermostable acetyl xylan esterase which catalyzes the removal of acetyl group from acetylxylan making easy access of xylanases to the substrate leading to its complete degradation (Yang and Liu, 2008). Thermostable and alkalistable enzymes capable of 


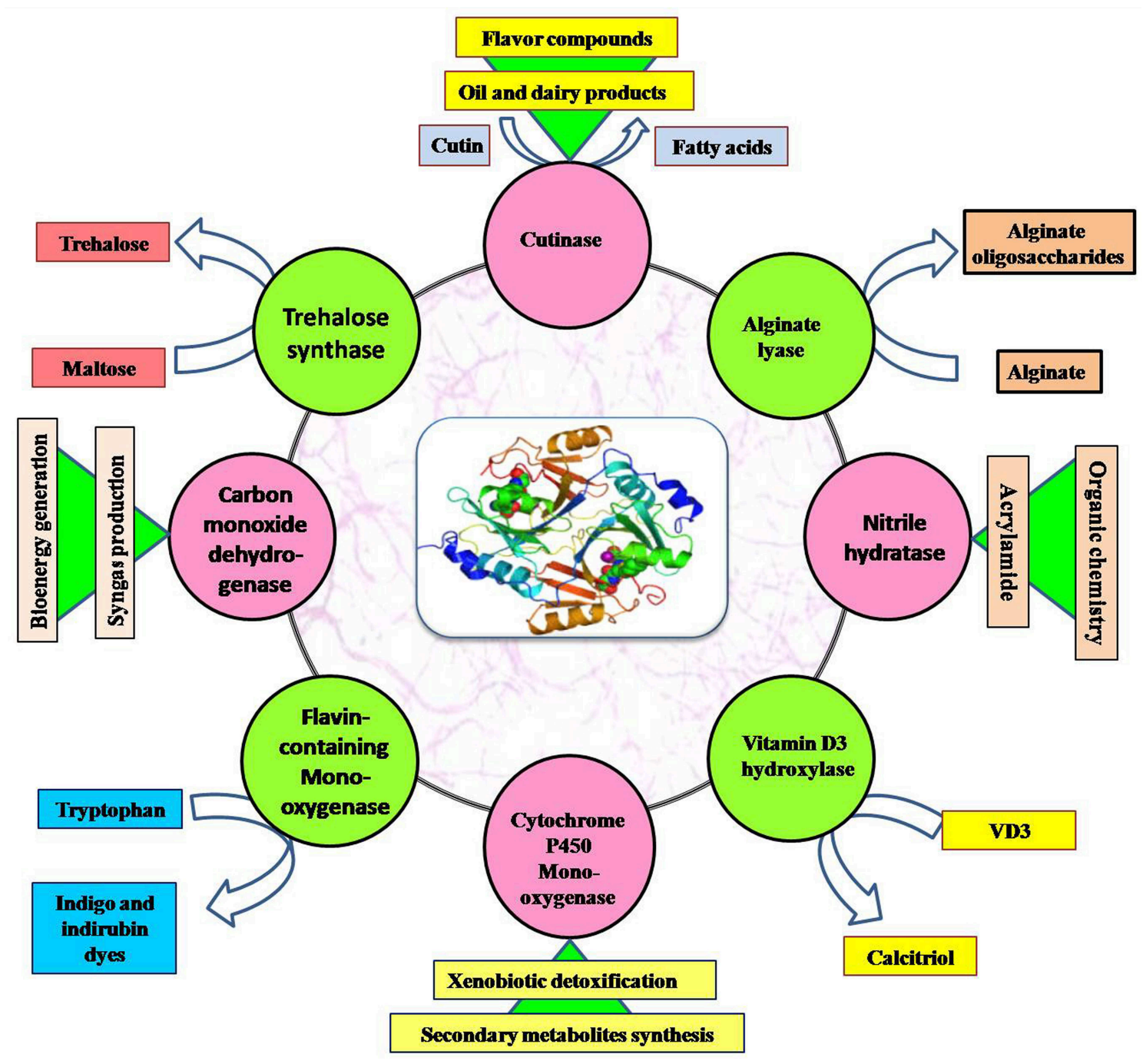

FIGURE 4 | Application of important enzymes produced by thermophilic and alkaliphilic actinobacteria.

degrading lignocelluloic substrate have also been characterized from other thermophilic and alkaliphilic actinobacteria (listed in Table 5).

\section{Dextranase}

The process of sugar production from sugarcane juice requires high temperature and alkaline $\mathrm{pH}$. The indigenous microorganisms present in the juice may produce dextran which needs to be degraded, otherwise it blocks the filter and slows down the clarification process, thus, decreasing the yield and quality of sugar produced (Purushe et al., 2012). Since the process occurs at high temperature and alkaline $\mathrm{pH}$, the addition of alkalithermostable dextranase before processing can improve the yield as well as quality of sugar produced. Therefore, dextranase produced by some thermoalkaliphilic actinobacteria such as Streptomyces sp. NK458 is well-suited for such application (Purushe et al., 2012).

\section{Nitrile Hydratase}

Another enzyme kown as nitrile hydratase has been reported from a large number of mesophilic and thermophilic actinobacteria, and is involved in the biotransformation of nitriles into useful compounds such as amines, amides, amidines, carboxylic acids, esters, aldehydes, and ketones (Banerjee et al., 2002). The industrial applicability of thermostable nitrile hydratases demands detailed investigation on enzymes from thermophilic actinobacteria. The thermostable nitrile hydratase from Pseudonorcardia thermophila has recently been immobilized in the gel matrix for acrylamide production (Martinez et al., 2014).

\section{Laccase}

Laccase catalyzes the oxidation of phenolics (2,6dimethylphenylalanine and $\mathrm{p}$-aminophenol) and produces colors, therefore, it is being used as a hair coloring agent. The 
coloring occurs best at alkaline $\mathrm{pH}$, as in alkaline condition, hair tends to swell up leading to easy penetration of dye molecules. Therefore, an alkalistable laccase would be the best candidate to be used for such application. Actinobacteria are known to produce thermoalkalistable laccase (e.g., Thermobifida fusca BCRC 19214; Chen et al., 2013). Therefore, laccase can be produced from such actinobacterial strains for hair coloring application.

\section{Alginate Lyase}

The alginate is a linear acidic polysaccharide and produced as a major component of cell wall of seaweeds. It consists of 1,4linked $\alpha$-d-mannuronate $(M)$ and its epimer $\alpha$-l-guluronate $(G)$. These monomers polymerize in three ways: homopolymerization of $\mathrm{G}$ blocks [poly $(\mathrm{G})$ ] and homopolymerization of M blocks [poly (M)], and heteropolymerization of MG blocks [poly (MG)] (Gacesa, 1992). Alginate lyases act on these polymers to produce alginate oligosaccharides which can be used as therapeutic agents (anticoagulant, antitumor agent. and anti-inflammatory agent; Iwamoto et al., 2005). Alginate lyases are classified into two types (monofunctional and bifunctional) on the basis of their substrate specificity. Monofunctional enzymes can either act on $\operatorname{poly}(\mathrm{M})$ or $\operatorname{poly}(\mathrm{G})$ and bifunctional enzymes prefer the poly(MG) (Tondervik et al., 2010). But there are fewer reports on bifunctional and thermostable alginate lyase. An alkalitolerant actinobacterium, Isoptericola halotolerans CGMCC 5336 has been shown to produce moderately thermostable bifunctional alginate lyase (Dou et al., 2013).

\section{Alditol oxidase}

Oxidation of primary and secondary alcohols yields oxidative products that are used to synthesize other useful compounds. Chemical oxidation methods mediate the reaction by using heavy metals such as chromium and manganese. Interestingly, biocatalysts can also be employed to derive such oxidation reactions e.g., alcohol dehydrogenase. However, this enzyme requires $\mathrm{NAD}(\mathrm{P})^{+}$as cofactor for the reaction which is very costly. To overcome this demerit, the research is being focused on isolating and characterizing thermostable flavoprotein alditol oxidase (AldO) from microbial sources for industrial applications. The gene of AldO of a thermophilic actinobacterium (Acidothermus cellulolyticus) was identified while searching for the homologs of the well-characterized AldO of Streptomyces coelicolor in the genome database (Winter et al., 2012). The gene of AldO was cloned and expressed in E. coli and the recombinant enzyme AldO displays a high thermostability (half-life at $75^{\circ} \mathrm{C}$ of $112 \mathrm{~min}$ ) and requires cheaper molecular oxygen as terminal electron acceptor. Therefore, this enzyme can be used as an alternative of chemical catalysts in industrial processes.

\section{Carbon Monoxide Dehydrogenase}

Carbon monoxide dehydrogenase is an oxidoreductase enzyme that catalyzes the interconversion between carbon monoxide and carbon dioxide. This enzyme is produced in both anaerobic and aerobic microbes during autotrophic mode of nutrition. The enzyme has a great affinity to bind $\mathrm{CO}$, thereby trapping the
$\mathrm{CO}$ from the environment, therefore, can be applied in biofilters to purify these toxic gases released by industries. Streptomyces sp. G26 (Bell et al., 1988) and Streptomyces thermoautotrophicus (Gadkari et al., 1990) have been reported to produce the thermostable carbon monoxide dehydrogenase which is wellsuited for filtering the hot air released from industries. This can also be employed in the biosensor to detect and quantitate atmospheric CO concentration.

\section{Cutinase}

Cutinase is a serine esterase that acts on the ester bonds of cutin (a component of cuticle layer of plant aerial parts). Thermobifida fusca produces two types of cutinases which display higher thermostability than the fungal cutinases (Chen et al., 2010). The enzyme exhibits broad substrate specificity such as plant cutin and soluble/insoluble esters and hydrolyzes them into hydroxyl and hydroxy epoxy fatty acids as end products. These fatty acids can be used as substrate in the enantioselective esterification reactions or in the production of phenolic compounds as well as the oil and dairy products. The enzyme can also metabolize the synthetic polyesters and other organic pollutants (Kleeberg et al., 2005), therefore, could be used in the in vitro biodegradation processes.

\section{Genome Annotation, Molecular Insights, and Genetic Manipulation of Thermophilic and Alkaliphilic Actinobacteria}

The mechanisms, biosynthetic pathways and mode of action of several antibiotics of mesophilic origin have been elucidated. Classical random mutagenesis and rational genetic methods such as ribosome engineering, genome shuffling, down-regulation, and up-regulation of structural genes have been used to manipulate the genetic makeup of wild type actinobacteria strain for obtaining strains with desirable properties for e.g., enhancement in the antibiotic production titer (Olano et al., 2008). However, despite having prospective and novel characteristics, the biosynthetic pathways of bioactive compound and enzymatic system of the thermophilic and alkaliphilic actinobacteria are comparatively less explored. The inadequate information is available related to the heterologous gene expression, in vitro genetic engineering, structural elucidation and molecular insight on the catalysis of thermostable and alkalistable enzymes of actinobacteria. Only two thermophilic actinobacterial species, Thermobifida fusca and Acidothermus cellulyticus have been well-studied which are known to secrete a large array of highly thermostable and broad $\mathrm{pH}$ stable glycoside hydrolases. Their glycoside hydrolases are gaining considerable attention in the fuel biotechnology. The genes of thermo- or alkali-stable enzymes of some other thermophilic and alkaliphilic actinobacteria were cloned and expressed as well (shown in Table 6).

The complete genome sequence analysis reveals the presence of genes encoding industrially useful enzymes or enzymes involved in the biosynthetic pathway of novel bioactive compounds (Velásquez and van der Donk, 2011). This also 
TABLE 6 | Summary of heterologous expression of proteins of thermophilic and alkaliphilic actinobacteria.

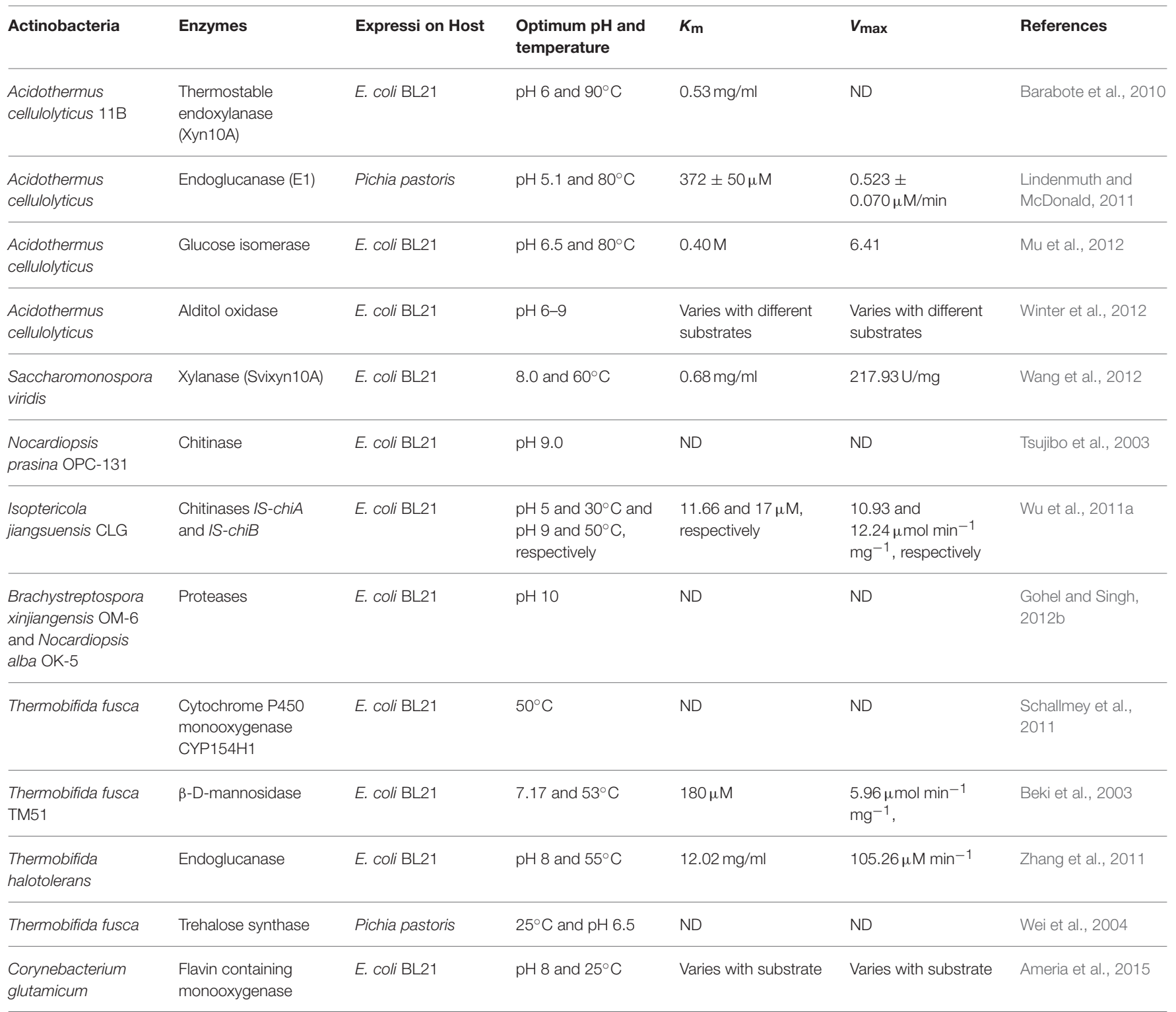

${ }^{\star} N D$, not determined.

provides better understanding of the genetic makeup and cellular mechanisms of an organism which enables us to engineer microbes in order to enhance their efficacy for biotechnological purposes. The genome sequence of some important thermophilic and alkaliphilic actinobacteria were annotated and analyzed which provides some valuable information related to these microbes (summarized in Table 7). For instance, the genome annotation of cellulolytic actinobacterium, Thermobifida fusca revealed the presence of additional 29 putative glycoside hydrolases (cellulose-, dextran/starch-, and xylan-degrading enzymes) than the previously characterized glycosidases (Lykidis et al., 2007). This actinobacterium has been designated as a model organism for the cellulose degradation. Thermobifida fusca YX has been metabolically engineered to be used in biofuel production (Deng and Fong, 2011). The gene of bifunctional butyraldehyde/alcohol dehydrogenase (adhE2) from Clostridium acetobutylicum ATCC 824 was introduced into the genome of T. fusca to enhance its efficacy for cellulose degradation. This genetically engineered strain can utilize untreated lignocellulose and convert it directly into primary alcohols (1-propanol and 1-butanol). T. fusca is known to produce six structurally and functionally distinct cellulases (El-E6; Irwin et al., 1993). Out of these, the three enzymes [E1 (Cel9B), E2 (Cel6A), and E5 $(\mathrm{Cel} 5 \mathrm{~A})]$ are $\beta$ - $(1,4)$-endoglucanases and catalyze the conversion of insoluble cellulose into cellobiose and other simpler sugars ( $\mathrm{Hu}$ and Wilson, 1988). The other two cellulases such as E6 (Cel48A) and E3 (Cel6B) (Zhang et al., 1995) are $\beta$ - $(1,4)$ exoglucanases and one cellulase E4 (Cel9A) has the ability to catalyze the endo- and exo-cellulysis. These six cellulases are produced in small quantities under uninduced conditions. But 


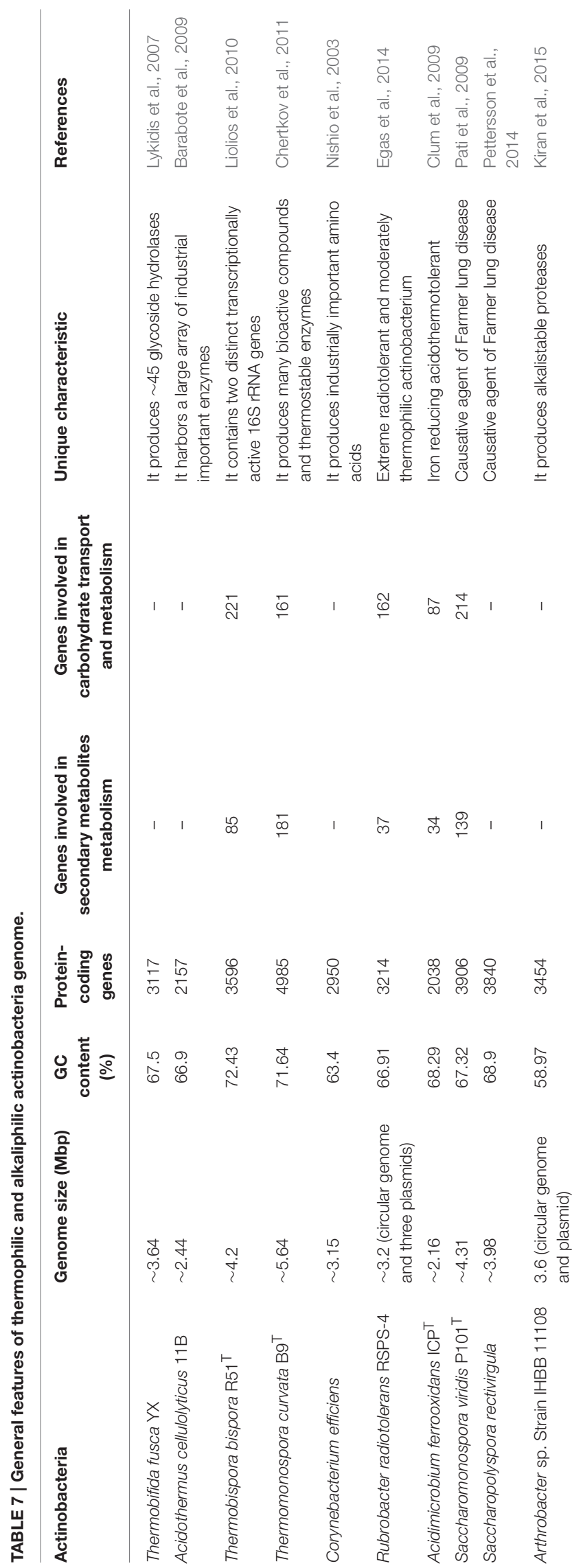

the constitutive expression of E2 was comparatively higher than others. The cellulase E2 has been shown to play a vital role in the early growth period of T. fusca (Spiridonov and Wilson, 1998). A transcriptional regulator CelR (340-residue polypeptide) binds to the operator (14-base pair inverted repeat) which is present in the upstream region of genes of six cellulases and represses the transcription of the cellulase genes in T. fusca (Spiridonov and Wilson, 1999). The binding of CelR is controlled by the presence of cellobiose which acts as an inducer and binds with repressor protein (CelR). Binding of cellobiose brings conformational changes in CelR protein and facilitates its dissociation from operators, thereby inducing the transcription of mRNA of cellulases. The cellulase Cel9A-90 (E4) shows highest activity among other cellulases in crystalline form. It has catalytic domain (CD) of a family 9 cellulases, a cellulose binding module (CBM3c), a fibronectin III-like domain, and a family 2 CBM domain (Li et al., 2010). A active site cleft is present in the CD that consists of six glucose binding sites, numbered from -4 to +2 . These residues are aligned with a flat binding surface of the CBM3c. The mutein Cel9A-51 (without CBM3c) revealed the significant role of $\mathrm{CBM} 3 \mathrm{c}$ in processivity of the enzyme. The enzymatic activity of Cel9A was shown to be enhanced upon replacement of a conserved residue (D513) of the CBM domain (Li et al., 2007b). A mutein Cel9A-68 was constructed by deleting CBM2 domain from a Cel9A-90 gene, which showed comparatively higher cellulolytic activity (Li et al., 2010). Another mutein Cel9A-68 (T245-L251) R252K (DEL) showed slightly improved filter paper activity and increased binding affinity toward bacterial microcrystalline cellulose (Zhou et al., 2004). An enzyme E5 (Cel5A) was found to be detergent stable, which has total six cysteine residues involved in the formation of three disulfide bonds. Among them, one bond is exposed outside which gets easily reduced to free sulfahydryl group while the other two bonds are not accessible. The reduction of one accessible bond does not affect the activity of an enzyme (McGinnis and Wilson, 1993). Thermobifida fusca also produces other thermostable enzymes (amylase, xylanase, and mannase). Xylanase reported from $T$. fusca is thermostable. Random mutagenesis was carried out to improve catalytic efficiency (12-fold increased), substrate affinity (4.5-fold decreased) and alkalistability of this xylanase. The thermostability of the mutein, however, decreased with the improvement of other functional characteristics (Wang and Xia, 2008).

Another cellulolytic actinobacterium, Acidothermus cellulyticus, is reported as a potent decomposer of plant cell material. The complete genome annotation revealed that it harbors 43 genes encoding carbohydrate active enzymes. Out of 43 , total 35 proteins are glycoside hydrolases and remaining eight belong to carbohydrate esterases type. The 17 plant cell wall degrading enzymes (cellulolytic and hemicellulose hydrolysis), 10 fungal cell wall degrading enzymes (chitinases, $\mathrm{N}$-acetylglucosaminidase, GH16 endo-1,3-beta-glucanase and others) and 16 other proteins (glycogen and trehalose synthesizing and degrading enzymes including GH13 family $\alpha$-amylase) were identified from this actinobacterium. Among 43 enzymes, only 21 are actively secreted, while others are produced intracellularly (Barabote et al., 2009). The endoglucanase 
(E1 or Cel5A) of A. cellulolyticus is well-studied, which is ultra-thermostable, acid-stable, and displays higher substrate specificity (Tucker et al., 1989). The Cel5A belongs to glucoside hydrolases family 5 and 4/7 superfamily, and has been cloned in a number of hosts such as transgenic plants [tobacco (Dai et al., 2000), maize (Biswas et al., 2006), rice (Chou et al., 2011), and many others], and Pichia pastoris (Lindenmuth and McDonald, 2011). The endoglucanase producing transgenic plants ease the process of bioconversion of lignocellulosic materials into biofuels. The catalytic efficiency of Cel5A was increased by replacing of Tyr245 of WT-Cel5A with Gly (Y245G). This mutation reduces the end product inhibition and enhances the activity by $1480 \%$. The mutein also releases $40 \%$ extra soluble sugar than wild type E1 enzyme (Baker et al., 2005). The gene of GH12 endoglucanase (not previously characterized) of $A$. cellulolyticus along with Cel5A gene were expressed into the Zymomonas mobilis to construct a consolidated bioprocessing (CBP) organism. Consolidated bioprocessing (CBP) is a new biotechnological approach to convert pretreated lignocellulosic materials to ethanol by using a single organism producing multiple hydrolytic enzymes (Linger et al., 2010).

Xylanase producing alkalitolerant actinobacterium, Streptomyces viridochromogenes strain M11 was isolated from marine sediment samples collected from the Xiaoping Island, China. This Streptomyces sp. produces thermostable and a broad $\mathrm{pH}$ stable xylanase. The xylanase production in this strain was increased (14\% higher activity) by ribosome engineering. The ribosome engineering is an approach to introduce mutation in ribosome by using high concentrations of various antibiotics [10 times more concentration than minimal inhibitory concentration (MIC)]. This engineered strain produces antibiotic resistant mutants by causing mutation in the gene rpsL (ribosomal protein S12) and gene rsmG (16S rRNA methyltransferase). The K88R mutation of rpsL of this strain enhanced the xylanase production level (Liu et al., 2013). The UV mutants of Streptomyces griseoaurantiacus have also been shown to produce efficient cellulases (stable at high temperature and broad $\mathrm{pH}$ range) in relatively higher titers (Kumar, 2015). Crude oil degrading alkalitolerant actinobacterium, Dietzia strain DMYR9 has been isolated from oilfield and was metabolically engineered by irradiating with ${ }^{12} \mathrm{C}^{6+}$ heavy ions to enhance its biodegradability (Zhou et al., 2013).

\section{Conclusions and Future Perspectives}

Thermophilic and thermotolerant actinobacteria are found in 25 genera belonging to four major classes (Actinobacteria, Acidimicrobiia, Rubrobacteria, and Thermoleophilia). The taxonomic status of many thermophilic actinobacteria is ambiguous, therefore, has been revised repeatedly in the past. Bioprospecting of thermophilic actinobacteria represents an extensive pool of industrial and pharmaceutically relevant biomolecules. Their high abundance and metabolic versatility offer a new robust gateway to bioremediation of pollutants and organic residues. Although the first description on alkaliphilic actinobacteria appeared 70 years ago, the literature available on biodiversity, physiology, and ecology of alkaliphilic actinobacteria is quite inadequate. The growing industrial demand for alkalistable enzymes and biomolecules calls for further research on isolation, characterization, and bioprospecting of novel alkaliphilic actinobacteria. The use of metagenomic approaches will throw light on the novel genera of non-culturable actionobacteria and their genes in alkaline and hot environments. The availability of genome sequences of alkaliphilic and thermophilic actinobacteria is expected to encourage microbiologists and biotechnologists to go for gene mining that may lead to the discovery of novel biomolecules.

\section{Acknowledgments}

The authors gratefully acknowledge financial assistance from the Department of Biotechnology (BT/PR4771/PID/6/636/2012) and University Grants Commission, Government of India, New Delhi (Sch/SRF/AA/139/F-361/2012-2013), while writing this review.

\section{References}

Abdulla, H. (2009). Bioweathering and biotransformation of granitic rock minerals by actinomycetes. Microbiol. Ecol. 58, 753-761. doi: 10.1007/s00248-0099549-1

Ahmad, A., Senapati, S., Khan, M. I., Kumar, R., and Sastry, M. (2003a). Extracellular biosynthesis of monodisperse gold nanoparticles by a novel extremophilic actinomycetes Thermomonospora spp. Langmuir 19, 3550-3553. doi: 10.1021/la0267721

Ahmad, A., Senapati, S., Khan, M. I., Kumar, R., and Sastry, M. (2003b). Intracellular synthesis of gold nanoparticles by a novel alkalotolerant actinomycete Rhodococcus species. Nanotechnology 14, 824-828. doi: 10.1088/0957-4484/14/7/323

Albuquerque, L., Johnson, M. M., Schumann, P., Rainey, F. A., and da Costa, M. S. (2014). Description of two new thermophilic species of the genus Rubrobacter, Rubrobacter calidifluminis sp. nov. and Rubrobacter naiadicus sp. nov., and emended description of the genus Rubrobacter and the

species Rubrobacter bracarensis. Syst. Appl. Microbiol. 37, 235-243. doi: 10.1016/j.syapm.2014.03.001

Ali, M. I., Ahmad, M. S., and Hozzein, W. N. (2009). WA 52 - a Macrolide antibiotic produced by alkalophile Nocardiopsis dassonvilleli WA 52. Aust. J Basic Appl. Sci. 3, 607-616.

Alloisio, N., Marechal, J., Heuvel, B. V., Normand, P., and Berry, A. M. (2005). Characterization of a gene locus containing squalene-hopene cyclase (shc) in Frankia alni ACN14a, and an shc homolog in Acidothermus cellulolyticus. Symbiosis 39, 83-90.

Al-Mailem, D. M., Eliyas, M., Khanafer, M., and Radwan, S. S. (2015). Biofilms constructed for the removal of hydrocarbon pollutants from hypersaline liquids. Extremophiles 19, 189-196. doi: 10.1007/s00792-0140698-x

Alonso-Gutiérrez, J., Teramoto, M., Yamazoe, A., Harayama, S., Figueras, A., and Novoa, B. (2011). Alkane-degrading properties of Dietzia sp. H0B, a key player in the prestige oil spill biodegradation (NW Spain). J. Appl. Microbiol. 111, 800-810. doi: 10.1111/j.1365-2672.2011.05104.x 
Ameria, S. P. L., Jung, H. S., Kim, H. S., Han, S. S., Kim, H. S., and Lee, J. H. (2015). Characterization of a flavin-containing monooxygenase from Corynebacterium glutamicum and its application to production of indigo and indirubin. Biotechnol. Lett. 37, 1637-1644. doi: 10.1007/s10529-015-1824-2

An, H. R., Park, H. J., and Kim, E. S. (2000). Characterization of benzoate degradation via ortho- cleavage by Streptomyces setonii. J. Microbiol. Biotechnol. 10, 111-114

Ara, I., Daram, D., Baljinova, T., Yamamura, H., Hozzein, W. N., Bakir, M. A., et al. (2013). Isolation, classification, phylogenetic analysis and scanning electron microscopy of halophilic, halotolerant and alkaliphilic actinomycetes isolated from hypersaline soil. Afr. J. Microbiol. Res. 7, 298-308. doi: 10.5897/AJMR12.498

Asgarani, E., Soudi, M. R., Borzooee, F., and Dabbagh, R. (2012). Radioresistance in psychrotrophic Kocuria sp. ASB 107 isolated from Ab-e-Siah radioactive spring. J. Environ. Radioact. 113, 71-176. doi: 10.1016/j.jenvrad. 2012.04.009

Augustine, N., Wilson P. A., Kerkar, S., and Thomas, S. (2012). Arctic actinomycetes as potential inhibitors of Vibrio cholerae biofilm. Curr. Microbiol. 64, 338-342. doi: 10.1007/s00284-011-0073-4

Bahn, Y. S., Park, J. M., Bai, D. N., Takase, S., and Yu, J. H. (1998). YUA001, a novel aldose reductase inhibitor isolated from alkalophilic Corynebacterium sp. YUA25 I. Taxonomy, fermentation, isolation and characterization. J. Antibiot. 51, 902-907. doi: 10.7164/antibiotics.51.902

Baker, J. O., McCarley, J. R., Lovett, R., Yu, C. H., Adney, W. S., Rignall, T. R., et al. (2005). Catalytically enhanced endocellulase CeI5A from Acidothermus cellulolyticus. Appl. Biochem. Biotechnol. 121-124, 129-148. doi: 10.1007/9781-59259-991-2_12

Baldacci, E. (1944). Contributo alla systematica degli actenomyceti: X-XVI Actinomyces madurae; Proactinomyces ruber; Proactinomyces pseudomadurae; Proactinomyces polychromogenus; Proactinomyces violaceus; Actinomyces coeruleus; cjn un elencj alfabetico delle specie e delle varieta finora studiate. Atti. Ist. Dot. Univ. Pavia Ser. 3, 139-193.

Banerjee, A., Sharma, R., and Banerjee, U. C. (2002). The nitrile-degrading enzymes: current status and future prospects. Appl. Microbiol. Biotechnol. 60, 33-44. doi: 10.1007/s00253-002-1062-0

Bansode, V. B., and Bajekal, S. S. (2006). Characterization of chitinases from microorganisms isolated from Lonar Lake. Ind. J. Biotechnol. 5, 357-363.

Barabote, R. D., Parales, J. V., Guo, Y. Y., Labavitch, J. M., Parales, R. E., and Berry, A. M. (2010). Xyn10A, a thermostable endoxylanase from Acidothermus cellulolyticus11B. Appl. Environ. Microbiol. 76, 7363-7366. doi: 10.1128/AEM.01326-10

Barabote, R. D., Xie, G., Leu, D. H., Normand, P., Necsulea, A., Daubin, V., et al. (2009). Complete genome of the cellulolytic thermophile Acidothermus cellulolyticus 11B provides insights into its ecophysiological and evolutionary adaptations. Genome Res. 19, 1033-1043. doi: 10.1101/gr.084848.108

Barakate, M., Ouhdouch, Y., Oufdou, K., and Beaulieu, C. (2002). Characterization of rhizospheric soil Streptomycetes from Moroccan habitats and their antimicrobial activities. World J. Microbiol. Biotechnol. 18, 49-54. doi: 10.1023/A:1013966407890

Baranasic, D., Gacesa, R., Starcevic, A., Zucko, J., Blazic, M., Horvat, M., et al. (2013). Draft genome sequence of Streptomyces rapamycinicus Strain NRRL 5491, the producer of the immunosuppressant rapamycin. Genome Announc. 1, 1-2. doi: 10.1128/genomeA.00581-13

Battistuzzi, F. U., and Hedges, S. B. (2009). A major clade of prokaryotes with ancient adaptation to life on land. Mol. Biol. Evol. 26, 335-343. doi: 10.1093/molbev/msn247

Becker, B., Lechevalier, M. P., Gordon, R. E., and Lechevalier, H. A. (1964). Rapid differentiation between Nocardia and Streptomyces by paper chromatography of whole-cell hydrolysates. Appl. Microbiol. 12, 421-423.

Beki, E., Nagy, I., Vanderleyden, J., Jager, S., Kiss, L., Fulop, L., et al. (2003). Cloning and heterologous expression of a $\beta$-D-mannosidase (EC 3.2.1.25)-encoding gene from Thermobifida fusca TM51. Appl. Environ. Microbiol. 69, 1944-1952. doi: 10.1128/AEM.69.4.1944-1952.2003

Bell, J. M., Colby, J., and Williams, E. (1988). CO oxidoreductase from Streptomyces strain G26 is a molybdenum hydroxylase. Biochem. J. 250, 605-612. doi: 10.1042/bj2500605

Bentley, S. D., Maiwald, M., Murphy, L. D., Pallen, M. J., Yeats, C. A., Dover, L. G., et al. (2003). Sequencing and analysis of the genome of the Whipple's disease bacterium Tropheryma whipplei. Lancet 361, 637-644. doi: 10.1016/S01406736(03)12597-4

Beveridge, T. J., and Murray, R. G. E. (1980). Site of metal deposition in the cell wall of Bacillus subtilis. J. Bacteriol. 141, 876-887.

Bihari, Z., Szabó, Z., Szvetnik, A., Balázs, M., Bartos, P., Tolmacsov, P., et al. (2010). Characterization of a novel long-chain $n$-alkane-degrading strain, Dietzia sp. E1. Z. Naturforsch. [C]. 65, 693-700. doi: 10.1515/znc-2010$11-1210$

Biswas, G. C. G., Ransom, C., and Sticklen, M. (2006). Expression of biologically active Acidothermus cellulolyticus endoglucanase in transgenic maize plants. Plant Sci. 171, 617-623. doi: 10.1016/j.plantsci.2006.06.004

Boer, L. D., Dijkhuizen, L., Grobben, G., Goodfellow, M., Stackebrandt, E., Parlett, J. H., et al. (1990). Amycolatopsis methanolica sp. nov. a facultatively methylotrophic actinomycete. Int. J. Syst. Bacteriol. 40, 194-204. doi: 10.1099/00207713-40-2-194

Boondaeng, A., Ishida, Y., Tamura, T., Tokuyama, S., and Kitpreechavanich, V. (2009). Microbispora siamensis sp. nov., a thermotolerant actinomycete isolated from soil. Int. J. Syst. Evol. Microbiol. 59, 3136-3139. doi: 10.1099/ijs.0. 009613-0

Bull, A. T. (2010). “Actinobacteria of the extremobiosphere," in Extremophiles Handbook, eds K. Horikoshi, G. Antranikian, A. T. Bull, F. Robb, and K. Stelter (Berlin: Springer-Verlag GmbH), 1203-1240.

Carreto, L., Moore, E., Nobre, M. F., Wait, R., Riley, P. W., Sharp., R. J., et al. (1996). Rubrobacter xylanophilus sp. nov., a new thermophilic species isolated from a thermally polluted effluent. Int. J. Syst. Evol. Microbiol. 46, 460-465.

Carrillo, L., Benítez Ahrendts, M. R., and Maldonado, M. J. (2009). Alkalithermophilic actinomycetes in a subtropical area of Jujuy, Argentina. Rev. Argent. Microbiol. 41, 112-116.

Chakraborty, S., Raut, G., Khopade, A., Mahadik, K., and Kokare, C. (2012). Study on calcium ion independent $\alpha$-amylase from haloalkaliphilic marine Streptomyces strain A3. Indian J. Biotechnol. 11, 427-437.

Chang, X., Liu, W., and Zhang, X. H. (2011). Spinactinospora alkalitolerans gen. nov., sp. nov., an actinomycete isolated from marine sediment. Int. J. Syst. Evol. Microbiol. 61, 2805-2810. doi: 10.1099/ijs.0.027383-0

Chen, C. Y., Huang, Y. C., Wei, C. M., Meng, M., Liu, W. H., and Yang, C. H. (2013). Properties of the newly isolated extracellular thermo-alkalistable laccase from thermophilic actinomycetes, Thermobifida fusca and its application in dye intermediates oxidation. AMB Express 3, 1-9. doi: 10.1186/2191-0855-3-49

Chen, M. Y., Wu, S. H., Lin, G. H., Lu, C., P., and Lin, Y. T., Chang, W. C., et al. (2004). Rubrobacter taiwanensis sp. nov., a novel thermophilic, radiationresistant species isolated from hot springs. Int. J. Syst. Evol. Microbiol. 54, 1849-1855. doi: 10.1099/ijs.0.63109-0

Chen, M., Xu, P., Zeng, G., Yang, C., Huang, D., and Zhang, J. (2015) Bioremediation of soils contaminated with polycyclic aromatic hydrocarbons, petroleum, pesticides, chlorophenols and heavy metals by composting: applications, microbes and future research needs. Biotechnol. Adv. 33, 745-755. doi: 10.1016/j.biotechadv.2015.05.003

Chen, S., Su, L., Billig, S., Zimmermann, W., Chen, J., and Wu, J. (2010). Biochemical characterization of the cutinases from Thermobifida fusca. J. Mol. Catal. B Enzym. 63, 121-127. doi: 10.1016/j.molcatb.2010.01.001

Chertkov, O., Sikorski, J., Nolan, M., Lapidus, A., Lucas, S., Rio, T. G. D., et al. (2011). Complete genome sequence of Thermomonospora curvata type strain $\left(\mathrm{B}^{\mathrm{T}}\right)$. Stand. Genomic Sci. 4, 13-22. doi: 10.4056/sigs. 1453580

Chitte, R. R., and Dey, S. (2002). Production of a fibrinolytic enzyme by thermophilic Streptomyces species. World J. Microbiol. Biotechnol. 18, 289-294. doi: 10.1023/A:1015252607118

Chitte, R. R., Deshmukh, S. V., and Kanekar, P. P. (2011). Production, purification, and biochemical characterization of a fibrinolytic enzyme from thermophilic Streptomyces sp. MCMB-379. Appl. Biochem. Biotechnol. 165, 1406-1413. doi: 10.1007/s12010-011-9356-2

Chou, H. L., Dai, Z., Hsieh, C. W., and Ku, M. S. B. (2011). High level expression of Acidothermus cellulolyticus $\beta$-1,4-endoglucanase in transgenic rice enhances the hydrolysis of its straw by cultured cow gastric fluid. Biotechnol. Biofuels 4, 1-13. doi: 10.1186/1754-6834-4-58

Chua, T. K., Tseng, M., and Yang, M. K. (2013). Degradation of Poly( $\varepsilon-$ caprolactone) by thermophilic Streptomyces thermoviolaceus subsp. thermoviolaceus 76T-2. AMB Express 3, 1-7. doi: 10.1186/2191-0855-3-8 
Clark, D. A., and Norris, P. R. (1996). Acidimicrobium ferrooxidans gen. nov., sp. nov.: mixed culture ferrous iron oxidation with Sulfobacillus species. Microbiology 141, 785-790. doi: 10.1099/00221287-142-4-785

Clum, A., Nolan, M., Lang, E., Rio, T. G. D., Tice, H., and Copeland, A. (2009). Complete genome sequence of Acidimicrobium ferrooxidans type strain $\left(\mathrm{ICP}^{\mathrm{T}}\right)$. Stand. Genomic Sci. 1, 38-45. doi: 10.4056/sigs.1463

Cockell, C. S., Kelly, L. C., and Marteinsson, V. (2013).Actinobacteria - an ancient phylum active in volcanic rock weathering. Geomicrobiol. J. 30, 706-720. doi: 10.1080/01490451.2012.758196

Corbaz, R., Gregory, P. H., and Lacey, M. E. (1963). Thermophilic and mesophilic actinomycetes in mouldy hay. J. Gen. Microbiol. 32, 449-455. doi: 10.1099/00221287-32-3-449

Cross, T., and Goodfellow, M. (1973). "Taxonomy and classification of the actinomycetes," in Actinomycetales: Characteristics and Practical Importance, eds. G. Sykes, and F. A. Skinner (London: Academic Press), 11-112.

Dai, Z., Hooker, B. S., Anderson, D. B., and Thomas, S. R. (2000). Expression of Acidothermus cellulolyticus endoglucanase E1 in transgenic tobacco: biochemical characteristics and physiological effects. Transgenic Res. 9, 43-54. doi: 10.1023/A:1008922404834

Das, P., Banerjee, P., Zaman, A., and Bhattacharya, P. (2015). Biodegradation of two azo dyes using Dietzia sp. PD1: process optimization using response surface methodology and artificial neural network. Desalin. Water Treat. doi: 10.1080/19443994.2015.1013993. [Epub ahead of print].

Demir, T., Gübe, Ö., Yücel, M., and Hames-Kocabas, E. E. (2013). Increased alkalotolerant and thermostable ribonuclease (RNase) production from alkaliphilic Streptomyces sp. M49-1 by optimizing the growth conditions using response surface methodology. World J. Microbiol. Biotechnol. 29, 1625-1633. doi: $10.1007 /$ s11274-013-1325-1

Deng, Y., and Fong, S. S. (2011). Metabolic engineering of Thermobifida fusca for direct aerobic bioconversion of untreated lignocellulosic biomass to 1propanol. Metab. Eng. 13, 570-577. doi: 10.1016/j.ymben.2011.06.007

Dewendar, A., Mourad, F. E., and Sheha, H. (1979). Thermomonospora sp. TSA-125 and its production of a growth promoting antibiotic. Folia Microbiol. (Praha) 24, 396-402. doi: 10.1007/BF02927122

Dhanasekaran, D., and Panneerselvam, N. T. A. (2008). An antifungal compound: $4^{\prime}$ phenyl-1- napthyl-phenyl acetamide from Streptomyces sp. DPTTB16. Med. Biol. 15, 7-12.

Diab, A., and Al-Gounaim, M. Y. (1985). Thermotolerant actinomycetes in soil and rhizosphere of plant communities in the desert of Kuwait. J. Univ. Kuwait (Sci.) $12,69-76$

Dietera, A., Hamm, A., Fiedler, H. P., Goodfellow, M., Muller, W. E., Brun, R., et al. (2003). Pyrocoll, an antibiotic, antiparasitic and antitumor compound produced by a novel alkaliphilic Streptomyces strain. J. Antibiot. 56, 639-646. doi: 10.7164/antibiotics.56.639

Dimise, E. J., Widboom, P. F., and Bruner, S. D. (2008). Structure elucidation and biosynthesis of fuscachelins, peptide siderophores from the moderate thermophile Thermobifida fusca. Proc. Natl. Acad. Sci. U.S.A. 105, 15311-15316. doi: 10.1073/pnas.0805451105

Diraviyam, T., Radhakrishnan, M., and Balagurunathan, R. (2011). Antioxidant activity of melanin pigment from Streptomyces species D5 isolated from Desert soil, Rajasthan, India. Drug Discov. Today 3, 12-13.

Dou, W., Wei, D., Li, H., Li, H., Rahman, M. M., Shi, J., et al. (2013). Purification and characterisation of a bifunctional alginate lyase from novel Isoptericola halotolerans CGMCC5336. Carbohydr. Polym. 98, 1476-1482. doi: 10.1016/j.carbpol.2013.07.050

Duan, Y. Y., Ming, H., Dong, L., Yin, Y. R., Zhang, Y., Zhou, E. M., et al. (2014). Streptomyces calidiresistens sp. nov., isolated from a hot spring sediment. Antonie Van Leeuwenhoek 106, 189-196. doi: 10.1007/s10482-014-0180-x

Duckworth, A., Grant, S., Grant, W. D., Jones, B. E., and Meijer, D. (1998). Dietzia natronolimnaios sp. nov., a new member of the genus Dietzia isolated from an east African soda lake. Extremophiles 2, 359-366. doi: 10.1007/s0079200 50079

Egas, C., Barroso, C., Froufe, H. J. C., Pacheco, J., Albuquerque, L., and da Costa, M. S. (2014). Complete genome sequence of the radiation-resistant bacterium Rubrobacter radiotolerans RSPS-4. Stand. Genomic Sci. 9, 1062-1075. doi: 10.4056/sigs.5661021

Eisenhart, A. E., and Disso, N. M. (2012). "Thermostability determination of antibiotics at high temperatures by liquid chromatography-mass spectrometry," in Proceedings of the National Conference On Undergraduate Research (NCUR) 2012 (Ogden, UT: Weber State University), 351-356.

Ekkelenkamp, M. B., de Jong, W., Hustinx, W., and Thijsen, S. (2004). Streptomyces thermovulgaris bacteremia in Crohn's disease patient. Emerg. Infect. Dis. 10, 1883-1885. doi: 10.3201/eid1010.040300

Ellaiah, P., Srinivasulu, B., and Adinarayana, K. (2002). A review on microbial alkaline proteases. J. Sci. Ind. Res. 61, 690-704.

Ensign, J. C. (1992). "Introduction to the Actinomycetes," in The Prokaryotes, 2nd Edn. Vol. II, eds A. Balows, H. G. Truper, M. Dworkin, W. Hardeer, and K. H. Schleifer (New York, NY: Springer-Verlag), 811-815.

Ferreira, A. C., Nobre, M. F., Moore, E., Rainey, F. A., Battista, J. R., and da Costa, M. S. (1999). Characterization and radiation resistance of new isolates of Rubrobacter radiotolerans and Rubrobacter xylanophilus. Extremophiles 3, 235-238.

Fink, J. N., Resnick, A. J., and Salvaggio, J. (1971). Presence of thermophilic actinomycetes in residential heating systems. Appl. Microbiol. 22, 730-731.

Francis, I., Holsters, M., and Vereecke, D. (2010). The gram-positive side of plant microbe interactions. Environ. Microbiol. 12, 1-12. doi: 10.1111/j.14622920.2009.01989.x

Frey, B., Rieder, S. R., Brunner, I., Plötze, M., Koetzsch, S., Lapanje, A., et al. (2010). Weathering-associated bacteria from the Damma Glacier Forefield: physiological capabilities and impact on granite dissolution. Appl. Environ. Microbiol. 76, 4788-4796. doi: 10.1128/AEM.00657-10

Fudou, R., Jojima, Y., Seto, A., Yamada, K., Kimura, E., Nakamatsu, T., et al. (2002). Corynebacterium efficiens sp. nov., a glutamic acid-producing species from soil and vegetables. Int. J. Syst. Evol. Microbiol. 52, 1127-1131. doi: 10.1099/00207713-52-4-1127

Fujii, Y., Kabumoto, H., Nishimura, K., Fujii, T., Yanai, S., Takeda, K., et al. (2009). Purification, characterization, and directed evolution study of a vitamin D3 hydroxylase from Pseudonocardia autotrophica. Biochem. Biophys. Res. Commun. 385, 170-175. doi: 10.1016/j.bbrc.2009.05.033

Gabani, P., Copeland, E., Chandel, A. K., and Singh, O. V. (2012). Ultravioletradiation-resistant isolates revealed cellulose-degrading species of Cellulosimicrobium cellulans (UVP1) and Bacillus pumilus (UVP4). Biotechnol. Appl. Biochem. 59, 395-404. doi: 10.1002/bab.1038

Gacesa, P. (1992). Enzyme degradation of alginates. Int. J. Biochem. 24, 545-552. doi: 10.1016/0020-711X(92)90325-U

Gadkari, D., Schricker, K., Acker, G., Kroppenstedt, R. M., and Meyer, O. (1990). Streptomyces thermoautotrophicus sp. nov., a thermophilic CO- and $\mathrm{H}_{2}$-oxidizing obligate chemolithoautotroph. Appl. Environ. Microbiol. 56, 3727-3734.

Gallert, C. (2000). Degradation of latex and of natural rubber by Streptomyces strain La 7. Syst. Appl. Microbiol. 23, 433-441. doi: 10.1016/S07232020(00)80075-2

Gao, B., and Gupta, R. S. (2005). Conserved indels in protein sequences that are characteristic of the phylum Actinobacteria. Int. J. Syst. Evol. Microbiol. 55, 2401-2412. doi: 10.1099/ijs.0.63785-0

Gardner, H. L., and Dukes, C. D. (1955). Haemophilus vaginalis vaginitis. A newly defined specific infection previously classified 'non-specific' vaginitis. Am.J. Obstet. Gynecol. 69, 962-976.

Gharibzahedi, S. M. T., Razavi, S. H., and Mousavi, M. (2014). Carotenoid production from hydrolyzed molasses by Dietzia natronolimnaea HS-1 using batch, fed-batch and continuous culture. Ann. Microbiol. 64, 945-953. doi: 10.1007/s13213-013-0728-4

Gharibzahedi, S. M. T., Razavi, S. H., and Mousavi, M. (2015). Optimal development of a new stable nutraceutical nanoemulsion based on the inclusion complex of 2-Hydroxypropyl-b-cyclodextrin with canthaxanthin accumulated by Dietzia natronolimnaea HS-1 using ultrasound-assisted emulsification. J. Dispersion Sci. Technol. 36, 614-625. doi: 10.1080/01932691.2014.921188

Gholami, M., Etemadifar, Z., and Bouzari, M. (2015). Isolation a new strain of Kocuria rosea capable of tolerating extreme conditions. J. Environ. Radioact. 144, 113-119. doi: 10.1016/j.jenvrad.2015.03.010

Glymph, J. L., and Stutzenberger, F. J. (1977). Production, purification, and characterization of alpha-amylase from Thermomonospora curvata. Appl. Environ. Microbiol. 34, 391-397.

Gohel, S. D., and Singh, S. P. (2012a). Purification strategies, characteristics and thermodynamic analysis of a highly thermostable alkaline protease from a salt-tolerant alkaliphilic actinomycete, Nocardiopsis alba OK-5. J. 
Chromatogr. B Analyt. Technol. Biomed. Life Sci. 889-890, 61-68. doi: 10.1016/j.jchromb.2012.01.031

Gohel, S. D., and Singh, S. P. (2012b). Cloning and expression of alkaline protease genes from two salt-tolerant alkaliphilic actinomycetes in E. coli. Int. J. Biol. Macromol. 50, 664-671. doi: 10.1016/j.ijbiomac.2012.01.039

Goodfellow, M., and Simpson, K. E. (1987). Ecology of Streptomycetes. Front. Appl. Microbiol. 2, 97-125.

Goodfellow, M., Kampfer, P., Busse, H. J., Trujillo, M. E., Suzuki, K., Ludwig, W., et al. (2012). Bergey's Manual of Systematic Bacteriology, 2nd Edn., Vol. 5. The Actinobacteria, Part A and B. New York, NY; Dordrecht; Heidelberg; London: Springer.

Goodfellow, M., Lacey, J., and Todd, C. (1987). Numerical classification of thermophilic Streptomycetes. J. Gen. Microbiol. 133, 135-149. doi: 10.1099/00221287-133-11-3135

Goodfellow, M., Maldonado, L. A., and Quintana, E. T. (2005). Reclassification of Nonomuraea flexuosa (Meyer 1989) Zhang et al. 1998 as Thermopolyspora flexuosa gen. nov., comb. nov., nom. rev. Int. J. Syst. Evol. Microbiol. 55, 1979-1983. doi: 10.1099/ijs.0.63559-0

Gousterova, A., Paskaleva, D., and Vasileva-Tonkova, E. (2014). Characterization of culturable thermophilic actinobacteria from Livingston Island, Antarctica. Int. Res. J. Biol. Sci. 3, 30-36.

Groth, I., Schumann, P., Rainey, F. A., Martin, K., Schuetze, B., and Augsten, K. (1997). Bogoriella caseilytica gen. nov., sp. nov., a new alkaliphilic actinomycete from a soda lake in Africa. Int. J. Syst. Bacteriol. 47, 788-794. doi: 10.1099/00207713-47-3-788

Gtari, M., Ghodhbane-Gtari, F., Nouioui, I., Beauchemin, N., and Tisa, L. S. (2012). Phylogenetic perspectives of nitrogen-fixing actinobacteria. Arch. Microbiol. 194, 3-11. doi: 10.1007/s00203-011-0733-6

Gupta, G. N., Srivastava, S., Khare, S. K., and Prakash, V. (2014). Extremophiles: an overview of microorganism from extreme environment. Int. J. Agricult. Environ. Biotechnol. 7, 371-380. doi: 10.5958/2230-732X.2014.00258.7

Gupta, R. S. (2011). Origin of diderm (Gram-negative) bacteria: antibiotic selection pressure rather than endosymbiosis likely led to the evolution of bacterial cells with two membranes. Antonie Van Leeuwenhoek 100, 171-182. doi: 10.1007/s10482-011-9616-8

Gurielidze, M., Pataraya, D., Cholokava, N., and Nutsubidze, N. (2010). Extremophilic actinomycetes, distributed in various types of soils of Georgia and their protease activity. Bull. Georg. Natl. Acad. Sci. 4, 81-85.

Habbeche, A., Saoudi, B., Jaouadi, B., Haberra, S., Kerouaz, B., Boudelaa, M., et al. (2014). Purification and biochemical characterization of a detergentstable keratinase from a newly thermophilic actinomycete Actinomadura keratinilytica strain Cpt29 isolated from poultry compost. J. Biosci. Bioeng. 117, 413-421. doi: 10.1016/j.jbiosc.2013.09.006

Hallmann, J., Rodriguez-Kabana, R., and Kloepper, J. W. (1999). Chitin-mediated changes in bacterial communities of the soil, rhizosphere and within roots of cotton in relation to nematode control. Soil Biol. Biochem. 31, 551-560. doi: 10.1016/S0038-0717(98)00146-1

Harper, D. B., and Gibbs, P. A. (1979). Identification of isobutyronitrile and isobutyraldoxime O-methyl ether as volatile microbial catabolites of valine. Biochem. J. 182, 609-611. doi: 10.1042/bj1820609

Hasegawa, T., Tanida, S., and Ono, H. (1986). Thermomonospora formosensis sp. nov. Int. J. Syst. Bacteriol. 36, 20-23. doi: 10.1099/00207713-36-1-20

Hatanaka, T., Usuki, H., Arima, J., Uesugi, Y., Yamamoto, Y., Kumagai, Y., et al. (2011a). Extracellular production and characterization of two Streptomyces Lasparaginases. Appl. Biochem. Biotechnol. 163, 836-844. doi: 10.1007/s12010010-9087-9

Hatanaka, T., Yamasato, A., Arima, J., Usuki, H., Yamamoto, Y., and Kumagai, Y. (2011b). Extracellular production and characterization of Streptomyces Xprolyl dipeptidyl aminopeptidase. Appl. Biochem. Biotechnol. 164, 475-486. doi: 10.1007/s12010-010-9149-Z

Henssen, A. (1957). Beitrage zur morphologie und systematik der thermophilen actinomyceten. Arch. Mikrobiol. 26, 373-414. doi: 10.1007/BF004 07588

Henssen, A., and Schnepf, E. (1967). Zur Kenntnis thermophiler Actinomyceten. Arch. Mikrobiol. 57, 214-231. doi: 10.1007/BF00405948

Hsu, K. J., Tseng, M., Don, T. M., and Yang, M. K. (2012). Biodegradation of poly( $\beta$ hydroxybutyrate) by a novel isolate of Streptomyces bangladeshensis 77T-4. Bot. Studies 53, 307-313.
Hu, X., Thumarat, U., Zhang, X., Tang, M., and Kawai, F. (2010). Diversity of polyester-degrading bacteria in compost and molecular analysis of a thermoactive esterase from Thermobifida alba AHK119. Appl. Microbiol. Biotechnol. 87, 771-779. doi: 10.1007/s00253-010-2555-x

$\mathrm{Hu}, \mathrm{Y}$., and Wilson, D. B. (1988). Cloning of Thermomonospora fusca genes coding for beta 1-4 endoglucanases E1, E2, and E5. Gene 71, 331-337. doi: 10.1016/0378-1119(88)90050-9

Hu, Y., Phelan, V., Ntai, I., Farnet, C. M., Zazopoulos, E., and Bachmann, B. O. (2007). Benzodiazepine biosynthesis in Streptomyces refuineus. Chem. Biol. 14, 691-701. doi: 10.1016/j.chembiol.2007.05.009

Huang, H., Yao, Y., He, Z., Yang, T., Ma, J., Tian, X., et al. (2011). Antimalarial $\beta$-carboline and indolactam alkaloids from Marinactinospora thermotolerans, a deep sea isolate. J. Nat. Prod. 74, 2122-2127. doi: 10.1021/np200399t

Huang, Y., Chen, C., Chen, W., Ciou, Y., Yang, T., and Yang, C. (2013). Production and antioxidant properties of the ferulic acid-rich destarched wheat bran hydrolysate by feruloyl esterases from thermophilic actinomyces. BioResources 8, 4981-4991. doi: 10.15376/biores.8.4.4981-4991

Huang, Z., Bao, Y. Y., Yuan, T. T., Wang, G. X., He, L. Y., and Sheng, X. F. (2015). Arthrobacter nanjingensis sp. nov., a mineral-weathering bacterium isolated from forest soil. Int. J. Syst. Evol. Microbiol. 65, 365-369. doi: 10.1099/ijs.0.069492-0

Huang, Z., Sheng, X. F., Zhao, F., He, L. Y., and Wang, H. J. (2012). Isoptericola nanjingensis sp. nov., a mineral-weathering bacterium. Int. J. Syst. Evol. Microbiol. 62, 971-976. doi: 10.1099/ijs.0.033043-0

Ibrahim, E. M., Arenskötter, M., Luftmann, H., and Steinbüchel, A. (2006). Identification of Poly(cis-1,4-Isoprene) degradation intermediates during growth of moderately thermophilic actinomycetes on rubber and cloning of a functional lcp homologue from Nocardia farcinica Strain E1. Appl. Environ. Microbiol. 72, 3375-3382. doi: 10.1128/AEM.72.5.3375-3382.2006

Iijima and Ryusuke. (1996). Plant Activator and Mycelial Fertilizer and Method. Yokohama City. US Patent 5529597.

Irwin, D. C., Spezio, M., Walker, L. P., and Wilson, D. B. (1993). Activity studies of eight purified cellulases: specificity, synergism, and binding domain effects. Biotechnol. Bioeng. 42, 1002-1013.

Itoh, T., Yamanoi, K., Kudo, T., Ohkuma, M., and Takashina, T. (2011). Aciditerrimonas ferrireducens gen. nov., sp. nov., an iron-reducing Thermoacidophilic actinobacterium isolated from a solfataric field. Int. J Syst. Evol. Microbiol. 61, 1281-1285. doi: 10.1099/ijs.0.023044-0

Ivanova, V., Kolarova, M., Aleksieva, K., Gräfe, U., Dahse, H. M., and Laatsch, H. (2007). Microbiaeratin, a new natural indole alkaloid from a Microbispora aerata strain, isolated from Livingston Island, Antarctica. Prep. Biochem. Biotechnol. 37, 161-168. doi: 10.1080/10826060701199122

Ivanova, V., Laatsch, H., Kolarova, M., and Aleksieva, K. (2013). Structure elucidation of a new natural diketopiperazine from a Microbispora aerata strain isolated from Livingston Island, Antarctica, Nat. Prod. Lett. 27, 164-170. doi: 10.1080/14786419.2012.665911

Iwamoto, M., Kurachi, M., Nakashima, T., Kim, D., Yamaguchi, K., Oda, T., et al. (2005). Structure-activity relationship of alginate oligosaccharides in the induction of cytokine production from RAW264.7 cells. FEBS Lett. 579, 4423-4429. doi: 10.1016/j.febslet.2005.07.007

Jani, S. A., Chudasama, C. J., Patel, D. B., Bhatt, P. S., and Patel, H. N. (2012). Optimization of extracellular protease production from alkali thermo tolerant actinomycetes: Saccharomonospora viridis SJ-21. Bull. Environ. Pharmacol. Life Sci. 1, 84-92.

Jani, S. A., Soni, R., Patel, H., Prajapati, B., and Patel, G. (2014). Screening, isolation and characterization of keratin degrading actinomycetes: Streptomyces sp. and Saccharothrix xinjiangensi and analyzing their significance for production of keratinolytic protease and feed grade amino acids. Int. J. Curr. Microbiol. Appl. Sci. 3, 940-955.

Jarerat, A., and Tokiwa, Y. (2001). Degradation of poly(tetramethylene succinate) by thermophilic actinomycetes. Biotechnol. Lett. 23, 647-651. doi: 10.1023/A:1010314316103

Jiang, C., and Xu, L. (1993). Actinomycete diversity in unusual habitats. Actinomycetes 4, 47-57.

Jin, Q., Hu, Z., Jin, Z., Qiu, L., Zhong, W., and Pan, Z. (2012). Biodegradation of aniline in an alkaline environment by a novel strain of the halophilic bacterium, Dietzia natronolimnaea JQ-AN. Bioresour. Technol. 117, 148-154. doi: 10.1016/j.biortech.2012.04.068 
Jin, X., Xu, L. H., Mao, P. H., Hseu, T. H., and Jiang, C. L. (1998). Description of Saccharomonospora xinjiangensis sp. nov. based on chemical and molecular classification. Int. J. Syst. Bacteriol. 48, 1095-1099. doi: 10.1099/00207713-484-1095

Johnson, D. B., Bacelar-Nicolau, P., Okibe, N., Thomas, A., and Hallberg, K. B. (2009). Ferrimicrobium acidiphilum gen. nov., and Ferrithrix thermotolerans gen. nov., sp. nov.: heterotrophic, iron-oxidizing, extremely acidophilic actinobacteria. Int. J. Syst. Evol. Microbiol. 59, 1082-1089. doi: 10.1099/ijs.0.65409-0

Jones, B. E., Grant, W. D., Duckworth, A. W., Schumann, P., Weiss, N., and Stackebrandt, E. (2005). Cellulomonas bogoriensis sp. nov., an alkaliphilic cellulomonad. Int. J. Syst. Evol. Microbiol. 55, 1711-1714. doi: 10.1099/ijs.0.63646-0

Kan, J., Obraztsova, A.,Wang, Y., Leather, J., Scheckel, K. G., Nealson, K. H., et al. (2013). Apatite and chitin amendments promote microbial activity and augment metal removal in marine sediments. O. J. Metal. 51-61. doi: 10.4236/ojmetal.2013.32a1007

Kaneko, T., Ohno, T., and Ohisa, N. (2005). Purification and characterization of a thermostable raw starch digesting amylase from a Streptomyces sp. isolated in a milling factory. Biosci. Biotechnol. Biochem. 69, 1073-1081. doi: 10.1271/bbb.69.1073

Kaur, N., Rajendran, M. K., Kaur, G., and Shanmugam, M. (2014). Isoptericola rhizophila sp. nov., a novel actinobacterium isolated from rhizosphere soil. Antonie Van Leeuwenhoek 106, 301-307. doi: 10.1007/s10482-014-0197-1

Kielak, A. M., Cretoiu, M. S., Semenov, A. V., Sørensen, D. J., and Elsa, J. D. (2013). Bacterial chitinolytic communities respond to chitin and $\mathrm{pH}$ alteration in soil. Appl. Environ. Microbiol. 79, 263-272. doi: 10.1128/AEM.02546-12

Kim, B., Sahin, N., Minnikin, D. E., Zakrewska-Czerwinska, J., Mordarski, M., and Goodfellow, M. (1999). Classification of thermophilic Streptomycetes, including the description of Streptomyces thermoalcalitolerans sp. nov. Int. J. Syst. Evol. Microbiol. 49, 7-17. doi: 10.1099/00207713-49-1-7

Kim, S. B., Falconer, C., Williams, E., and Goodfellow, M. (1998). Streptomyces thermocarboxydovorans sp. nov. and Streptomyces thermocarboxydus sp. nov., two moderately thermophilic carboxydotrophic species from soil. Int. J. Syst. Evol. Microbiol. 48, 59-68. doi: 10.1099/00207713-48-1-59

Kim, Y. J., Kim, D. O., Chun, O. K., Shin, D. H., Jung, H., Lee, C. Y., et al. (2005). Phenolic extraction from apple peel by cellulases from Thermobifida fusca. J. Agric. Food Chem. 53, 9560-9565. doi: 10.1021/jf052052j

King, G. M., and Weber, C. F. (2007). Distribution, diversity and ecology of aerobic CO-oxidizing bacteria. Nat. Rev. Microbiol. 5, 107-118. doi: 10.1038/nrmicro1595

Kiran, S., Swarnkar, M. K., Pal, M., Thakur, R., Tewari, R., Singh, A. K., et al. (2015). Complete genome sequencing of protease-producing novel Arthrobacter sp. strain IHBB 11108 using pacbio single-molecule real-time sequencing technology. Genome Announc. 3:e00346-15. doi: 10.1128/genomeA.00346-15

Kleeberg, I., Hetz, C., Kroppenstedt, R. M., Müller, R. J., and Deckwer, W. D. (1998). Biodegradation of aliphatic-aromatic copolyesters by Thermomonospora fusca and other thermophilic compost isolates. Appl. Environ. Microbiol. 64, 1731-1735.

Kleeberg, I., Welzel, K., VandenHeuvel, J., Müller, R. J., and Deckwer, W. D. (2005). Characterization of a new extracellular hydrolase from Thermobifida fusca degrading aliphatic-aromatic copolyesters. Biomacromolecules 6, 262-270. doi: $10.1021 / \mathrm{bm} 049582 \mathrm{t}$

Klibanov, A. M. (2001). Improving enzymes by using them in organic solvents. Nature 409, 241-246. doi: 10.1038/35051719

Koch, A. L. (2003). Were Gram-positive rods the first bacteria? Trends Microbiol. 11, 166-170. doi: 10.1016/S0966-842X(03)00063-5

Krasilnikov, N. A., and Agre, N. S. (1964). On two new species of Thermopolyspora. Hindustan Antibiot. Bull. 6, 97-107.

Krasil'nikov, N. A., Agre, N. S., and El-Reghistan, G. I. (1968). New thermophilic species of the genus Micropolyspora. Mikrobiologiya 37, 1065-1072.

Krishna, P., Arora, A., and Reddy, M. S. (2008). An alkaliphilic and xylanolytic strain of actinomycetes Kocuria sp. RM1 isolated from extremely alkaline bauxite residue sites. World J. Microbiol. Biotechnol. 24, 3079-3085. doi: 10.1007/s11274-008-9801-8

Krishnakumar, S., Rajan, R., A., and Ravikumar, S. (2011). Extracellular production of L-glutaminase by marine alkalophilic Streptomyces sp. SBU1 isolated from Cape Comorin Coast. Indian J. Mar. Sci. 40, 717-721.
Kroppenstedt, R. M. (1992). "The genus Nocardiopsis," in The Prokaryotes. A Handbook on the Biology of Bacteria: Ecophysiology, Isolation, Identification, Applications, eds A. Balows, H. G. Trusper, W. Dworkin, W. Harder and K. H. Schleifer (New York, NY: Springer) 1139-1156.

Kroppenstedt, R. M., Stackebrandt, E., and Goodfellow, M. (1990). Taxonomic revision of the actinomycete genera Actinomadura and Microtetraspora. Syst. Appl. Microbiol. 13, 148-160. doi: 10.1016/S0723-2020(11)80162-1

Kumar, A. K. (2015). UV mutagenesis treatment for improved production of endoglucanase and $\beta$-glucosidase from newly isolated thermotolerant actinomycetes, Streptomyces griseoaurantiacus. Bioresour. Bioprocess. 2, 1-10. doi: 10.1186/s40643-015-0052-x

Kumar, L., Awasthi, G., and Singh, B. (2011). Extremophiles: a novel source of industrially important enzymes. Biotechnology 10, 121-135. doi: 10.3923/biotech.2011.121.135

Kunisawa, T. (2007). Gene arrangements characteristic of the phylum Actinobacteria. Antonie Van Leeuwenhoek 92, 359-365. doi: 10.1007/s10482-007-9165-3

Kurapova, I., Zenova, G. M., Sudnitsyn, I. I., Kizilova, A. K., Manucharova, N. A., Norovsuren, Z. H., et al. (2012). Thermotolerant and thermophilic actinomycetes from soils of Mongolia Desert Steppe Zone. Microbiology 81, 98-108. doi: 10.1134/s0026261712010092

Lacey, J., Goodfellow, M., and Alderson, G. (1978). "The genus Actinomadura Lechevalier and Lechevalier," in Nocardia and Streptomyces, eds M. Modarski, W. Kurylowicz, and J. Jeljaszewicz (New York, NY: G. Fischer Verlag), 107-117.

Ladenstein, R., and Ren, B. (2006). Protein disulfides and protein disulfide oxidoreductases in hyperthermophiles. Fed. Eur. Biochem. Soc. Lett. 273, 4170-4185. doi: 10.1111/j.1742-4658.2006.05421.x

Lechevalier, H. A. (1965). Priority of the generic name Microbisporu over Waksmuniu and Thermopolyspora. Int. Bull. Bacteriol. Nomencl. Taxon. 15, 139-142.

Lechevalier, H., Lechevalier, M. P., and Becker, B. (1966). Comparison of the chemical composition of cell-walls of nocardiae with that of other aerobic actinomycetes. Int. J. Syst. Bacteriol. 16, 151-160. doi: 10.1099/00207713-162-151

Lengeler, J. W., Drews, G., and Schlegel, H. G. (1999). Biology of the Prokaryotes. Stuttgart: Blackwell.

Li, W. J., Chen, H. H., Zhang, Q. Y., Kim, C., J., and Park, D. J., Lee, C. J., et al. (2005). Citricoccus alkalitolerans sp. nov., a novel actinobacterium isolated from a desert soil in Egypt. Int. J. Syst. Evol. Microbiol. 55, 87-90. doi: 10.1099/ijs.0.63237-0

Li, W. J., Zhang, Y. Q., Schumann, P., Chen, H. H., Hozzein, W. N., Tian, X. P., et al. (2006). Kocuria aegyptia sp. nov., a novel actinobacteria isolated from a saline, alkaline desert soil in Egypt. Int. J. Syst. Evol. Microbiol. 56, 733-737. doi: 10.1099/ijs.0.63876-0

Li, Y. Q., Li, M. G., Li, W., Zhao, J. Y., Ding, Z. G., Cui, X. L., et al. (2007a). A new pyranonaphthoquinone derivative from a alkaphilic Nocardiopsis sp. J. Antibiot. 60, 757-761. doi: 10.1038/ja.2007.100

Li, Y., Irwin, D. C., and Wilson, D. B. (2007b). Processivity, substrate binding, and mechanism of cellulose hydrolysis by Thermobifida fusca Cel9A. Appl. Environ. Microbiol. 73, 3165-3172. doi: 10.1128/AEM.02960-06

Li, Y., Irwin, D. C., and Wilson, D. B. (2010). Increased crystalline cellulose activity via combinations of amino acid changes in the family 9 catalytic domain and family $3 c$ cellulose binding module of Thermobifida fusca Cel9A. Appl. Environ. Microbiol. 76, 2582-2588. doi: 10.1128/aem.02735-09

Lindenmuth, B. E., and McDonald, K. A. (2011). Production and characterization of Acidothermus cellulolyticus endoglucanase in Pichia pastoris. Protein Expr. Purif. 77, 153-158. doi: 10.1016/j.pep.2011.01.006

Linger, J. G., Adney, W. S., and Darzins, A. (2010). Heterologous expression and extracellular secretion of cellulolytic enzymes by Zymomonas mobilis. Appl. Environ. Microbiol. 76, 6360-6369. doi: 10.1128/AEM.00230-10

Liolios, K., Sikorski, J., Jando, M., Lapidus, A., Copeland, A., Rio, T. G. D., et al. (2010). Complete genome sequence of Thermobispora bispora type strain $\left(\mathrm{R}^{2} 1^{\mathrm{T}}\right)$. Stand. Genomic Sci. 2, 318-326. doi: 10.4056/sigs. 962171

Liu, Z., Zhao, X., and Bai, F. (2013). Production of xylanase by an alkaline-tolerant marine-derived Streptomyces viridochromogenes strain and improvement by ribosome engineering. Appl. Microbiol. Biotechnol. 97, 4361-4368. doi: $10.1007 / \mathrm{s} 00253-012-4290-\mathrm{y}$ 
Lovley, D. R., Coates, J. D., Blunt-Harris, E. L., Phillips, F. J. P., and Woodward, J. C. (1996). Humic substances as electron acceptors for microbial respiration. Nature 382, 445-448. doi: 10.1038/382445a0

Lu, Z., Liu, Z., Wang, L., Zhang, Y., Qi, W., and Goodfellow, M. (2001). Saccharopolyspora flava sp. nov. and Saccharopolyspora thermophila sp. nov., novel actinomycetes from soil. Int. J. Syst. Evol. Microbiol. 51, 319-325. doi: 10.1099/00207713-51-2-319

Luo, H. Y., Wang, Y. R., Miao, L. H., Yang, P. L., Shi, P. J., Fang, C. X., et al. (2009). Nesterenkonia alba sp. nov., an alkaliphilic actinobacterium isolated from the black liquor treatment system of a cotton pulp mill. Int. J. Syst. Evol. Microbiol. 59, 863-868. doi: 10.1099/ijs.0.003376-0

Lykidis, A., Mavromatis, K., Ivanova, N., Anderson, I., Land, M., DiBartolo, G., et al. (2007). Genome sequence and analysis of the soil cellulolytic actinomycete Thermobifida fusca YX. J. Bacteriol. 189, 2477-2486. doi: 10.1128/JB. 01899-06

Madhusudhan, D. N., Mazhari, B. B. Z., Dastager, S. G., and Agsar, D. (2014). Production and cytotoxicity of extracellular insoluble and droplets of soluble melanin by Streptomyces lusitanus DMZ-3. Biomed. Res. Int. 2014:306895. doi: $10.1155 / 2014 / 306895$

Maltseva, O., and Oriel, P. (1997). Monitoring of an alkaline 2,4,6-trichlorophenoldegrading enrichment culture by DNA fingerprinting methods and isolation of the responsible organism, haloalkaliphilic Nocardioides sp. strains M6. Appl. Environ. Microbiol. 63, 4145-4149.

Manivasagan, P., Venkatesan, J., Sivakumar, K., and Kim, S. K. (2013). Marine actinobacterial metabolites: current status and future perspectives. Microbiol. Res. 168, 311-332. doi: 10.1016/j.micres.2013.02.002

Mansour, F. A., and Mohamedin, A. H. (2001). Candida albicans cell wall lytic enzyme produced by Streptomyces thermodiastaticus. Microbios 105, 87-101. doi: 10.1556/amicr.48.2001.1.6

Maréchal, J., Clement, B., Nalin, R., Gandon, C., Orso, S., Cvejic, J. H., et al. (2000). A recA gene phylogenetic analysis confirms the close proximity of Frankia to Acidothermus. Int. J. Syst. Evol. Microbiol. 50, 781-785. doi: 10.1099/0020771350-2-781

Martinez, S., Kuhna, M. L., Russell, J. T., Holza, R. C., and Elgren, T. E. (2014). Acrylamide production using encapsulated nitrile hydratase from Pseudonocardia thermophila in a sol-gel matrix. J. Mol. Catal. B: Enzym. 100, 19-24. doi: 10.1016/j.molcatb.2013.11.014

McCarthy, A. J. (1989). "Thermomonospora and related genera," in Bergey's Manual of Systematic Bacteriology, Vol. 4, eds S. T. Williams, M. E. Sharpe, and J. G. Holt (Baltimore, MD: Williams and Wilkins), 2552-2572.

McCarthy, A. J., and Cross, T. (1984). A taxonomic study of Thermomonospora and other monosporic actinomycetes. J. Gen. Microbiol. 130, 5-25. doi: 10.1099/00221287-130-1-5

McCarthy, A. J., Peace, E., and Broda, P. (1985). Studies on the extracellular xylanase activity of some thermophilic actinomycetes. Appl. Microbiol. Biotechnol. 21, 238-244. doi: 10.1007/BF00295129

McGinnis, K., and Wilson, D. B. (1993). Disulfide arrangement and functional domains of 6- 1,4-endoglucanase E5 from Thermomonospora fusca. Biochemistry 32, 8151-8156. doi: 10.1021/bi00083a014

Mikami, Y., Miyashita, K., and Arai, T. (1982). Diaminopimelic acid profiles of alkalophilic and alkaline-resistant strains of actinomycetes. J. Gen. Microbiol. 128, 1709-1712. doi: 10.1099/00221287-128-8-1709

Mitsuiki, S., Takasugi, M., Moriyama, Y., Futagami, T., Goto, M., Kanouchi, H., et al. (2010). Identification of an alkaliphilic actinomycetes that produces a $\mathrm{PrP}^{\mathrm{Sc}}$-degrading enzyme. Ann. Microbiol. 60, 349-353. doi: 10.1007/s13213010-0049-9

Mohagheghi, A., Grohmann, K., Himmel, M., Leighton, L., and Updegraff, D. M. (1986). Isolation and characterization of Acidothermus cellulolyticus gen nov., sp. nov., a new genus of thermophilic, acidophilic, cellulolytic bacteria. Int. J. Syst. Bacteriol. 36, 435-443. doi: 10.1099/00207713-36-3-435

Mu, W., Wang, X., Xue, Q., Jiang, B., Zhang, T., and Miao, M. (2012). Characterization of a thermostable glucose isomerase with an acidic $\mathrm{pH}$ optimum from Acidothermus cellulolyticus. Food Res. Int. 47, 364-367. doi: 10.1016/j.foodres.2011.09.006

Nair, M. G., Putnam, A. R., Mishra, S. K., Mulks, M. H., Taft, W. H., Keller, J. E., et al. (1989). Faeriefungin: a new broad- spectrum antibiotic from Streptomyces griseus ver. Autotrophicus. J. Nat. Prod. 52, 797-809.
Nakano, M., Kihara, M., Iehata, S., Tanaka, R., Maeda, H., and Yoshikawa, T. (2011). Wax ester-like compounds as biosurfactants produced by Dietzia maris from $n$-alkane as a sole carbon source. J. Basic Microbiol. 51, 490-498. doi: 10.1002/jobm.201000420

Ningthoujam, D. S., Kshetri, P., Sanasam, S., and Nimaichand, S. (2009). Screening, identification of best producers and optimization of extracellular proteases from moderately halophilic alkalithermotolerant indigenous actinomycetes. World Appl. Sci. J. 7, 907-916.

Nishio, Y., Nakamura, Y., Kawarabayasi, Y., Usuda, Y., Kimura, E., Sugimoto, S. et al. (2003). Comparative complete genome sequence analysis of the amino acid replacements responsible for the thermostability of Corynebacterium efficiens. Genome Res. 13, 1572-1579. doi: 10.1101/gr.1285603

Nonomura, H., and Ohara, Y. (1971). Distribution of actinomycetes in soil. X. New genus and species of monosporic actinomycetes in soil. J. Ferment. Technol. 49, 895-903.

Nonomura, H., and Ohara, Y. (1974). Distribution of actinomycetes in soil. XII. A new species of actinomycetes, Thermononospora mesouviformis, sp. nov. J. Ferment. Technol. 52, 10-13.

Normand, P., Orso, S., Cournoyer, B., Jeannin, P., Chapelon, C., Dawson, J., et al. (1996). Molecular phylogeny of the genus Frankia and related genera and emendation of the family Frankiaceae. Int. J. Syst. Bacteriol. 46, 1-9. doi: 10.1099/00207713-46-1-1

Norris, P. R., Davis-Belmar, C. S., Brown, C. F., and Calvo-Bado, L. A. (2011). Autotrophic, sulfur-oxidizing actinobacteria in acidic environments. Extremophiles 15, 155-163. doi: 10.1007/s00792-011-0358-3

Ohta, Y., and Ikeda, M. (1978). Deodorization of pig feces by actinomycetes. Appl. Environ. Microbiol. 36, 487-491.

Okajima, S., Kinouchi, T., Mikami, Y., and Ando, A. (1995). Purification and some properties of a chitosanase of Nocardioides sp. J. Gen. Appl. Microbiol. 41, 351-357. doi: 10.2323/jgam.41.351

Olano, C., Lombó, F., Méndez, C., and Salas, J. A. (2008). Improving production of bioactive secondary metabolites in actinomycetes by metabolic engineering. Metab. Eng. 10, 281-292. doi: 10.1016/j.ymben.2008.07.001

Palaniyandi, S. A., Yang, S. H., Zhang, L., and Suh, J. W. (2013). Effects of actinobacteria on plant disease suppression and growth promotion. Appl. Microbiol. Biotechnol. 97, 9621-9636. doi: 10.1007/s00253-0135206-1

Pati, A., Sikorski, J., Nolan, M., Lapidus, A., Copeland, A., Rio, T. G. D., et al. (2009). Complete genome sequence of Saccharomonospora viridis type strain (P101T). Stand. Genomic Sci. 1, 141-149. doi: 10.4056/sigs.20263

Pettersson, B. M. F., Behra, P. R. K., Manduva, S., Das, S., Dasgupta, S., Bhattacharya, A., et al. (2014). Draft genome sequence of Saccharopolyspora rectivirgula. Genome Announc. 2, e01117-e01113. doi: 10.1128/genomeA.01117-13

Phillips, R. W., Wiegel, J., Berry, C. J., Fliermans, C., Peacock, A. D., White, D. C., et al. (2002). Kineococcus radiotolerans sp. nov., a radiationresistant, gram-positive bacterium. Int. J. Syst. Evol. Microbiol. 52, 933-938. doi: 10.1099/ijs.0.02029-0

Primarini, D., and Ohta, Y. (2000). Some enzyme properties of raw starch digesting amylases from Streptomyces sp. No. 4. Starch 52, 28-32. doi: 10.1002/(SICI)1521-379X(200001)

Pritchard, D. (2005). Sourcing a chemical succession for cyclosporin from parasites and human pathogens. Drug Discov. Today. 10, 688-691. doi: 10.1016/S13596446(05)03395-7

Purushe, S., Prakash, D., Nawani, N. N., Dhakephalkar, P., and Kapadnis, B. (2012). Biocatalytic potential of an alkalophilic and thermophilic dextranase as a remedial measure for dextran removal during sugar manufacture. Bioresour. Technol. 115, 2-7. doi: 10.1016/j.biortech.2012.01.002

Quadri, S. R., and Agsar, D. (2012). Detection of melanin producing thermoalkaliphilic Streptomyces from limestone quarries of the Deccan traps. World J. Sci. Technol. 2, 8-12.

Radhakrishnan, M., Balaji, S., and Balagurunathan, R. (2007). Thermotolerant actinomycetes from Himalayan Mountain- antagonistic potential, characterization and identification of selected strains. Malaysian Appl. Biol. 36, 59-65.

Raja, A., and Prabakarana, P. (2011). Actinomycetes and drug-an overview. Am. J. Drug Discov. Develop. 1, 75-84. doi: 10.3923/ajdd.2011.75.84 
Raut, G. R., Chakraborty, S., Chopade, B. A., and Kokare, C. R. (2013). Isolation and characterization of organic solvent protease from alkaliphilic marine Saccharopolyspora species. Ind. J. Mar. Sci. 42, 131-138.

Rawat, S., and Johri, B. N. (2013). "Role of thermophilic microflora in composting," in Thermophilic Microbes in Environmental and Industrial Biotechnology, eds T. Satyanarayana, J. Littlechild, and Y. Kawarabayasi (Heidelberg; Dordrecht; New York, NY; London: Springer), 137-169.

Ribbe, M., Gadkari, D., and Meyer, O. (1997). $\mathrm{N}_{2}$ fixation by Streptomyces thermoautotrophicus involves a molybdenum-dinitrogenase and a manganesesuperoxide oxidoreductase that couple $\mathrm{n}_{2}$ reduction to the oxidation of superoxide produced from $\mathrm{O}_{2}$ by a molybdenum-CO dehydrogenase. J. Biol. Chem. 272, 26627-26633. doi: 10.1074/jbc.272.42.26627

Roberts, M. F. (2005). Organic compatible solutes of halotolerant and halophilic microorganisms. Saline Systems 1, 1-30. doi: 10.1186/17461448-1-5

Rosazza, J., Huang, Z., Dostal, L., Volm, T., and Rosseau, B. (1995). Biocatalytic transformation of ferulic acid, an abundant aromatic natural product. J. Ind. Microbiol. 15, 457-471. doi: 10.1007/BF01570016

Sanghvi, G. V., Ghevariya, D., Gosai, S., Langa, R., Dhadukc, N., Kunjadiac, P. D., et al. (2014). Isolation and partial purification of erythromycin from alkaliphilic Streptomyces werraensis isolated from Rajkot, India. Biotechnol. Rep. 1-2, 2-7. doi: 10.1016/j.btre.2014.05.003

Sasaki, T., Yoshida, J., Itoh, M., Gomi, S., Shomura, T., Shomura, T., et al. (1988). New antibiotics SF2315A and B produced by an Excellospora sp. I. Taxonomy of the strain, isolation and characterization of antibiotics. J. Antibiot. 41, 835-842.

Sato, M., Arima, K., and Beppu, T. (1985). Fermentation of Antimycin A by alkalophilic Streptomyces and taxonomical studies on the producing strain. Biotechnol. Lett. 7, 159-164. doi: 10.1007/BF01027810

Scalbert, A., Monties, B., Lallemand, J. Y., Guittet, E. R., and Rolando, C. (1985). Ether linkage between phenolic acids and lignin fractions of wheat straw. Phytochemistry 24, 1359-1362. doi: 10.1016/S0031-9422(00)81133-4

Schallmey, A., den Besten, G., Teune, I. G. P., Kembaren, R. F., and Janssen, D. B. (2011). Characterization of cytochrome P450 monooxygenase CYP154H1 from the thermophilic soil bacterium Thermobifida fusca. Appl. Microbiol. Biotechnol. 89, 1475-1485. doi: 10.1007/s00253-010-2965-9

Schippres, A., Bosecker, K., Willscher, S., Sproer, C., Schumann, P., and Kroppenstedt, R. M. (2002). Nocardiopsis metallicus sp. nov., a metal-leaching actinomycetes isolated from an alkaline slag dump. Int. J. Syst. Evol. Microbiol. 52, 2291-2295. doi: 10.1099/00207713-52-6-2291

Schone, R. (1951). An antibiotic which inhibits Cornebacterium diphtheriae produced by S form of Streptomyces thermophiles. Antibiot. Chemother. 1, $176-180$.

Silver, S. (2003). Bacterial silver resistance: molecular biology and uses and misuses of silver compounds. FEMS Microbiol. Rev. 27, 341-353. doi: 10.1016/S01686445(03)00047-0

Singh, S. P., Purohit, M. K., Aoyagi, C., Kitaoka, M., and Hayashi, K. (2010). Effect of growth temperature, induction and molecular chaperones on the solubilization of over-expressed cellobiose phosphorylase from Cellvibrio gilvus under in vivo conditions. Biotechnol. Bioprocess. Eng. 15, 273-276. doi: 10.1007/s12257-009-0023-1

Singh, S. P., Shukla, R. J., and Kikani, B. A. (2013). "Molecular diversity and biotechnological relevance of thermophilic actinobacteria," in Thermophilic Microbes in Environmental and Industrial Biotechnology, eds T. Satyanarayana, J. Littlechild, and Y. Kawarabayasi (New York, NY; London: Springer), 459-479.

Sorokin, D. Y., van Pelt, S., Tourova, T. P., and Muyzer, G. (2007). Microbial isobutyronitrile utilization under haloalkaline conditions. Appl. Environ. Microbiol. 73, 5574-5579. doi: 10.1128/AEM.00342-07

Sorokin, D. Y., Tourova, T. P., Sukhacheva, M. V., Mardano, A. V., and Ravin, N. V. (2012). Bacterial chitin utilisation at extremely haloalkaline conditions. Extremophiles 16, 883-894. doi: 10.1007/s00792-012-0484-6

Sorokin, D. Y., van Pelt, S., Tourova, T. P., and Evtushenko, L. I. (2009). Nitriliruptor alkaliphilus gen. nov., sp. nov., a deep-lineage haloalkaliphilic actinobacterium from soda akes capable of growth on aliphatic nitriles, and proposal of Nitriliruptoraceae fam. nov. and Nitriliruptorales ord. nov. Int. J. Syst. Evol. Microbiol. 59, 248-253. doi: 10.1099/ijs.0.002204-0

Spiridonov, N. A., and Wilson, D. B. (1998). Regulation of biosynthesis of individual cellulases in Thermomonospora fusca. J. Bacteriol. 180, 3529-3532.
Spiridonov, N. A., and Wilson, D. B. (1999). Characterization and cloning of CelR, a transcriptional regulator of cellulase genes from Thermomonospora fusca. J. Biol. Chem. 274, 13127-13132. doi: 10.1074/jbc.274.19.13127

Srinivas, A., Rahul, K., Sasikala, Ch., Subhash, Y., Ramaprasad, E. V. V., and Ramana, Ch. V. (2012). Georgenia satyanarayanai sp. nov., an alkaliphilic and thermotolerant amylase-producing actinobacterium isolated from a soda lake. Int. J. Syst. Evol. Microbiol. 62, 2405-2409. doi: 10.1099/ijs.0.036210-0

Stone, I. M. (1960). Water Dispersible Antibiotics. Staten Island, NY. United States Patent No. 3089818 A.

Stutzenberger, F. J. (1971). Cellulase production by Thermomonospora curvata isolated from municipal solid waste compost. Appl. Microbiol. 22, 147-152.

Sugimori, D., Dake, T., and Nakamura, S. (2000). Microbial degradation of disodium terephthalate by alkaliphilic Dietzia sp. strain GS-1. Biosci. Biotechnol. Biochem. 64, 2709-2711. doi: 10.1271/bbb.64.2709

Suhre, K., and Claverie, J. M. (2003). Genomic correlates of hyperthermostability, an update. J. Biol. Chem. 278, 17198-17202. doi: 10.1074/jbc.M301327200

Suihko, M. L., Kroppenstedt, R. M., and Stackebrandt, E. (2006). Occurrence and characterization of actinobacteria and thermoactinomycetes isolated from pulp and board samples containing recycled fibres. J. Ind. Microbiol. Biotechnol. 33, 183-191. doi: 10.1007/s10295-005-0055-2

Sukkhum, S., Tokuyama, S., and Kitpreechavanich, V. (2012). Poly(L-lactide)degrading enzyme production by Actinomadura keratinilytica T16-1 in $3 \mathrm{~L}$ airlift bioreactor and its degradation ability for biological recycle. J. Microbiol. Biotechnol. 22, 92-99. doi: 10.4014/jmb.1105.05016

Sultanpuram, V. R., Mothe, T., and Mohammed, F. (2014). Streptomyces alkalithermotolerans sp. nov., a novel alkaliphilic and thermotolerant actinomycete isolated from a soda lake. Antonie Van Leeuwenhoek 107, 337-344. doi: 10.1007/s10482-014-0332-z

Suzuki, K., Collins, M. D., Iijima, E., and Komagata, K. (1988). Chemotaxonomic characterization of a radiotolerant bacterium, Arthrobacter radiotolerans: description of Rubrobacter radiotolerans gen. nov., comb. nov. FEMS Microbiol. Lett. 52, 33-40. doi: 10.1111/j.1574-6968.1988.tb02568.x

Suzuki, K., Nagao, K., Monnai, Y., Yagi, A., and Uyeda, M. (1998). Topostatin, a novel inhibitor of topoisomerases I and II Produced by Thermomonospora alba Strain No. 1520 I. taxonomy, fermentation, isolation and biological activities. J. Antibiot. 51, 991-998. doi: 10.7164/antibiotics.51.991

Suzuki, K., Yahara, S., Maehata, K., and Uyeda, M. (2001). Isoaurostatin, a novel topoisomerase inhibitor produced by Thermomonospora alba. J. Nat. Prod. 64, 204-207. doi: 10.1021/np0004606

Taber, W. A. (1960). Studies on isaria cretacea morphogenesis of the synnema and endogenous nutrition. Can. J. Microbiol. 6, 53-63. doi: 10.1139/m60-008

Takahashi, K., Totsuka, A., Nakakuki, T., and Nakamura, N. (1992). Production and application of a maltogenic amylase by a strain of Thermomonospora viridis TF-35. Starch 44, 96-101. doi: 10.1002/star.19920440304

Tamura, T., Ishida, Y., Otoguro, M., Hatano, K., Labeda, D., Price, N. P., et al. (2008). Reclassification of Streptomyces caeruleus as a synonym of Actinoalloteichus cyanogriseus and reclassification of Streptomyces spheroides and Streptomyces laceyi as later synonyms of Streptomyces niveus. Int. J. Syst. Evol. Microbiol. 58, 2812-2814. doi: 10.1099/ijs.0.65560-0

Tanaka, Y., Murata, A., and Hayashida, S. (1995). Accelerated composting of cereal shochu- distillery wastes by actinomycetes: promotive composting of Shochu-distillery waster (I). Seibutsu-kogaku Kais. 73, 365-372.

Tang, X., Zhou, Y., Zhang, J., Ming, H., Nie, G. X., Yang, L. L., et al. (2012). Actinokineospora soli sp. nov., a thermotolerant actinomycete isolated from soil, and emended description of the genus Actinokineospora. Int. J. Syst. Evol. Microbiol. 62, 1845-1849. doi: 10.1099/ijs.0.035832-0

Techapun, C., Charoenrat, T., Poosaran, N., Watanabe, M., and Sasaki, K. (2002). Thermostable and alkaline-tolerant cellulase-free xylanase produced by thermotolerant Streptomyces sp. Ab106. J. Biosci. Bioeng. 93, 431-433. doi: 10.1016/S1389-1723(02)80080-9

Thomas, S. R., Laymon, R. A., Chou, Y. C., Tucker, M. P., Vinzant, T. B., Adney, W. S., et al. (1995). "Initial approaches to artificial cellulase systems for conversion of biomass to ethanol," in Enzymatic Degradation of Insoluble Polysaccharides. ACS Series 618, eds J. N. Saddler, and M. H. Penner (Washington, DC: American Chemical Society), 208-236.

Thumar, J. T., and Singh, P. S. (2009). Organic solvent tolerance of an alkaline protease from salt-tolerant alkaliphilic Streptomyces clavuligerus strain Mit-1. J. Ind. Microbiol. Biotechnol. 36, 211-218. doi: 10.1007/s10295-008-0487-6 
Tiago, I., Pires, C., Mendes, V., Morais, P. V., Costa De, M., and Verıssimo, A. (2005). Microcella putealis gen. nov., sp. nov., a Gram-positive alkaliphilic bacterium isolated from a nonsaline alkaline groundwater. Syst. Appl. Microbiol. 28, 479-487. doi: 10.1016/j.syapm.2005.03.004

Tian, S., Yang, Y., Liu, K., Xiong, Z., Xu, L., and Zhao, L. (2014). Antimicrobial metabolites from anovel halophilic actinomycete Nocardiopsis terrae YIM 90022. Nat. Prod. Res. 28, 344-346. doi: 10.1080/14786419.2013. 858341

Tian, X. P., Tang, S. K., Dong, J. D., Zhang, Y. Q., Xu, L. H., Zhang, S., et al. (2009). Marinactinospora thermotolerans gen. nov., sp. nov., a marine actinomycete isolated from a sediment in the northern South China Sea. Int. J. Syst. Evol. Microbiol. 59, 948-952. doi: 10.1099/ijs.0.005231-0

Tokiwa, Y., and Calabia, B. P. (2004). Degradation of microbial polyesters. Biotechnol. Lett. 26, 1181-1189. doi: 10.1023/B:BILE.0000036599.15302.e5

Tøndervik, A., Klinkenberg, G., Aarstad, O. A., Drabløs, F., Ertesvåg, H., Ellingsen, T. E., et al. (2010). Isolation of mutant alginate lyases with cleavage specificity for di-guluronic acid linkages. J. Biol. Chem. 285, 35284-35292. doi: 10.1074/jbc.M110.162800

Tortora, G. J., Funke, B. R., and Case, C. L. (2007). Microbiology: An Introduction. San Francisco, CA: Pearson Benjamin Cummings.

Tseng, M., Hoang, K., Yang, M., Yang, S., and Chu, W. S. (2007). Polyesterdegrading thermophilic actinomycetes isolated from different environment in Taiwan. Biodegradation 18, 579-583. doi: 10.1007/s10532-006-9089-Z

Tseng, M., Liao, H. C., Chiang, W. P., and Yuan, G. F. (2011). Isoptericola chiayiensis sp. nov., isolated from mangrove soil. Int. J. Syst. Evol. Microbiol. 61, 1667-1670. doi: 10.1099/ijs.0.022491-0

Tseng, M., Yang, S. F., Hoang, K. C., Liao, H. C., Yuan, G. F., and Liao, C. C. (2009). Actinomadura miaoliensis sp. nov., a thermotolerant polyester-degrading actinomycetes. Int. J. Syst. Evol. Microbiol. 59, 517-520. doi: 10.1099/ijs.0.001479-0

Tsujibo, H., Kubota, T., Yamamoto, M., Miyamoto, K., and Inamori, Y. (2003). Characterization of chitinase genes from an alkaliphilic actinomycete, Nocardiopsis prasina OPC-131. Appl. Environ. Microbiol. 69, 894-900. doi: 10.1128/AEM.69.2.894-900.2003

Tucker, M. P., Mohagheghi, A., Grohmann, K., and Himmel, M. E. (1989). Ultra-thermostable cellulases from Acidothermus cellulolyticus: comparison of temperature optima with previously reported cellulases. Nat. Biotechnol. 7, 817-820. doi: 10.1038/nbt0889-817

Urzì, C., Brusetti, L., Salamone, P., Sorlini, C., Stackebrandt, E., and Daffonchio, D. (2001). Biodiversity of Geodermatophilaceae isolated from altered stones and monuments in the Mediterranean basin. Environ. Microbiol. 3, 471-479. doi: 10.1046/j.1462-2920.2001.00217.x

Valdés, M., Pérez, N. O., Estrada-de Los Santos, P., Caballero-Mellado, J., Peña-Cabriales, J. J., Normand, P., et al. (2005). Non-Frankia actinomycetes isolated from surface-sterilized roots of Casuarina equisetifolia fix nitrogen. Appl. Environ. Microbiol. 71, 460-466. doi: 10.1128/AEM.71.1.460466.2005

Valencia-Cantero, E., Hernandez-Calderon, E., Velazquez-Becerra, C., LopezMeza, J. E., Alfaro-Cuevas, R., and Lopez-Bucio, J. (2007). Role of dissimilatory fermentative iron- reducing bacteria in Fe uptake by common bean (Phaseolus vulgaris L.) plants grown in alkaline soil. Plant Soil 291, 263-273. doi: 10.1007/s11104-007-9191-y

Velásquez, J. E., and van der Donk, W. A. (2011). Genome mining for ribosomally synthesized natural products. Curr. Opin. Chem. Biol. 15, 11-21. doi: 10.1016/j.cbpa.2010.10.027

Ventura, M., Canchaya, C., Tauch, A., Chandra, G., Fitzgerald, G. F., Chater, K. F., et al. (2007). Genomics of Actinobacteria: tracing the evolutionary history of an ancient phylum. Microbiol. Mol. Biol. Rev. 71, 495-548. doi: 10.1128/MMBR.00005-07

Venugopalan, V., Tripathi, S. K., Nahar, P., Saradhi, P. P., Das, R. H., and Gautam, H. K. (2013). Characterization of canthaxanthin isomers isolated from a new soil Dietzia sp. and their antioxidant activities. J. Microbiol. Biotechnol. 23, 237-245. doi: 10.4014/jmb.1203.03032

Vetter, J. (2000). Plant cyanogenic glycosides. Toxicon 38, 11-36. doi: 10.1016/S0041-0101(99)00128-2

Vieille, C., and Zeikus, G. J. (2001). Hyperthermophilic enzymes: sources, uses, and molecular mechanisms for thermostability. Microbiol. Mol. Biol. Rev. 65, 1-46. doi: 10.1128/MMBR.65.1.1-43.2001
Wang, Q., and Xia, T. (2008). Enhancement of the activity and alkaline pH stability of Thermobifida fusca xylanase A by directed evolution. Biotechnol. Lett. 30, 937-944. doi: 10.1007/s10529-007-9508-1

Wang, X. B., Chi, C. Q., Nie, Y., Tang, Y. Q., Tan, Y., Wub, G., et al. (2011). Degradation of petroleum hydrocarbons (C6-C40) and crude oil by a novel Dietzia strain. Bioresour. Technol. 102, 7755-7761. doi: 10.1016/j.biortech.2011.06.009

Wang, Y. B., Wu, C. Y., Wang, X. J., and Zhou, S. G. (2009). The role of humic substances in the anaerobic reductive dechlorination of 2,4dichlorophenoxyacetic acid by Comamonas koreensis strain CY01. J. Hazard. Mater. 164, 941-947. doi: 10.1016/j.jhazmat.2008.08.097

Wang, Y., Zhang, Z., and Ruan, J. (1996). A proposal to transfer Microbispora bispora (Lechevalier 1965) to a new genus, Thermobispora gen. nov., as Thermobispora bispora comb. nov. Int. J. Syst. Bacteriol. 46, 933-938. doi: 10.1099/00207713-46-4-933

Wang, Z., Fu, P., Liu, P., Wang, P., Hou, J., Li, W., et al. (2013). New pyran-2-ones from alkaliphilic actinomycete Nocardiopsis alkaliphila sp. nov. YIM-80379. Chem. Biodivers. 10, 281-287. doi: 10.1002/cbdv.201200086

Wang, Z., Jin, Y., Wu, H., Tian, Z., Wu, Y., and Xie, X. (2012). A novel, alkalitolerant thermostable xylanase from Saccharomonospora viridis: direct gene cloning, expression and enzyme characterization. World J. Microbiol. Biotechnol. 28, 2741-2748. doi: 10.1007/s11274-012-1085-3

Webb, M. D., Ewbank, G., Perkins, J., and McCarthy, A. J. (2001). Metabolism of pentachlorophenol by Saccharomonosporaviridisstrains isolated from mushroom compost. Soil Biol. Biochem. 33, 1903-1914. doi: 10.1016/S00380717(01)00115-8

Wei, Y. T., Zhu, Q. X., Luo, Z. F., Lu, F. S., Chen, F. Z., Wang, Q. Y., et al. (2004). Cloning, expression and identification of a new trehalose synthase gene from Thermobifida fusca Genome. Acta Biochim. Biophys. Sin. 36, 477-484. doi: 10.1093/abbs/36.7.477

Weid, I. V. D., Marques, J. M., Cunha, C. D., Lippi, R. K., dos Santos, S. C. C., Rosado, A. S., et al. (2007). Identification and biodegradation potential of a novel strain of Dietzia cinnamea isolated from a petroleumcontaminated tropical soil. Syst. Appl. Microbiol. 30, 331-339. doi: 10.1016/j.syapm.2006.11.001

Wiegel, J., and Kevbrin, V. V. (2004). Alkalithermophiles. Biochem. Soc. Trans. 32, 193-198. doi: 10.1042/bst0320193

Williams, P. W., Eichstadt, S. L., Kokjohn, T. A., and Martin, E. L. (2007). Effects of ultraviolet radiation on the gram-positive marine bacterium Microbacterium maritypicum. Curr. Microbiol. 55, 1-7. doi: 10.1007/s00284-006-0349-2

Winter, R. T., Heuts, D. P. H. M., Rijpkema, E. M. A., van Bloois, E., Wijma, H. J., and Fraaije, M. W. (2012). Hot or not? Discovery and characterization of a thermostable alditol oxidase from Acidothermus cellulolyticus 11B. Appl. Microbiol. Biotechnol. 95, 389-403. doi: 10.1007/s00253-011-3750-0

Woo, S. G., Cui, Y., Kang, M. S., Jin, L., Kim, K. K., Lee, S. T., et al. (2012). Georgenia daeguensis sp. nov., isolated from 4-chlorophenol enrichment culture. Int. J. Syst. Evol. Microbiol. 62, 1703-1709. doi: 10.1099/ijs.0.033217-0

Wu, C. Y., Chen, N., Li, H., and Li, Q. F. (2014a). Kocuria rosea HN01, a newly alkaliphilic humus-reducing bacterium isolated from cassava dreg compost. J. Soils Sediments. 14, 423-431. doi: 10.1007/s11368-013-0679-1

Wu, C. Y., Zhuang, L., Zhou, S. G., Li, F. B., and He, J. (2011b). Corynebacterium humireducens sp. nov., an alkaliphilic, humic acid-reducing bacterium isolated from a microbial fuel cell. Int. J. Syst. Evol. Microbiol. 61, 882-887. doi: 10.1099/ijs.0.020909-0

Wu, H., Lian, Y., Liu, B., Ren, Y., Qin, P., and Huang, F. (2014b). Thermotunica guangxiensis gen. nov., sp. nov., isolated from mushroom residue compost. Int. J. Syst. Evol. Microbiol. 64, 1593-1599. doi: 10.1099/ijs.0.057562-0

Wu, Y., Liu, F., Liu, Y. C., Zhang, Z. H., Zhou, T. T., Liu, X., et al. (2011a). Identification of chitinases Is-chiA and Is-chiB from Isoptericola jiangsuensis CLG and their characterization. Appl. Microbiol. Biotechnol. 89, 705-713. doi: 10.1007/s00253-010-2917-4

Xiao, Y., Zeng, G. M., Yang, Z. H., Mac, Y. H., Huang, C., Xu, Z. Y., et al. (2011). Changes in the actinomycetal communities during continuous thermophilic composting as revealed by denaturing gradient gel electrophoresis and quantitative PCR. Bioresour. Technol. 102, 1383-1388. doi: 10.1016/j.biortech.2010.09.034

Xue, L., Xue, Q., Chen, Q., Lin, C., Shen, G., and Zhao, J. (2013). Isolation and evaluation of rhizosphere actinomycetes with potential application for 
biocontrol of Verticillium wilt of cotton. Crop Prot. 43, 231-240. doi: 10.1016/j.cropro.2012.10.002

Yamaki, T., Olikawa, T., Ito, K., and Nakamura, T. (1997). Cloning and sequencing of a nitrile hydratase gene from Pseudonocardia thermophila JCM3095. J. Ferment. Bioeng. 83, 474-477. doi: 10.1016/S0922-338X(97)83004-8

Yan, X., Yan, H., Liu, Z., Liu, X., Mo, H., and Zhang, L. (2011). Nocardiopsis yanglingensis sp. nov., a thermophilic strain isolated from a compost of button mushrooms. Antonie van Leeuwenhoek 100, 415-419. doi: 10.1007/s10482-0119597-7

Yang, C. H., and Liu, W. H. (2008). Purification and properties of an acetylxylan esterase from Thermobifida fusca. Enzyme Microb. Technol. 42, 181-186. doi: 10.1016/j.enzmictec.2007.09.007

Yap, W. H., Zhang, Z., and Wang, Y. (1999). Distinct types of rRNA operons exist in the genome of the actinomycete Thermomonospora chromogena and evidence for horizontal transfer of an entire rRNA operon. J. Bacteriol. 181, 5201-5209.

Yoon, J. H., Kim, I. G., Lee, M. H., Lee, C. H., and Oh, T. K. (2005). Nocardioides alkalitolerans sp. nov., isolated from an alkaline serpentinite soil in Korea. Int. J. Syst. Evol. Microbiol. 55, 809-814. doi: 10.1099/ijs.0.63374-0

Yoshinaka, T., Yano, K., and Yanaguchi, H. (1973). Isolation of a highly radioresistant bacterium, Arthrobacter radiotolerans nov. sp. Agric. Biol. Chem. 37, 2269-2275. doi: 10.1271/bbb1961.37.2269

You, Z. Q., Li, J., Qin, S., Tian, X. P., Wang, F. Z., and Zhang, S. (2013). Georgenia sediminis sp. nov., a moderately thermophilic actinobacterium isolated from sediment. Int. J. Syst. Evol. Microbiol. 63, 4243-4247. doi: 10.1099/ijs.0.051714-0

Yu, J., Zhang, L., Liu, Q., Qi, X., Ji, Y., and Kim, B. S. (2015). Isolation and characterization of actinobacteria from Yalujiang coastal wetland, North China. Asian Pac. J. Trop. Biomed. 5, 555-560. doi: 10.1016/j.apjtb. 2015.04.007

Yu, L., Lai, Q., Yi, Z., Zhang, L., Huang, Y., Gu, L., et al. (2013). Microbacterium sediminis sp. nov., a psychrotolerant, thermotolerant, halotolerant and alkalitolerant actinomycete isolated from deep-sea sediment. Int. J. Syst. Bacteriol. 63, 25-30. doi: 10.1099/ijs.0.029652-0

Zarilla, K. A., and Perry, J. J. (1984). Thermoleophilum album gen. nov. and sp. nov., a bacterium obligate for thermophily and n-alkane substrates. Arch. Microbiol. 137, 286-290. doi: 10.1007/BF00410723

Zarilla, K. A., and Perry, J. J. (1986). Deoxyribonucleic acid homology and other comparisons among obligately thermophilic hydrocarbonoclastic bacteria, with a proposal for Thermoleophilum minutum sp. nov. Int. J. Syst. Bacteriol. 36, 13-16. doi: 10.1099/00207713-36-1-13

Zenova, G. M., Manucharova, N. A., and Zvyagintsev, D. G. (2011). Extremophilic and extremotolerant actinomycetes in different soil types. Eurasian Soil Sci. 44, 417-436. doi: 10.1134/S1064229311040132

Zhang, F., Chen, J. J., Ren, W. Z., Nie, G. X., Ming, H., Tang, S. K., et al. (2011). Cloning, expression and characterization of an alkaline thermostable GH9 endoglucanase from Thermobifida halotolerans YIM, $90462^{\mathrm{T}}$. Bioresour. Technol. 102, 10143-10146. doi: 10.1016/j.biortech.2011.08.019

Zhang, G. Y., Liu, Q., Wang, H. F., Zhang, D. F., Zhang, M. Y., Park, D. H., et al. (2014). Haloactinopolyspora alkaliphila sp. nov., and emended description of the genus Haloactinopolyspora. Int. J. Syst. Evol. Microbiol. 64, 1945-1951. doi: 10.1099/ijs.0.062646-0

Zhang, S., Lao, G., and Wilson, D. B. (1995). Characterization of a Thermomonospora fusca exocellulase. Biochemistry 34, 3386-3395. doi: 10.1021/bi00010a030

Zhang, W., Zhu, H., Yuan, M., Yao, Q., Tang, R., Lin, M., et al. (2010). Microbacterium radiodurans sp. nov., a UV radiation-resistant bacterium isolated from soil. Int. J. Syst. Evol. Microbiol. 60, 2665-2670. doi: 10.1099/ijs.0.017400-0

Zhang, Z., Kudo, T., Nakajima, Y., and Wang, Y. (2001). Clarification of the relationship between the members of the family Thermomonosporaceae on the basis of 16S rDNA, 16S-23S rRNA internal transcribed spacer and 23S rDNA sequences and chemotaxonomic analyses. Int. J. Syst. Evol. Microbiol. 51, 373-383. doi: 10.1099/00207713-51-2-373

Zhang, Z., Wang, Y., and Ruan, J. (1998). Reclassification of Thermomonospora and Microtetraspora. Int. J. Syst. Bacteriol. 48, 411-422. doi: 10.1099/0020771348-2-411

Zhi, X. Y., Li, W. J., and Stackebrandt, E. (2009). An update of the structure and 16S rRNA gene sequence-based definition of higher ranks of the class Actinobacteria, with the proposal of two new suborders and four new families and emended descriptions of the existing higher taxa. Int. J. Syst. Evol. Microbiol. 59, 589-608. doi: 10.1099/ijs.0.65780-0

Zhou, E. M., Yang, L. L., Song, Z. Q., Yu, T. T., Nie, G. X., Ming, H., et al. (2012). Thermocatellispora tengchongensis gen. nov., sp. nov., a new member of the family Streptosporangiaceae. Int. J. Syst. Evol. Microbiol. 62, 2417-2423. doi: 10.1099/ijs.0.036897-0

Zhou, W., Irwin, D. C., Escovar-Kousen, J., and Wilson, D. B. (2004). Kinetic studies of Thermobifida fusca Cel9A active site mutant enzymes. Biochemistry 43, 9655-9663. doi: 10.1021/bi049394n

Zhou, X., Xin, Z. J., Lu, X. H., Yang, X. P., Zhao, M. R., Wang, L., et al. (2013). High efficiency degradation crude oil by a novel mutant irradiated from Dietzia strain by ${ }^{12} \mathrm{C}^{6+}$ heavy ion using response surface methodology. Bioresour. Technol. 137, 386-393. doi: 10.1016/j.biortech.2013.03.097

Zucchi, T. D., Tan, G. Y. A., Bonda, A. N. V., Frank, S., Kshetrimayum, J. D., and Goodfellow, M. (2012). Amycolatopsis granulosa sp. nov., Amycolatopsis ruanii sp. nov. and Amycolatopsis thermalba sp. nov., thermophilic actinomycetes isolated from arid soils. Int. J. Syst. Evol. Microbiol. 62, 1245-1251. doi: 10.1099/ijs.0.031039-0

Conflict of Interest Statement: The authors declare that the research was conducted in the absence of any commercial or financial relationships that could be construed as a potential conflict of interest.

Copyright (C) 2015 Shivlata and Satyanarayana. This is an open-access article distributed under the terms of the Creative Commons Attribution License (CC BY). The use, distribution or reproduction in other forums is permitted, provided the original author(s) or licensor are credited and that the original publication in this journal is cited, in accordance with accepted academic practice. No use, distribution or reproduction is permitted which does not comply with these terms. 